\title{
Evolutionary Psychology: The Academic Debate
}

\author{
Jean Suplizio
}

Dissertation submitted to the Faculty of Virginia Polytechnic Institute and State University in partial fulfillment of the requirements for the degree of

\section{Doctor of Philosophy in Science and Technology Studies}

\author{
Committee: \\ Valerie Hardcastle, Chair \\ Richard Burian \\ James Collier \\ Laura Perini \\ Barbara Reeves
}

July 28, 2005

Blacksburg, VA

Keywords: evolutionary psychology, Steven Pinker, Barbara King, George Lakoff, Mark Johnson, Annette Karmiloff-Smith, development

Copyright $\odot$ Jean Suplizio

ALL RIGHTS RESERVED 


\title{
Evolutionary Psychology: The Academic Debate
}

\author{
Jean Suplizio
}

\begin{abstract}
This dissertation examines the academic debate that surrounds the new field called 'Evolutionary Psychology.' Evolutionary psychology has emerged as the most popular successor theory to human sociobiology. Its proponents search for evolved psychological mechanisms and emphasize universal features of the human mind. My thesis is that in order to flourish evolutionary psychologists must engage other researchers on equal terms - something they have not been doing. To show this, I examine the stances of practitioners from three other social science fields whose claims have been shortchanged by evolutionary psychology: Barbara King in biological anthropology, George Lakoff and Mark Johnson in empirical linguistics and Annette Karmiloff-Smith in developmental psychology. These researchers are also involved in cognitive science investigations that bear on evolutionary psychology's key claims about the mind and how it works.
\end{abstract}

Evolutionary psychologists make three key claims about the mind. The first (1) is that the mind is massively modular; the second (2) is that this massively modular mind has been shaped by the processes of natural selection over evolutionary time; and the third (3) is that it is adapted to the Pleistocene conditions of our past. Evolutionary psychologists seek to elevate these three claims to the status of meta-theoretical assumptions making them the starting place from which our deliberations about human cognition ought proceed. These claims would constitute the framework for a new paradigm in the ultimate sense. I argue that elevating these claims to such a status is not only premature, but also unwarranted on the available evidence. This result is justified by evidence produced outside evolutionary psychology by those disciplines from which evolutionary psychologists explicitly seek to distance themselves. 


\section{Acknowledgements}

I would first like to thank my Chair, Valerie Hardcastle, for her steadfast support through the entire process of researching and writing this dissertation. In spite of all the demands on her time, I always felt like I had all Val's attention. I can't imagine our having had a better working relationship. I look forward to continuing the conversation we have started.

I wish to thank Dick Burian, with whom it has been a special privilege to work, for standing ready to answer any of my questions, particularly, in the final phases of this project. I am certain that Dick gave me more of his advice and time on a smorgasbord of issues than I deserve. I am truly, albeit contentedly, in his debt for challenging me to think more deeply about matters raised herein - work for another day.

My thanks to Laura Perini for probing questions at the proposal stage that kept me focused for the duration of this project and to Jim Collier for the unique perspective he brought to my committee as well as the interesting contributions he made to the discussion we had at my defense. Thanks to Barbara Reeves for providing the historian's standpoint, most memorably when we met over coffee, for generously sharing great ideas for future pursuits, and for making certain that I, like all her students, see metaphors everywhere.

Support comes in many forms. I would therefore like to acknowledge my Father for sharing my love of philosophy and for teaching me Marx; my Mother for always being a little bit prouder of me than she should be; my children, Aaron, Anthony, and Zachary for bearing with me over the years of my graduate study. An extra thanks goes to Aaron for driving me to Blacksburg for my defense and for on-the-spot troubleshooting of any (and all) computer difficulties.

Special friends: Theresa Cappo, the one most responsible for my high spirits (e.g., Old Peculiar, Guinness Stout, Yuengling Black and Tan...) Thanks for camaraderie that started long before and that I expect will last long after this project. Sonja Taylor, buddy from GMU, thanks for e-mails that always made me LOL and for going through it with me though we studied different subjects and at different universities... still we journeyed together. And Diana Hoyt, friend and colleague... Thanks for memorable lunches, an Arc d'Triumph key chain (lost but not forgotten), and, basically, just for looking out for me.

Virginia Tech People: Barbara Allen for classes spanning the gamut from Heidegger to Haraway; Chris Hunt for sage advice on anything I brought to his attention, but more importantly, for always sending me those e-mail wishes of 'Good Luck;' Rachel Hall, Crystal Harrell, Angela Webb, Karen Snider and Gwen Ewing for the smile that came along with their administrative communications; Harry Kriz and his awesome staff for superlative interlibrary loan services, as well as Bruce Pencek for responding to my e-mail inquiries whether he was at work, at home or out of the country.

Last, but not least, I thank my friend and mentor Victoria Salmon of George Mason University. Essentially, this dissertation got done because she said I could do it. 


\section{Evolutionary Psychology: The Academic Debate}

\section{Table of Contents}

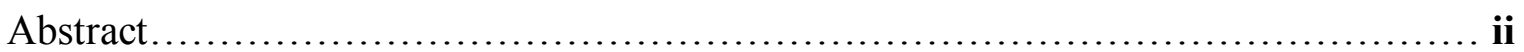

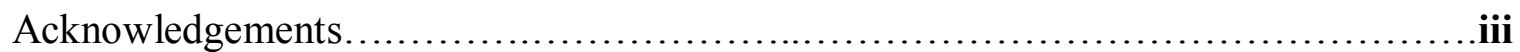

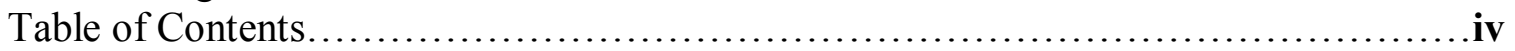

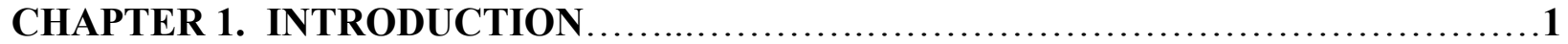

Background: The Blank Slate - Target or Trouble?............................... 3

Enter New Voices.........................................................

CHAPTER 2. SCIENCE, RHETORIC AND THE WAYS OF REASON................. 16

Evolutionary Psychology On Its Own Turf.............................................. 23

The Ways of Reason....................................................... 31

Where Things Now Stand/Where They Are Going............................ 37

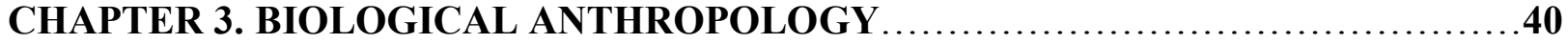

Continuity Versus Discontinuity - Divergent Paradigms................................. 46

Pinker's Synthesis - King's Persistence........................................................ 51

Finessing the Impasse.........................................................

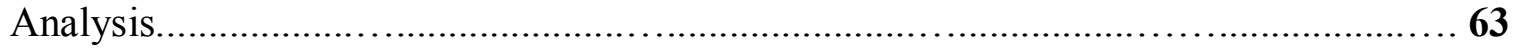

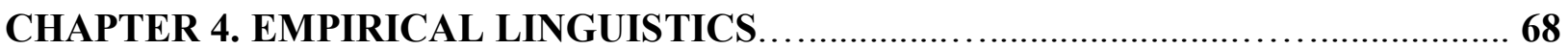

Noam Chomsky: Architect of Evolutionary Psychology's Deep Structure.............. 71

Evolutionary Psychology: The Surface Structure.......................................... 75

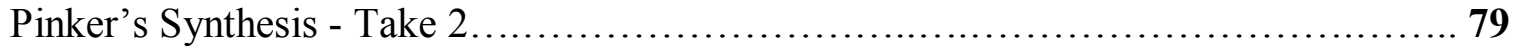

Two Views of Reality - Two Views of Cognition: Divergent Paradigms Again?.......... 84

Lakoff and Johnson's Cognitive Semantics.......................................99

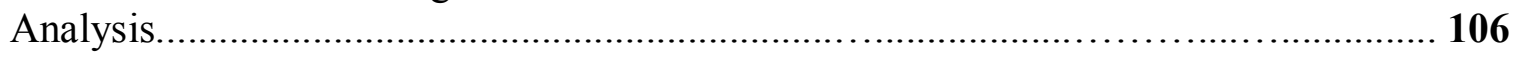

CHAPTER 5. DEVELOPMENTAL PSYCHOLOGY ...................................... 115

Development, Evolution and Jean Piaget: Against Risky Darwinism.................... 116

On Behalf of Pinker - Synthesis 3 By Bjorklund and Pellegrini.......................125

Karmiloff-Smith: From Modularity to Creativity - The Ultimate Synthesis.............. 134

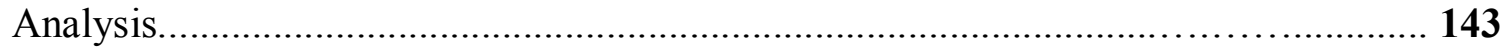

CHAPTER 6. CONCLUSION: EXPANDING PERSPECTIVE........................157

Interdisciplinary Objectivity............................................ 161

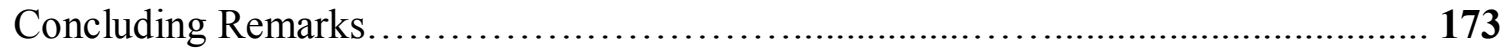

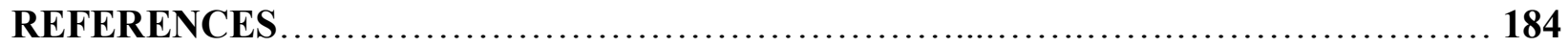




\section{CHAPTER I. INTRODUCTION}

In this dissertation I examine the academic debate that surrounds the new field called evolutionary psychology. Although, many evolutionary psychologists have written mainly for a popular audience, this has not prevented other social science academicians from critiquing their works and responding officially to their ideas in more academic (as well as in popular) genres. So there is an academic debate occurring despite a certain lopsidedness in the debate due to the failure of the evolutionary psychologists to respond adequately to their critics and to take account of the evidence put to them for consideration.

In particular, I believe that the evolutionary psychologists have shortchanged practitioners from the fields of biological anthropology, empirical linguistics and developmental psychology. I therefore take representative voices from these three fields and delineate the give and take that must occur between them (even if it has not transpired in actual fact) ${ }^{1}$ in order to suggest how their differences might be resolved and illuminate the issues that come more clearly into focus when their dialectical exchange is thought through. I undertake an analysis of evolutionary psychology's rhetorical maneuvers as a prerequisite task to this endeavor.

Specifically, I rely on Barbara King to represent biological anthropology, George Lakoff and Mark Johnson to provide the perspective from empirical linguistics, and Annette Karmiloff-Smith to stand in for developmental psychology. The husband and wife team of John Tooby and Leda Cosmides, the first an anthropologist, the other a psychologist, and the very popular psychologist-cum-linguist, Steven Pinker are the main evolutionary psychologists who figure into this dissertation. All these theorists are evolutionary-minded. One of my aims will be to show that evolutionary theory intersects their disciplines at different points and in different

\footnotetext{
${ }^{1}$ This is attested to by the paucity of inter-textual relationships.
} 
ways and that it morphs as it is constructed and reconstructed by these practitioners. I maintain that evolutionary theory is, therefore, not just some one theory.

I find that the specific issues clarified by cross-talk between the principals are as follows: Disagreements between biological anthropologists and evolutionary psychologists raise the question of the relevance of comparative data for an understanding of evolved human cognitive capacities. This subject is discussed in Chapter 3. The empirical linguists reassert the issue, thought to be put to rest by evolutionary psychology's combinatorial explosion argument against domain general mechanisms and what they can do, ${ }^{2}$ of the legitimacy of speaking of modularized and autonomous compartments of reason. Instead, the linguists maintain that the mind's modularity is contraindicated by the common derivation of language and reason from our embodied experiences in the world in a similar fashion to other cognitive categories in general. In addition, reciprocity between the evolutionary psychologists and empirical linguists highlights the place of neurobiology in settling differences of opinion on this matter. This is discussed in Chapter 4. Finally, in Chapter 5, the role of development in the evolution of cognition comes to the fore and, in particular, the question of whether incorporation of the biological facts of development, which are trivialized by evolutionary psychology, forces the core tenets of evolutionary psychology to give way.

Having discovered that juxtaposition of the aforementioned views actually reveals how each of the perspectives challenges and alters the others and especially how 'development' challenges and alters them all, I arrive at a view of interdisciplinary objectivity, which I present

\footnotetext{
${ }^{2}$ Evolutionary psychology got off the ground due to recognition of the information-processing problem associated with domain-general computers. The problem is that domain-general computers lack the specialized processing rules that are necessary to hone down the infinite number of options that rapidly arise in any given choice situation as possible solutions. This is where the idea of combinatorial explosion comes in (Tooby and Cosmides, 1992, p. 102+). Evolutionary psychologists solve it by supposing that special programming rules are in place to narrow the number of possibilities open for selection. Hence, evolutionary psychology's posit that the brain may house hundreds, even thousands, of modules (1992, p. 40; 1995, p. xiii).
} 
at the close of this dissertation. In a manner similar to the developmental process itself, I submit that it is through the unanticipated connections generated by continually reconstituted disciplinary interrelationships that enhanced perspective is achieved and knowledge is advanced. To this end, equality of intellectual authority, eschewed by evolutionary psychology, is essential. In all, I draw two conclusions from my examination of the academic debate. The first is (1) that the evolutionary psychologists must engage other researchers on equal terms if they are to flourish as participants in the conversation on the nature of human cognition; and secondly (2) that evolutionary psychologists' attempts to elevate their core tenets to the status of meta-theoretical assumptions, - i.e., to make them the starting place from which our deliberations about human cognition ought proceed - is not only premature, but unwarranted on the available evidence. This result rests on evidence produced outside evolutionary psychology by those disciplines from which evolutionary psychologists explicitly seek to distance themselves.

\section{Background: The Blank Slate -Target Or Trouble?}

The human sociobiology debate initiated by E.O. Wilson in 1975 spawned several different evolutionary approaches to the study of human behavior. Evolutionary psychology, which searches for evolved psychological mechanisms and emphasizes universal features of the human mind, has emerged as its most popular successor theory. Forsaking any intellectual debt to Wilson whose work has been identified with racism and right wing political views, evolutionary psychology's proponents renamed their field in a manner acceptable to some, less so to others who regarded the new name too limited to describe the number of fields it cut across (Barkow, p. 1989, p. 8).

Evolutionary psychology took off in the late 1980s. The Center for Evolutionary Psychology (CEP) was founded in 1994 at the University of California at Santa Barbara. Since 
the time of its inception the new field's practitioners have promoted their theory as being 'revolutionary' despite its derivative relation to sociobiology ${ }^{3}$ and have expressed the highest aspirations for it (esp. Buss, 1999). Leda Cosmides, a founding member of the Center for Evolutionary Psychology, has pronounced that in the not too distant future 'evolutionary' will be dropped as a descriptor of her field because 'evolutionary psychology' and 'psychology' will be one and the same. ${ }^{4}$

Proponents of revolutionary views are notorious for taking on big targets to ready the intellectual terrain for their ideas. In the 1950s, for example, the philosopher A.J. Ayer targeted metaphysics. In his small and provocative book, Language, Truth and Logic (1952), Ayer 'eliminated' metaphysics in Chapter 1 thereby banishing the 'superstitions' of his readership, then moved on to discuss the new function of philosophy (in chapter 2) and the nature of philosophical analysis (in chapter 3 ) for the tradition of thinking (called logical positivism) which he thus imported to the English-speaking world. Similarly, evolutionary psychologists have identified a target, which they seek to overturn, in order to be positioned to advance their ideas to receptive readers who have been freed of their superstitions and prejudice.

That target is The Blank Slate Doctrine. The Blank Slate Doctrine encapsulates a view of human nature. Specifically, it states that the human mind has nothing in it to start out with and contains only what is put into it via the senses (and filtered through one's cultural lens) at the

\footnotetext{
${ }^{3}$ Wilson himself insisted that evolutionary psychology was the same as human sociobiology. Sociobiology was not, after all, a static account. Along with others, Wilson developed and revised it in significant ways over the years. For example, in Genes, Mind and Culture (Lumsden and Wilson, 1981) published six years after Sociobiology (1975), and four years before one of the founding members of CEP, Leda Cosmides, completed her graduate studies, Wilson invoked the notion of rules for the epigenetic development of human cognition, thus inserting between genes and behavior the missing link i.e., the psychological mechanisms, onto which evolutionary psychologists would later claim to have uniquely fastened. According to Wilson, the name change merely reflected the desire of these thinkers to get professional, academic credit in their home field - the discipline of psychology (Segerstrale, 2000, p. 317). At least one difference, though, is that evolutionary psychology starts with the mind and all its intricacies laid on the table, rather than backing into it in the manner Wilson did. In itself, this may be regarded as an advance over prior theorizing.

${ }^{4}$ Interview with Leda Cosmides: On-Line: www.psych.ucsb.edu/research/cep/ledainterview.htm
} 
end. The doctrine represents the dogma it attacks as a mighty foe from which we need to be liberated, just as metaphysics was for Ayer. Steven Pinker, for example, claims that the Blank Slate view is truly held by academicians (and other people) and is not merely conjured for rhetorical effect. Ayer managed to eliminate metaphysics in something less than 15 pages. Pinker tries to do the same with the theory of the Blank Slate (in The Blank Slate, 2002) in roughly 500 .

Following Pinker, John Tooby and Leda Cosmides show that the Blank Slate (or tabula rasa empiricism) is integral to the Standard Social Science Model (SSSM) for the organization of the sciences. According to Tooby and Cosmides, the SSSM justifies the social sciences' autonomy from biology (1992, p. 23). By denying that human nature "can play any notable role as a generator of significant organization in human life" the SSSM "removes from the concept of human nature all substantive content, and relegates...the mind to the delimited role of embodying the "capacity for culture"” (1992, p. 28). Against this model Tooby and Cosmides oppose their own Integrated Causal Model (ICM) for the organization of the sciences - a model designed to amend the defects of the SSSM's "impossible psychology" (1992, p. 34) by returning the nativist elements of our nature back to the equation and granting the biological side its priority place.

These evolutionary psychologists counter the Blank Slate Doctrine with three affirmations: (1) that the mind is massively modular; (2) that this massively modular mind has been shaped by the processes of natural selection over evolutionary time; and (3) that it is adapted to the Pleistocene conditions of our past. Why Pleistocene conditions? Because these are the conditions under which humans have lived most of their lives; hence, natural selection has had time to establish, but not to displace, the various features appropriate to Pleistocene 
conditions. Modern minds, according to evolutionary psychology, are adapted to the Stone Age not the Computer Age (Pinker, 1997, p. 42). This explains why we fear spiders, snakes and darkness, not cars and electrical outlets (Buss et. al., 1999a). In fact evolutionary psychologists believe that our responses to problem situations give us clues to the past. They tell us the fitness relevant features of the ancestral environment from which we have evolved (Tooby and Cosmides, 1992).

Like Tooby and Cosmides, Steven Pinker identifies the Blank Slate Doctrine rather loosely with empiricism (2002, p. 10) an identification that measurably increases the momentousness of the attack being made through ratcheting it up in scale albeit at the cost of some distortion. For empiricism just is a much larger, more heterogeneous and subtle tradition than the Blank Slate taken by itself which may, presumably, be subsumed by it, but to which it ought not be essentially connected. At least today's empiricists (I have in mind philosophers of science like Helen Longino (1990) and Bas van Fraassen (1980)) do not accept the mind's total emptiness or its passivity in the face of environmental influences. More likely, they will say that empiricism is a justificatory approach, a theory of knowledge, not a theory of mind or human nature, and while these sorts of theories are necessarily linked, they are nevertheless not mandated one by the other. Hence, contemporary empiricist philosophers may express their commitment to the idea that no belief can be justified without appeal to experience, not to the idea that there is nothing at all in the mind before experience occurs.

Compromising the accuracy, if not propriety, of their attack on the theory of the Blank Slate is the fact that, as Pinker himself points out, not even Locke, its purported originator, subscribed to the doctrine. That is to say, Locke did not really espouse the view that the human mind is a purely empty and passive receptacle at birth - that there isn't anything inside it that is 
innate. Somewhat inconsistently, Locke held that the human mind possesses certain primitive (intuitive) resources for thinking logically (such as, for instance, the law of non-contradiction, 1689/1952, Bk IV, Ch II, 1) that are conditions for its functioning as a mental entity at all. In addition, and just as significantly, he believed that the human mind contains moral archetypes (1689/1952, Bk IV, Ch IV, 8).

So Locke's empiricism was not of the absolutely radical sort that would make his theory of mind a true exemplification of the Blank Slate Doctrine. Locke was only more or less guilty of endorsing it and less so if we consider moral archetypes to be rather substantial additions to any conception of the mind's intrinsic nature. Obviously, too, Locke recognized what evolutionary psychologists duly note: that a blank slate can’t do anything (Pinker, 2002, p. 34). Inertness in its fullest (and most deleterious) sense is its correlative notion. ${ }^{5}$ Many, I suspect, are likely to find this phlegmatic quality a more objectionable feature of the Slate than its nature as a medium with writeable properties. However, even Pinker suggests (although he may not mean to) that the passivity of people needn't follow from the hollowness of their minds at birth since he tells us that the mind that has no inherent structure "can be inscribed at will by society or ourselves" (2002, p. 2, emphasis added). This asserts the issue: "How far can one depart from the Blank Slate theory and still be thought to adhere to it? Who really holds the doctrine? ${ }^{6}$

\footnotetext{
${ }^{5}$ Or so it appears. If the idea that humans have no essential nature is logically tied to humanity's passivity then the philosophy of existentialism is incoherent. For, according to the philosophy, it is the very fact that we have no nature that we are condemned to be free and, hence, why we are responsible for acting.

${ }^{6}$ One might also protest that evolutionary psychology's proclamation that the mind has innate capacities, contrary to the Blank Slate, can't be its revolutionary notion for if it is it comes belatedly by centuries. Leibniz followed fairly quickly on Locke's heels with the rationalist rebuttal to the doctrine that: 'There is nothing in the intellect except that which enters in through the senses' - that rebuttal being: 'except the intellect itself.' Stephen Pinker is well aware of this. As well, he is clearly aware that the roots of the altercation lie much deeper still. Compelling intellectual foes die hard, though. They tend to rear their heads whenever the pendulum swings back one way or the other towards rationalism and away from empiricism - towards the mind's fullness and contentful nature or its lack thereof so evolutionary psychology's present act of resistance is, arguably, a timely accommodation to, and antidote for, current beliefs. For this reason, if evolutionary psychologists are, in fact, correct in their reading of the contemporary intellectual scene, they would be justified in professing their theory's revolutionary character.
} 
In The Blank Slate (2002), Steven Pinker, evolutionary psychology's most famous ambassador, tries to pin the doctrine on a diverse conglomerate of academic intellectuals in contemporary culture. A popular book written for a broad and general audience, Pinker's purpose is conspicuously not to educate the masses regarding the perniciousness of a doctrine that has trickled down to them and which, he wishes to advise, they should forthwith abandon. This goes directly contrary to his own good sense of their intelligence and determination to resist writing works that, as he himself puts it, have been 'dumbed down.' When writing for the "Third Culture," that culture that spans the gap between science and literature, one writes simultaneously to one's colleagues as well as the public, according to Pinker (2001, p. 91). Part of what we learn from Third Culture manifestos, therefore, is to be wary of what the experts believe.

We also learn from Pinker that the Blank Slate Doctrine has insinuated itself into the scientific thinking of behaviorists in psychology, relativists in cultural anthropology, constructionist thinkers in neuroscience and evolutionary biology, and for that matter, any other social constructionist thinker who might hazard to come along. Pinker does his best to establish the pervasiveness and obstinacy of this doctrine in the current academic and popular/political scene. He reinforces its irksome permeability by making a case for the Slate's compatibility with romanticism, encapsulated by Rousseau's conception of a Noble Savage, and Descartes' Ghost in the Machine, also known as mind/body dualism. It is, however, almost too easy a point of criticism that the Noble Savage, being noble, can't be blank and so, as the philosopher Colin McGinn explains, these "quite distinct ideas" are "in clear tension with each other" (2002, p. 4). A similar point of criticism can be made about dualism, particularly dualism of the Cartesian variety, for while the mind is conceived as an entity independent of biology for Cartesian 
dualists, it is an entity associated with 'goodness' in nature while the body is (like 'society' on Rousseau's view) associated with corruption.

However, representatives in these fields are not going to take Pinker's charge lying down. Social constructionists will be the first to mimic the objection of the empiricists and say that theirs is not a theory of mind, but a theory of knowledge, too, not any more logically tied to the proposition that human nature is empty from the outset than is empiricism. In fact, many social constructionists may find evolutionary psychology's conception of a person wholly compatible with their views about how knowledge is produced, circulated, and validated and can join Pinker in his contention that "while conflict is a human universal, so is conflict resolution" (2002, p. 58), a contention that is specifically born out by their theories. For social constructionist theories, by taking account of their actors' (mainly scientists and technologists) interests, power needs, and negotiating skills, show how their protagonists use these interests, needs, and skills to effectively bully or cajole other actors (mainly scientists and technologists but also interest groups and other public entities) to come to accept their views about the nature of Nature. Indeed, the main actors in a scientific network are presented in model evolutionary psychology terms as "high spec, specialized problem solvers just waiting to spring into action" (Pinker, 2002a).

Additionally, it will not pass the notice of psychologists that behaviorism, which evolutionary psychologists attack as a Blank Slate theory, was Darwinian in its foundation sharing "with all systematic psychologies since Wundt...the conviction that human psychological processes have evolved, are present in lower forms of life, and are the outcome of transactions between the organism and the environment" (Robinson, 1995, p. 350). Even the eminent philosopher W.V. Quine found the need to stress the point that "innate biases and 
dispositions are the cornerstone of behaviorism" (1969, p. 96). At the same time, anthropologists will urge that whereas, perhaps, some wayward practitioners have gone to the extreme of embracing something approximating the Blank Slate theory of mind (e.g., Clifford Geertz) many have rejected the notion that the mind is born an empty vessel. Indeed, the important conclusion reached by anthropology in its very early years when Darwinism was in its infancy, was that cultural phenomena could not be reduced to psychological phenomena (Brown, 1999, p. 119). This caused them to bracket the psychological facts and withdraw from evolutionary theorizing, but this is not the same as to say that they denied the existence, influence or relevance of these facts upon culture altogether.

Evolutionary psychology's treatment of constructionist neuroscientists will be a focal concern of this dissertation. Suffice it to say, that if as these neuroscientists claim the brain participates in its own construction as it interacts with its internal and external environments (a process Pinker calls a 'mystery' but which he concedes nevertheless occurs $(2002$, p. 91)), then the idea that it has no nature of its own is - at a most basic level - contradicted. Developmental plasticity so understood is surely not tantamount to 'nothing.' Furthermore, the Blank Slate is contradicted, at a rudimentary level, when evolutionary biologists, like Richard Lewontin, maintain that human beings are capable of negating and thereby transcending the constraints imposed by their biology (1981); for to transcend and negate means there is something substantial there to be transcended and negated. Once more, the question becomes: who among the aforementioned theorists really subscribes to the theory of the Blank Slate? Is it, perhaps, not the target evolutionary psychology needs to overturn to instigate its conceptual revolution?

Of all the alleged advocates of their target view, the evolutionary psychologists most interesting omission are the existentialists. One wonders why its proponents are not included in 
evolutionary psychology's coterie of Blank Slate sympathizers when they seem to be the only ones who unabashedly proselytize the doctrine. As is well-known, the existentialists take as their most fundamental principle the idea that existence precedes essence. They are not averse to pithily saying: man has no nature. To my mind, the existentialists are the only ones audacious enough to proclaim that there is nothing 'there' at all, dismissing the claim that human logic is a part of our nature, pace Locke, and rejecting all inborn sources of value. Yet, they bear no brunt of evolutionary psychology's theoretical attack. And indeed they should not, as it turns out, for the existentialist stance is importantly different from the scientific one about the developmental plasticity of our nature. Existentialists mean to affirm the primary significance of the conscious subject before science and philosophy ever figure in (Lavine, 1984, p. 328). In sum, the only intellectuals who fit Pinker's view fit it for the wrong reasons.

Interesting, too, is that Pinker lets the Marxists off easy. He takes the position that they are merely guilty of believing the mind has no enduring properties even as it emerges in the course of interactions with other people under particular material conditions. But this is not the Blank Slate (Pinker, 2002, p. 155). One wonders, why, if the Marxists are let off the hook, the others aren't let off, too? I suspect that not a single one of the theorists I have mentioned (except, perhaps, the existentialists) would deny being interactionists as well.

The Blank Slate Doctrine proves to be a porous doctrine, an amorphous sprawling entity, with many half-hearted supporters, if any supporters at all, a theory embraced by and associated with academicians in every possible discipline and yet not sufficiently embraced by any particular discipline to constitute the threat the evolutionary psychologists make it out to be. In taking the Blank Slate as their target, which begins to appear as rather nothing more than a caricature of their adversaries' view, evolutionary psychologists miss the opportunity to deflect 
the charges leveled against them by very real and identifiable contenders. This dissertation brings some of their voices into the fray.

\section{Enter New Voices}

The theorists I have in mind, who hail from the fields of biological anthropology, empirical linguistics and developmental psychology, are evolutionarily informed in their perspective of human nature. They are not personages from the past of philosophy, psychology, or any other discipline but are right there in the trenches practicing science alongside the evolutionary psychologists. Barbara King in anthropology, George Lakoff and Mark Johnson in linguistics, and Annette Karmiloff-Smith in psychology are the social science counterparts to the evolutionary biologists most vocally rebuked by evolutionary psychologists in the public forum. These figures' criticisms are as important as those of the late paleontologist Stephen Jay Gould and the geneticist Richard Lewontin.

Yet, these thinkers have fallen off - or better yet, they have been deliberately forced off evolutionary psychology's conceptual radar. And they are forced off the radar because they are worthy opponents of evolutionary psychology whose criticisms need to be paid serious attention. Their theories in fact draw attention to details that show that the supposedly Blank Slate was always already substantially marked up to begin with. Yet, the doctrine of the Blank Slate is so constructed as to enable its opponents to overlook these other in-between views.

Biological anthropologists, empirical linguists, and developmental psychologists have made significant advances in their thinking on the evolution of cognition. Practitioners from these fields have been marginalized, however, as participants in the conversation with the evolutionary psychologists, with the result that crucial knowledge deriving from them is submerged. This knowledge issues from the different kinds of questions that they raise about 
how our cognitive capacities evolved and the different model conceptions of a person with which they work. If, as Alfred North Whitehead instructed, ${ }^{7}$ one ought not focus chiefly on the intellectual claims the exponents of a position defend, but rather on the fundamental assumptions which they (unconsciously or otherwise) presuppose then these views, marginalized by evolutionary psychology, may tell us something significant about what it takes as obvious that may not be obviously so.

For example, many biological anthropologists urge that evolutionary psychology is an objectionably anthropocentric perspective, that it obscures the centuries-old debate that rages over the question of man's continuity (or discontinuity) with the rest of the animal kingdom. Thus, many biological anthropologists regard the species-specific form of language found in humans as differing from other non-human primate communication schemes in degree, but not in kind. Predictably, biological anthropologists also tend to reject syntax as definitive of language and alternatively take the view that language is "composed of various critical components or as a complex form of social communication that results in cohesive social groupings" (King, 2002a, p. 20). Biological anthropologists take human as 'animal' as their working model conception, not human as 'thinking machine' in the manner of evolutionary psychology. Empirical linguists bring to the table an emphasis on the universal experiences of people, not the universality of their genetic make-up. Notably, too, they do not buy the poverty of stimulus argument used to buttress the case for the innateness of language enthusiastically

\footnotetext{
${ }^{7}$ This is a liberal application of Alfred North Whitehead's dictum that philosophy and the sciences in any given period are governed by a seldom mentioned and taken for granted set of assumptions (Science and the Modern World, 1925 Chapter 1). The philosopher F.M. Cornford also quotes Whitehead as writing: "When you are criticizing the philosophy of an epoch, do not chiefly direct your attention to those intellectual positions which its exponents feel it necessary explicitly to defend. There will be fundamental assumptions which adherents of all variant systems within the epoch unconsciously presuppose." This passage is quoted in turn by W.K.C. Guthrie in The Greek Philosophers, 1950, p. 11. Whitehead's words make clear that significant common ground can be presumed to exist between evolutionary psychologists and the practitioners brought forward in this dissertation.
} 
embraced by evolutionary psychologists and many other thinkers. The poverty of stimulus argument says that children acquire grammars on the basis of little instruction and meager data; hence, the general rules of language must come from somewhere else, i.e., the mind itself. Empirical linguists regard the mind, fundamentally, as an embodied entity. They reject the view that the mind is comprised of a multiplicity of specialized modules or mini-computer programs that processes information, which figuratively at least, grounds a more disembodied view of the person. With respect to language, empirical linguists emphasize the importance of meaning over syntax and grammar.

Finally, developmental psychology is an important perspective to bring forward if only for the reason that historically, after the advent of genetics at the beginning of the twentieth century, the notion of development has been glossed over by evolutionarily oriented thinkers. As it turns out, evolutionary psychologists have glossed over it as well. Evolutionary psychology has been criticized for conceiving development, even though it may require triggering and maintenance by environmental factors, as nothing more than an automatic process set in motion by our genes. For developmental psychologists this is a limited, one-sided notion of development that belies real epigenetic developmental processes (Lickliter, 2003). Developmental psychologists, like the biological anthropologists and empirical linguists before them, are also uniquely poised to speak to the issue of human variability - to aid in resolving the diversity of unity question raised 2500 years ago by the Greeks, the question of how the many and the one, human nature and human variability, can be reconciled. Developmental psychologists take the 'growing child' as their working model conception of a person. All of these fields attach greater significance to the role of the environment in the evolution of cognition than do the evolutionary psychologists. For the latter, the environment 
functions mainly as a trigger for the development of cognitive traits and a poser of survival problems (Lickliter, 2003, p., 829). The psychologist Susan Oyama calls this a "bloodless interactionism” equivalent to simply saying 'the environment is important, too' (e.g. Buss et al., 1999)" (2001, p. 179). The biological anthropologists emphasize, by contrast, the importance of the social environment in developing, shaping, and sustaining our cognitive capacities and argue, consequently, that social learning and social flexibility are evolution's bequest to our species.

While conceiving the role of the environment in terms as general and abstract as the evolutionary psychologists, the empirical linguists nonetheless play up the importance of the environment for, as they explain, it is our embodied experiences in the world that ground our cognitive faculties. Experience is central. Finally, the developmental psychologists present the most sophisticated account of the role of the environment in the development of our cognitive capacities integrating both social and neurobiological factors. For developmental psychologists human cognition is grounded in ontogenetic processes that take shape as these processes occur and is sustained by our own active participation in their construction. In short, developmental processes enfold evolutionary ones and determine their final biological expression.

Nonetheless, The Blank Slate garners all of evolutionary psychology's attention. The Slate defines what evolutionary psychology does not stand for and what its views are not. In the following chapter I show how its strategic deployment serves to reinforce the preconceived notion evolutionary psychologists have (and which they seek to promulgate) about their proper relation to the other disciplines and the role that all the disciplines should play towards the end of advancing knowledge. The modernistic architectonic that they devise to define these relations (the Integrated Causal Model) coheres amicably with their highly theoretical, ultimately reductive, either/or reasoning. All these facets of their argumentation will be discussed. They 
are counterbalanced by the more historical approach of practitioners in the cognate disciplines to whom their views shall be compared. Most importantly, I will show that evolutionary psychologists would profit greatly by taking seriously the work done in these other disciplines and modifying their hard-edged stance to allow them to profit from the insights that they could thus incorporate into their own work.

\section{CHAPTER 2. SCIENCE, RHETORIC AND THE WAYS OF REASON}

The terms of the evolution debate must be broadened to incorporate the voices of practitioners from fields outside evolutionary psychology if we are to make progress in our thinking about the nature and design of human cognition. The three disciplines I wish to bring in lay greater stress on learning and flexibility (neural learning and flexibility as well as social learning and flexibility) as key factors. My contention is that evolutionary psychologists, by downplaying these factors (or tactically redefining them), have adopted an alienating stratagem designed to suggest research in these other disciplines does not count. Bad as this is, it is made worse by the fact that learning and flexibility are perceived by biological anthropologists, empirical linguists and developmental psychologists, if not as uniquely human, then as laying the foundation for development of capacities that are uniquely human. ${ }^{8}$

Emphasis on 'learning' is directly correlatable with emphasis on the environment's role in the development of our cognitive capacities. For what is not inside the mind must come from the outside by some special means. By conceiving cognition as modular and hence fully formed in its own right, evolutionary psychologists (metaphor of choice is to) say that the mind's modules 'grow' rather than develop through constructivist learning processes. The mind does

\footnotetext{
${ }^{8}$ As Karmiloff-Smith puts it "non-nativist theories of language can actually be thought of as a new machine built out of old parts." She goes on: "From this point of view, it is claimed that human adaptations do not reflect an evolutionary dissociation between humans and their primate relatives" Pathways to Language: From Fetus to Adolescent (2001), pgs. 220-221.
} 
not need to extract crucial information from the environment in its problem-solving. It has the unlearned native knowledge it needs already at hand.

By contrast, Barbara King in anthropology describes social learning and social flexibility as the "twin pillars of the human evolutionary legacy." She sees in evolutionary psychology the tendency "to empower past selection pressures to the exclusion of social learning and social flexibility which are key facets of the human evolutionary past" (2002a, p. 35). It would nevertheless be erroneous to regard King as among the many social scientists Pinker criticizes who, "believe that learning is some pinnacle of evolution that humans have scaled from the lowlands of instinct, so that our ability to learn can be explained by our exalted braininess" (1994, p. 242).

King is quite clear that learning is much more deeply rooted than that. Certainly, she recognizes, as Pinker points out, that even bacteria learn. However, King would not say that the flexibility that attends the capacity to learn (in the robust sense of the term she endorses) puts people at the mercy of society and open to indoctrination as Pinker suggests. Learning in the trial and error experiential sense, however, is a sense Pinker strictly associates with the Blank Slate Doctrine. As reconceived by evolutionary psychology, learning is a consequence of the brain's having in place innate circuitry that presupposes a great deal of mental content and structure already (Pinker, 2002b).

The empirical linguists place their emphasis on neural learning, not social learning as King does or ready-made knowledge as does evolutionary psychology. Their concern is with the growth of new neurological connections set off by our embodied experiences in the world and the concepts to which they give rise. The linguists do not take much interest in behavioral flexibility either even as they grant the brain's plasticity. The reason is that they believe only a 
small percentage of our conceptual categories are formed by conscious acts, and that we "cannot make massive changes in our category systems through conscious acts of recategorization (though, through experience in the world, our categories are subject to unconscious reshaping and partial change)" (1999, p.18). 'We are not our brains' for the empirical linguists as we tend to be for the evolutionary psychologists ${ }^{9}$ who render experience, an extra-mechanical process involving our bodies, incidental and secondary, if not dispensable (as with machines).

Like Pinker, Karmiloff-Smith in developmental psychology emphasizes endogenous factors and is inclined to call the new knowledge that arises spontaneously and unconsciously from these factors 'learning' as well. Karmiloff-Smith sees the adaptive role of lengthy postnatal periods of learning in all forms (neural, individual, social) as essential to the development of the capacities human beings share with other primates, some of which were once thought to be evolutionarily unique, such as the pincer grip (2001, p. 221). This very long developmental period is what makes us special, on her view, "because it gives us a greater capacity for adapting to, learning from, and ultimately changing our environment” (2001, p. 222).

Karmiloff-Smith stresses that spontaneous learning as well as learning from being taught is a consequence of the brain's plasticity. She believes that the specialized, localized circuits found in the human brain emerge from the brain's interaction with its environment during development at the neurological level, individual level and sociocultural level. These brain circuits are not ready-made nor are they universal in character. For Karmiloff-Smith, different specialized cognitive domains are progressively selected for in different cultures. Thus, unlike Pinker, Karmiloff-Smith acknowledges the role of sociocultural interaction patterns in imparting

\footnotetext{
${ }^{9}$ In her review of The Blank Slate, the philosopher Mary Midgley quotes Pinker as saying: "We are our brains." She responds in her review: "If that is what we are some people might wonder what has happened to the rest of our bodies" ("It's All in the Mind," The Guardian (London), September 21, 2002, Available from: http://books.guardian.co.uk/review/story/1,12084,795048,00.html
} 
new knowledge (1992, p. 122). She considers all these different influences on development to be important.

Evolutionary psychologists' decision to target the Blank Slate exacerbates the tension among all these researchers and stands in the way of their making interesting, interdisciplinary connections. What is more, the Blank Slate is a view that probably no one has ever held and therefore as close to a straw man as it gets. The evolutionary psychologists direct all their arguments against it, however, then proceed to contest all of the criticisms that give equal play to cultural factors and to biology, claiming that they are last ditch efforts to keep the Slate propped up before it finally keels over and that they constitute the Slate's Last Stand. ${ }^{10}$ Their rhetorical maneuver of choice, in short, is to couch their arguments and divide through theorists in either/or terms: either one subscribes to their understanding of how the mind works or by default one commits to an anti-evolutionary or non-evolutionary stance.

Two things are worthy of note. The first that this particular tactic is deployed in the first instance against disagreeable evolutionary biologists - the very practitioners with whom evolutionary psychology seeks to strike its main alliance. ${ }^{11}$ The philosopher Daniel Dennett, who is most sympathetic with evolutionary psychology, has gone so far as to call Gould a non-evolutionist (1995, p. 391 fn). Tooby and Cosmides accuse Lewontin of "expressing a thoroughly orthodox SSSM skepticism towards the idea that the human psychological architecture is functionally organized" (1992, p. 57). Obviously, this sort of sleight of hand dismissal of recalcitrant biological researchers makes serious engagement with practitioners in

\footnotetext{
${ }^{10}$ See especially Steven Pinker's The Blank Slate (2002), Chapter 5.

${ }^{11}$ Elsewhere Pinker states: "Most intellectuals think that the human mind must somehow have escaped the evolutionary process. Human behavior is too subtle and complex to be a product of evolution, they think. It must come from somewhere else - from, say, "culture"” (Pinker, 1998, "A Mind to Love" The Guardian Newspapers (London), January 17, 1998, Weekend Page, p. 22). The philosopher Patricia Churchland responds to Pinker accordingly: "But I can't think of anyone who thinks that... of course there is an evolutionary basis of the mind. The tricky part is to figure out how it all works." (Pinker, 1997b, Time, book review by J. Madeline Nash).
} 
outlying fields, with whom evolutionary psychology seeks no special partnership at all, all the more unlikely. Pinker explicitly challenges social scientists with "pretending evolution has nothing to do with the 'fantastically complex design' of the human mind" (1997b). Few honest, inter-textual relationships with social science researchers have therefore been established. What is more, these academicians do glean insights from evolutionary theory as well.

The second notable fact about evolutionary psychologists' rhetorical use of either/or thinking is that they are the ones who argue that this cognitive reasoning style has an evolutionary basis. Discerning this, two defenders of evolutionary psychology, Jason Young and Roger Persell, have urged that the natural tendency to reduce complex data into two piles explains their critics' imputation of simplified and erroneous assumptions to their view, particularly, as applied to the heritability of behavioral traits in terms of one-gene per trait (2000). Sociobiology's founder E.O. Wilson did speak as if there were a straightforward correspondence between genes and behavior. Nevertheless, the succeeding generation of whole-animal biologists realized that the way he spoke was wrong (Bateson, 1985).

Thus, the tendency to lump and simplify appears to be more appropriately attributed to Young and Persell for they misrepresent evolutionary psychology's critics on this issue. Its sharpest critics are attuned to evolutionary psychology's differences from sociobiology, although these differences are less extreme when it comes to gene-centered talk than Young and Persell let on. Pinker may claim, for instance, that he is smarter than his selfish genes and tell them to jump in a lake (1998) whenever he wishes, but the ready-made gene-centered talk is still there as it comprises the nomenclature he espouses. Developmentalists, on the other hand, eschew gene-centered talk of this sort. 
Evolutionary psychologists maintain not only that advocates of the Standard Social Science Model (SSSM) ignore evolution because it is irrelevant, ${ }^{12}$ but also that they use the SSSM to justify the insertion of a wall of separation between the natural and social sciences (Tooby and Cosmides, 1992, p. 49). In the place of this wall evolutionary psychologists seek to effect, "reasoned connections with other branches of knowledge" (1992, p. 22); "to break down the barrier that logically insulates the social sciences from the natural sciences" (1992, p. 48). In short, their goal is to unify all the sciences within the emerging framework they call the Integrated Causal Model (ICM).

Thus, evolutionary psychology is not just a hybrid field created at the margin of evolutionary biology and cognitive psychology. ${ }^{13}$ Hybrids are a consequence of the fragmentation of specialties that accompanies normal disciplinary growth and the diminishing returns that research brings in crowded fields (Dogan and Pahre, 1990, p.7). Evolutionary psychology is also a transdisciplinary perspective and has the same transdisciplinary aims that sociobiology before it had. It constitutes a paradigm or worldview that "transcends narrow disciplinary worldviews through overarching synthesis (Miller, 1982, 20-22)" (Klein, 1996, p. 11). Consequently, evolutionary psychologists are just as concerned to change disciplinary identities if the presently accepted postulates of those disciplines pose a challenge to evolutionary psychology, and not merely to facilitate syntheses between the accepted postulates of disciplines.

\footnotetext{
${ }^{12}$ In "The Psychological Foundations of Culture," Tooby and Cosmides assimilate Richard Lewontin's stance to the SSSM because he suggests that, "human cognition may have developed as the purely epiphenomenal consequence of the major increase in brain size which, in fact, may have been selected for quite other reasons (Lewontin, 1990a, p. 244)" (The Adapted Mind, 1992).

${ }^{13}$ According to Linnda R. Corporael and Marilynn B. Brewer evolutionary psychology is a problematic term "because it supposes that a model of evolution can be discipline specific" ("Metatheories, Evolution and Psychology: Once More With Feeling, 2000).
} 
It should come as no surprise, then, that the evolutionary psychologists employ various tactics to police the intellectual territory that falls at the interstices of evolutionary biology and cognitive psychology which they seek to own. Their policing, as I see it, is intended to keep the right kind of researchers in and the wrong kind out. ${ }^{14}$ The state of affairs they have created is an interesting one. While evolutionary psychologists do make overtures to researchers from a wide range of fields to cross disciplinary boundaries and take an interest in their investigations their message can be interpreted in two quite different ways: as an invitation to contribute to cognitive science, broadly conceived, and as an invitation to contribute to cognitive science as evolutionary psychologists understand it. In ostensibly suggesting the former, evolutionary psychologists probably intend the latter. ${ }^{15}$

With regard to the first, little professional risk is involved. Darwin, after all, is prophet for this cause. In fact, today cognitive science is a well-organized multidisciplinary endeavor, one which has grown considerably in recent years. It draws on research from psychology, linguistics, neuroscience, computer science and philosophy. Practitioners can stay safely within

\footnotetext{
${ }^{14}$ This way of understanding disciplinary relationships is not universally accepted. According to Dogan and Pahre, "A formal discipline is not like an empire preoccupied with defending its frontiers. No Great Wall is possible, and no such wall could keep the 'barbarians' out: scholars move from one territory to the other without passports" (Creative Marginality, 1990, p. 230). But compare Smith writing before disciplinary boundary talk was in vogue: "One of the evils of specialization in modern thought has been the official division of reality into fields, topics, or subject matters which are declared to be the exclusive property of this or that science or discipline. Once the parceling out has taken place, the "no trespassing" signs are posted and poaching is strictly forbidden. In order to inquire, one must have an official field of inquiry, and it is strictly against the rules for anyone to make pronouncements about regions of reality already owned by someone else" ("William James as Philosophical Psychologist" in Themes in American Philosophy by John Smith, 1970, pgs. 61-62).

${ }^{15}$ In "Mind, Morality, and Evolution: An Interview with Steven Pinker," Free Inquiry, Spring, 2000 (located in the References Section of this paper under 'Pinker'), Pinker acknowledges the 'ambiguity' of the term evolutionary psychology but distinguishes the two senses differently. He states: One sense of evolutionary psychology is...the desire to connect psychology to evolutionary biology. A more specific version says that the mind has many parts, and that the design of many of those parts can be explained in terms of selection and adaptation. So, the broad version is really a methodological approach. It is a meta-scientific desire to unify all the sciences. The narrower one is an empirical hypothesis that would be refuted if it turned out that one general-purpose learning algorithm could account for all our thoughts and feelings." Notably, evolutionary psychologists own the entire field given these senses of the terms. For the value of pluralism and difference is submerged by assumption of a common methodology, yet different approaches are precisely what need to be compared and evaluated before the intelligent assessment of specific claims can take place.
} 
their own fields at the same time they engage in cross-disciplinary communication. They need never risk "finding themselves homeless, in a state of social and intellectual marginality" as can happen in the case of some interdisciplinary endeavors (Klein, 1990, p. 13).

With regard to making contributions to cognitive science as evolutionary psychologists understand it, there is a bit more at stake. It means subscribing to the ICM and accepting an antecedently laid out conception of what work needs to be done. It means tolerating the top-down hierarchical structure that evolutionary psychology sanctions, giving it the dominant voice to pass or not pass on research activities. As its framers, Tooby and Cosmides put it: "In this alternative framework, nothing is autonomous and all the components of the model must mesh" (1992, p. 23).

Finally, with regard to alternative approaches to the development of cognitive science, which would grant to researchers in other fields of study their autonomy, particularly, with respect to methodology, at the same time that they addressed shared concerns ${ }^{16}$ evolutionary psychology has been remarkably silent. It has chosen to relate to other disciplinary fields mainly through engulfing them.

\section{Evolutionary Psychology: On Its Own Turf}

Evolutionary psychology's goal is to secure alliances with researchers prepared to embrace the ICM and take their theoretical claims regarding modularity, universality and adaptation as the paradigmatic framework for conducting 'normal science.' Such normal science tasks would involve identifying all the mind's modules, making explicit the decision rules by which each module operates, contriving plausibility arguments about the Environment of Evolutionary Adaptedness (EEA), i.e., the conditions that existed during the Pleistocene, through

\footnotetext{
${ }^{16}$ See proposals of Haig and Durrant, (2000) and Hardcastle, (1993) on alternative theoretical structures within which cognitive science might develop.
} 
empirical investigation of current hunter-gatherer societies, and so on. Evolutionary

psychologists seek to stimulate formation of a scientific community of a certain sort, in other

words, not just to stimulate formation of a scientific community. They aim to motivate

researchers to accept their meta-theoretical claims above all, not merely motivate researchers to participate in the interdisciplinary endeavor of understanding human cognition in its own right.

One can thus take exception to evolutionary psychology's claim to inspire interdisciplinarity when compared, for example, to the efforts of Dobzhansky, Schrödinger and E.O. Wilson as described by Leah Ceccarelli in her work, Shaping Science with Rhetoric (2001). Dobzhansky, Schrödinger and Wilson, were expressly not concerned to validate any particular scientific truth-claims, according to Ceccarelli. Their aim was simply to build an interdisciplinary bridge - a formidable task in its own right. ${ }^{17}$ So what Ceccarelli calls 'polysemy' - a rhetorical device successfully deployed by Dobzhansky and Schrödinger (less so by Wilson) to motivate the collaboration of scientists to explore new fields of inquiry - is actually exemplified by the textual construction 'evolutionary psychology' and the two ways it can be read. Polysemy refers to text that lends itself to the diverse interpretations of its readers. Polysemy enables the writer to speak simultaneously to different (disciplinary) audiences whose constituents then understand the writer's words in their own terms. Evolutionary psychologists

\footnotetext{
${ }^{17}$ Cecarelli is a rhetorician so she augments the reasons, from a rhetorical perspective, that Wilson was less successful than Dobzhansky and Schrödinger. Her finding is that Wilson's rhetoric was impolitic and could have been better designed to persuade his target audiences since many of his critics accepted the sociobiological thesis that humans have a biological nature. But while Wilson's critics may have agreed with the general outline of his project, they may also have been more skeptical than Dobzhansky and Schrödinger's audiences were because his notion of 'consilience' was transdisciplinary in the sense noted above. Wilson's project involved more than interdisciplinary bridge-building. Interdisciplinary bridge-building tends to avoid critical reflection, to take place between complete and firm disciplines and to concentrate on synthesizing presently accepted postulates, not changing their parts or altering disciplinary identities (Klein, 1990, p. 27). Like evolutionary psychology's ICM, Wilson recommended a restructuring of disciplinary schemata and new integrative categories of thought that posed a potential challenge to current categories and practices.
} 
engage in polysemy with a twist, however, for they hope to achieve even more than did Dobzhansky and Schrödinger (as noted).

Because they seek to attract researchers congenial to their particular aims, evolutionary psychologists engage in what appears to be the inverse of polysemy, what we might describe as 'semantic restriction' or 'semantic replacement.' That is to say, instead of exploiting textual ambiguity to appeal to a wide range of researchers - evolutionary psychologists insinuate a particular determinate or inflexible meaning upon their text to restrict the interpretive abilities of the reader. Conclusions are then urged that may not seem to follow (from a more robust understanding of the concepts), though a common vocabulary has been used. The upshot is that evolutionary psychology's appeal to certain audiences is neutralized. All the key words - genes, culture, development, environment, interaction, plasticity, flexibility - tend to mean things and imply things quite specific to evolutionary psychologists that they do not necessarily mean or imply to other working scientists. While one gets the sense they are saying all the right things and paying attention to all the right factors - (development, for example, plays a central role in their writings, but not development as developmentalists understand it) - each of these words has a sub-text.

The battle over their meaning cannot be settled by evolutionary psychology's rhetorical efforts to speak past their opponents - their means of silencing the differand. Significantly, theoreticians in boundary work suggest that these sorts of communication practices constitute an inevitable consequence of cross-disciplinary communication. In cross-disciplinary communication the odds increase that specialties borrowing concepts from other specialty fields will distort the meaning of those concepts or change the way the concepts were originally used. At the very least, the importation and exportation of concepts from one specialty field to another 
creates a situation where concepts change meaning frequently. To cope with this problem, some researchers have embarked on the task of compiling a conceptual dictionary to serve as a basis for standardizing cross-disciplinary communication terminology (Dogan and Pahre, 1990, p. 233).

This endeavor completely misses the point of the many contentious exchanges, however, not just evolutionary ones. The point precisely is securing agreement on the meaning of shared terms through give and take, something that cannot get started by stipulating that a concept shall be used in this way rather than that. Tim Ingold discerns five meaningful albeit different uses of what constitutes a 'biological perspective' in Robert Hinde's book Individuals, Relationships and Culture: Links between Ethology and Social Science (1987) (Ingold, 1988, p. 783). As he puts it, this shows the concept of biology to be as protean as the concept of culture. ${ }^{18}$ Yet today while anthropologists debate the usefulness of the concept of culture, new fields of study, e.g., Cultural Studies, are constructed around it and its inherent meaningfulness. How these concepts should be unpacked is where the argument begins.

Most importantly, for the purposes of this dissertation, is how the concept of 'language' is defined; for that will determine our answers to other important questions, such as: "When do we first see evidence of language in hominids? Are precursors to language found in other primates?" If language is defined in terms of the system of rules governing word order or syntax, as evolutionary psychologists define it, then we are forced to understand language as a phenomenon unique to human beings. Biological anthropologists reject such understandings because they do not engage evolutionary questions (King, 2002a). Defining language in terms of

\footnotetext{
${ }^{18}$ In "An Anthropologists Looks at Biology" (Man, Vol. 25, No. 2, June 1990, 208-229), Ingold completely reconceptualizes the disciplines of biology and anthropology redefining what 'growth' means, what 'life' means, and 'evolution' along the way.
} 
syntax ties it to the human brain specifically and makes the search for precursors to language and inquiry into the selection pressures of these precursors unreasonable. In short, 'borderline' areas of research, such as ape language research (ALR), cannot be thought relevant to processes of human linguistic acquisition because apes lack the 'language gene' (Shanker, 2002, p. 128).

When a human standard for what counts as language is presupposed, not surprisingly, non-human primates fail to measure up (King, 1994, p. 6). Hence, the argument that in the last 50 years of paleoanthropological theory the tendency has been to redefine the meaning of traits like upright posture, large brains, technology, and language "whenever it was necessary to protect their axiomatic human uniqueness from the threat of empirical reality" (Cartmill, 1990, p. 179). In particular, as primatologists have uncovered impressive semantic abilities in animal communication, syntax has taken on increasing importance for linguists' appraisals of language (Cartmill, 1990). However, definitions of language that avoid the bias implicit in the human standard have been recommended and include, for instance, the social donation of information approach postulated by King. On this approach, the monkey directing an alarm call at her offspring as a predator approaches would be an instance of the social donation of information (King, 1991).

'Interactionism' is another example of an important term whose meaning precisely is the debate. Evolutionary psychologists claim to be interactionists. ${ }^{19}$ The academic debate over evolutionary psychology can even reasonably be viewed as a contest over the meaning of this term. Susan Oyama has observed that 'interactionist' has become something of a membership badge - everyone wears it - and, as a consequence, the term has become conceptually vacuous as

\footnotetext{
${ }^{19}$ Tooby and Cosmides are clear on this (1992, for example, p. 84); Pinker, on the other hand, inherits Chomsky's hostility to the notion (see Howard Gardner's "Foreword: Cognition Comes of Age" in Language and Learning: The Debate between Jean Piaget and Noam Chomsky edited by Massimo Piattelli-Palmarini, Harvard University Press1980, p. xxiii); although Chomsky does not resist employing the term 'interactionism' whenever necessary (Chomsky, 1980, p. 109).
} 
its proponents persist in filling in the term's details in their own ways (1985, p. 5). Specifically, critics of evolutionary psychology discern in their version of interactionism "a deep-seated ontological separation between causal components that represent nature (genes) and those that represent nurture and all else"(Lickliter, 2003, p. 821). Pinker shows his impatience with the metaphor of interactionism even as he embraces it when he suggests the metaphor poses as an excuse not to specify the innate part of the interaction (1997, p. 33). In this way, he confirms his critics' charge. He goes on to challenge the dualisms of biology and culture and innate and learned by showing that the elements in each duality are not opposed but that they work together in an explicit manner.

In all, Pinker views these dualisms as complementary, while he rejects the term 'complementary', too, because it is too nebulous. He wants the metaphor used to convey explicitly not vaguely what is intended. And what is intended is not the blending and merging of biological and social factors in such fashion that their precise cause and effect relation is left undetermined or that they cannot be teased apart. Evolutionary psychologists believe that these dualisms are not extremes, but that each part counts, even as the biological side counts for more since it explains precisely how and why the cultural side works as it does. The biological side has the causal force. "Complexity in the mind is not caused by learning," Pinker tells us, "learning is caused by complexity in the mind" (1994, p. 125). So we might call the relation of these terms, as evolutionary psychologists understand that relation, 'explicated complementarity. ${ }^{20}$

\footnotetext{
${ }^{20}$ In line with the notion of explicated complementarity, Pinker states: "But if the mind has a complex innate structure, that does not mean that learning is unimportant. Framing the issue in such a way that innate structure and learning are pitted against each other, either as alternatives or, almost as bad, as complementary ingredients or interacting forces is a colossal mistake" (1997, p. 32). He goes on: "It's not that the claim that there is an interaction between innate structure and learning (or between heredity and environment, nature and nurture, biology and culture) is literally wrong. Rather, it falls into the category of ideas that are so bad they are not even wrong" (1997 p. 32). For Pinker the two parts of the dichotomy augment one another; they do not trump one another. For
} 
Tooby and Cosmides' arrive at explicated complementarity in their own way. They explain that "the idea that the phenotype can be partitioned dichotomously into genetically determined and environmentally determined is deeply ill-formed, as is the notion that traits can be arrayed along a spectrum according to the degree that they are genetically versus environmentally caused" (1992, p. 33). Tooby and Cosmides agree with those normally regarded as their adversaries: "The critique of the SSSM that has been emerging from the cognitive and evolutionary communities is not that traditional accounts have underestimated the importance of biological factors relative to environmental factors in human life. Instead, the target is the whole framework that assumes 'biological factors' and 'environmental factors' refer to mutually exclusive sets of causes that exist in some kind of explanatory zero-sum relationship, so that the more one explains 'biologically' the less there is to explain 'socially' or 'environmentally." They conclude: "On the contrary... environmentalist claims necessarily require the existence of a rich, evolved psychological structure" (1992, p. 33-34).

The irony is that the proper relation of biology and culture that they uphold forces them to place practitioners of psychology and anthropology in precisely the zero-sum relationship that reconciliation of the opposition between biology and culture is supposed to counter. In spite of their rhetoric of explicated complementarity the thrust of evolutionary psychology's position is that biological factors do take precedence over cultural ones and that biological and cultural factors can be neatly distinguished. Pinker describes the language faculty as belonging more to biology than to culture (Pinker and Bloom, 1990); Tooby and Cosmides talk about the recurrent organization of the environment contributing to the biological inheritance of the organism (1992, p. 84), but not of the organism's role in codirecting human genetic evolution through the active

"learning is not an alternative to innateness; without an innate mechanism to do the learning, it could not happen at all" (1994, p. 408). In sum, for Pinker, "evolutionary psychology does not disrespect learning but seeks to explain it" (1994, p. 410). 
modification or creation of selection pressures (Laland, Odling-Smee and Feldman, 2000,

p. 132); and the evolutionary biologist Richard Dawkins talks about the family, the social group, and the environment that animals create as being parts of their phenotypes - the embodiment of their genes - and in terms of genetic encoding (1982) rather than in terms of their constructive role in developmental processes that shape the organism in successive interactions.

Biological anthropologists, empirical linguists, and developmental psychologists are not necessarily able to reconcile these dichotomies by showing that they are both complementary, but by showing that the boundaries between biology and culture, innate and learned behaviors are not merely not needed, but are not stable and do not remain fixed. They effect the reconciliation through dissolution of the boundaries that separate these factors, and reveal that a conception of the person that distinguishes the biological from the psychological and sociological cannot make scientific sense of human nature and development. Their thematic is that human beings are not hybrid entities made up of separate complementary parts but rather that they constitute "a singular locus of creative growth within a continually unfolding field of relationships" (Ingold, 1998, p. 23).

There is finally another facet to the contest over the meaning of terms; namely, its social dimension. In their desire to legislate meaning, the dictionarians overlook this facet. Obviously, academic exchanges are not just the disembodied confrontations of ideas. One who sees the conceptual dictionary as a possible solution to the communication problem brought about by interdisciplinarity abstracts from contingent, albeit highly influential social features. To take an example, if terminological confusion were all that were at stake, Dawkins and Gould, the two great contenders in the public altercation over how our cognitive capabilities evolved, would have wished to resolve their intellectual differences. But the best interpretation of their 
relationship of ongoing disputation is that it was symbiotic. Dawkins and Gould enjoyed their sport of dueling, Gould deliberately ignoring Dawkins' explanations on matters, however hard Dawkins tried to convey to him his message (Segerstrale, 2000, p. 324).

\section{The Ways Of Reason}

One of the consequences of evolutionary psychology's top-down hierarchical approach is that it is unable to countenance the contingent microhistorical processes that biological anthropologists, empirical linguists and developmental psychologists place at the center of their accounts. Their differing approaches are reflected in their differing uses of reason.

Evolutionary psychology's method of choice is to appeal to abstract reflective reason that shows a preference for theory. Biological anthropologists, empirical linguists and developmental psychologists give a larger role to historical (constructivist) reason that considers items of interest in their broader contexts. The struggle between reflective reason and historical reason is probably indispensable to the forward-movement of knowledge. Through the conversational give and take of these different uses of reason and the criticism of one tendency by the other, concepts are clarified, weaknesses redressed and positions articulated and developed more clearly. This suggests that, as a matter of practical fact, the only way evolutionary psychology can develop is by inviting the expression, not forcing the suppression, of antithetical viewpoints. Reflective reason and historical reason are synergistic in this way.

Abstract reflective reason and historical reason manifest different tendencies. ${ }^{21}$ Abstract reflective reason tends to treat items of interest in essentialist terms, detaching them from their context to treat them in isolation, often idealistically. Thus, evolutionary psychologists see people as fully formed entities first, separate from the world about which they think and upon

${ }^{21}$ Milton Fisk also employs this distinction in his essay, "History and Reason in Rawls' Moral Theory" in Reading Rawls: Critical Studies on Rawls' 'A Theory of Justice', edited by Norman Daniels, Stanford, CA: Stanford University Press, pgs. 53-80. 
which they act with brains that contain ready-made information. Their conception of a person is that of an "information-processing device with sociality tacked onto it" and not as one for whom sociality informs all aspects of cognition (Toren, 2002, p. 110). Language emerges suddenly at a predetermined stage, not as a means of coregulating and augmenting social relations (King, 2002). Meaning is pre-existent with all its principles and parameters intact, not socially constituted in such a way that the end result is both contingent and unpredictable (King, 2002, p. 82). Reflective reason grounds evolutionary psychology's hard and fast distinction between the linguistic and non-linguistic as well as its dichotomous consideration of verbal versus non-verbal kinds of behaviors.

Thus, evolutionary psychology backs up into its own form of essentialism - what we might call a naturalized essentialism. ${ }^{22}$ Evolutionary psychologists do not see the essence of human as something that matches up with a conception of human that is pre-given in an a priori metaphysical way; rather, they see the essence of human as having evolved through the causal interactions of a particular species with its environment. Evolution has produced in representatives of humanity ingrained instincts and reasoning proclivities. These cognitive processes are independently specifiable, pre-given and resistant to change in the same spirit of an essentialistic metaphysic. Evolutionary psychologists do not make much at all of the fact that it is a part of human nature to vary and change with ecological and sociological conditions.

Evolutionary psychologists describe a universal, content-rich human nature one that is biologically fixed. They argue that mating preferences, parental investment strategies, grammar,

\footnotetext{
${ }^{22}$ While critics tend to agree that essentialism is objectionable, recently the claim has been put forward that neoDarwinian orthodoxy embeds it as well. If this is so, then we should be less surprised to find evolutionary psychology meriting criticism on these grounds (though surprised the revelation had not been made earlier.) I refer to Tim Ingold's piece, “An Anthropologist Looks at Biology" (Man, Vol. 25, No. 2, June 1990). Ingold never uses the word essentialism but the gist of his argument is the same. He argues, for instance, that the established neoDarwinian synthesis fixes on 'events' not processes, and that a kind of relationship thinking, which is antithetical to essentialism, should be substituted for population thinking.
} 
conceptual structures, culture modules and much more are hard-wired into our brains.

Evolutionary psychologists stress that these adaptive traits have become stabilized. The cognitive abilities modern humans possess are no longer open to revision (no longer shifting with the environment, their internal neurobiological environment included) despite their ever-present interaction with a rapidly changing social and ecological (as well as neurobiological) scene. That is why our mental traits and cognitive processes can prove maladaptive. Attempts to transcend them may work, but not attempts to negate them.

Evolutionary psychology's conception of language, in particular, is essentialist. Evolutionary psychologists take syntax as the essential component of the mind and claim semantics is accidental, the particularized input of some cultural system or other. Evolutionary psychologists perfectly reverse the essential/variable (nature/culture) distinction for which (we shall find) they criticize the anthropologists. Following Chomsky, evolutionary psychologists accept the uniformity of the human species and seek to idealize away all aspects of variation to capture 'the initial state,' the state prior to experience that is fixed for all its representatives. This state is conceived as a complete system of syntactical rules unto itself; it is available to all newborn babies and mapped (or imposed) onto experience (Chomsky, 1980, p. 109).

The Environment of Evolutionary Adaptedness (EEA) constitutes another artifact of evolutionary psychology's essentialist reasoning. Arguably the EEA abstracts from important unknown particulars of a selective environment singled out from the past. It is intended to comprise a description of the recurrent structure of the (ancestral) world and hence, inevitably downplays certain facts of environmental variation. The cognitive archeologist Steven Mithen is adamant that evolutionary psychology shows a lack of concern with the actual, rather than the assumed nature of our hunter-gatherer past. He points out that two decades of archeological and 
paleoenvironmental work exhibit immense variability in the Pleistocene environment (1997).

What is more, that record is likely to reflect only a tiny portion of the variable lifestyles that once existed. Therefore, since our ancestral forbears lived in different places and exhibited different lifestyles, it is probably not the case that they were subject to the single set of selection pressures reflected by the EEA (King, 2002a, p. 34)

Furthermore, the abstract and formal models of game theory to which its exponents appeal to gain insight into the evolutionary process reinforce evolutionary psychology's essentialism. In his 1971 paper, "The Evolution of Reciprocal Altruism" published in the Quarterly Review of Biology, Robert Trivers argues that a broad range of human emotions are explainable as adaptations for regulating altruism in the social world. He arrives at this conclusion by setting up a problem situation and asking what sort of motivation would be required for cooperation to emerge among people so situated. The feelings that motivate the parties to a solution are postulated on the basis of his analysis to constitute a part of human nature. The division of essential facts from those less essential is an indispensable piece of Trivers' game theoretic reasoning. It is worth emphasizing, however, that evolution is a particular historical process, so contingencies and particularities are profoundly formative. Inasmuch as game theoretic models presuppose that the essential nature of organisms (and the specific conditions in which they find themselves) can be separated out from their contingent accidental attributes (as shaped by variable environments) it seems ill-suited to evolutionary reasoning. Essences are refuted by evolutionary biology.

In contrast, historical reason - as deployed by biological anthropologists, empirical linguists and developmental psychologists - treats objects holistically integrating all surrounding items of particular notice, in the present case, all items cognitive, emotional, and developmental 
pertinent to human beings. Human beings are understood to live 'in' the world and to transform the world as they themselves are transformed by it. Historical reason conceptualizes in fuzzy interactive terms: relationships become key and categories of description are always seen in a state of motion and change or becoming, not as static. Accordingly, Barbara King states, "What is meaningful in language is not static in structure, but constructed in use" $(1999$, p. 15). The anthropologists Stuart Shanker and Talbott Taylor concur. They maintain that learning how to do things with words is a form of socialization inseparable from a child's socioaffective development (2001, p. 55). "To the extent that developmentalists 'abstract' the child's acquisition of linguistic ability from its acquisition of other cultural abilities, they render the former both incomprehensible and inexplicable (except by a deus ex machina such as LAD)" [language acquisition device] (2001, p. 66). But static in structure, abstract and autonomous, is precisely Chomsky’s conception of language as the Universal Grammar, a genetically specialized component of the human brain.

Abstract reflective reason and historical reason both have their drawbacks. The inherent limitation of historical reason is its failure to recognize that theory is implicated even in the way that items of interest and social context are defined. There is also the tendency for historical reason to explain mental phenomena away in Wittgenstein-like fashion in order to avoid reifying language. Historical reason shows a preference for taking only behavioral manifestations as the real and substantial indicators of what is in the mind. This is particularly noticeable with biological anthropologists because their subjects do not speak. It is a consideration moderated, however, in the view of the empirical linguists because they embrace the world of metaphor even as they eschew representational thinking per se. We shall find that the developmental 
psychologists are the most successful of all in finding a place for the representational capacities of humans in terms that have grounding in the empirical (historical) facts.

Abstract reflective reason leads to "theory-thinking." This is its main drawback. Theory-thinking can lead to such claims as that natural selection must be the cause of human linguistic ability when, in fact, as Richard Lewontin points out, all that really can be said with certainty is that "if it was selected, then it was selected" (1990, p. 741). "Of course, the language faculty might have increased the survivorship and reproduction of its possessors relative to others, so it might have been selected." Lewontin urges: "But was it?" In short, theory thinking shows itself in the tendency to logically deduce empirical matters. There is also Tooby and Cosmides' assumption that the neurophysiological processes that execute the tasks performed by our mind's many modules have been realized as if such details did not make a difference their theory (1992, p. 66). But this assumption renders neurobiology irrelevant to their claims. No developing point of contact between their theory and the empirical facts becomes necessary, an erroneous (see Hardcastle and Buller, 2000) if not manifestly counter-intuitive position to hold.

Then there is Pinker's argument that selection for bigger brains (which allows computational abilities such as language to be viewed as a by-product) is the wrong way round. "Why would evolution ever have selected for sheer bigness of brain, that bulbous, metabolically greedy organ?"...Selection for more powerful computational abilities (language, perception, reasoning, and so on) must have given us a big brain as a by-product, not the other way around!" (1994, p. 363, emphasis added).

Pinker is guilty of theoretically generalizing over subtle details of the evolutionary process that show natural selection making trade-offs all along the way. He may even be guilty of equivocation, if not manufacturing a pseudo-problem for other scientists who attempt to 
explain the evolutionary emergence of large brains do so precisely in terms of selection for the capacities Pinker names. In other words, large brains are identified with these capacities, not seen as distinct from them. John Morgan Allman argues, for instance, that brain size has been correlated with longevity in humans, gorillas, orangutans, and chimpanzees (Allman, 1999, p. 172). He argues that large brains evolved "to deal with environmental uncertainty and the longer the life-span, the greater the uncertainty" (1999, p. 197).

Allman explains that to cope, people needed visual acuity to track and detect potentially dangerous animals and objects. They needed color vision to identify flowering plants as foodstuffs, social expertise and language to facilitate bonding and coordination of food acquisition. Selection for all these abilities had advantages as well as costs. Pinker's argument appears to smuggle in the notion that evolution is an optimizer, however, not a tinkerer and such an assumption is precisely what his opponents, like Allman, would disallow. Even Darwin noted that when one part of an organism is modified, other parts also change "through the principle of correlation of which we have instances in many curious cases of correlated monstrosities" (1871/1952, p. 590). Pinker neglects to convey these finer details of the evolutionary process that have been advanced to account for the brain's big size and to show how selected-for adaptations and bigness go hand in hand. The idea that sheer bigness was selected for is not any part of the argument. Yet Pinker wants to say it is entailed by his opponents' view.

\section{Where Things Now Stand/Where They Are Going}

As they repel the interest of some through their rhetorical tactics evolutionary psychologists capture the interest of others, particularly, students newly-initiated into the subject. Students are bound to find appealing the real-world connections of the theory. Attracting students is also of prime importance because the longevity of a new discipline depends upon 
them. Students will do the normal science work that carries the emergent research tradition into the future. And how much easier could the evolutionary psychologists have made it for them? Just as social constructivism handed their graduates rigid conceptual guidelines for doing case studies of particular technologies with a view to developing SCOT (the social construction of technology), so too evolutionary psychology provides a rigid structure for work with its framework - all devoted to case studies of our myriad mental modules.

Nevertheless, there is inherent strength in a view, like evolutionary psychology's, whose main tenets - that the human mind is universal, modular, and adapted to the Pleistocene past can be clearly (if not all too simplistically) articulated and (claimed to be) fixed in a perspective, such as evolutionary theory, whose intellectual reach is limited only by its proponents' imagination. Other fields of study take issue with these core tenets but none including those discussed in this dissertation - biological anthropology, empirical linguistics and developmental psychology - is so ambitious as to promote itself as an all-embracing architectonic for melding the natural and social sciences together, and then staging the place human cognition should take in the resulting structure. Evolutionary psychology does all this.

The disciplines whose contributions to the study of human cognition which I bring forward show varying degrees of desire to move beyond the highly specific interdisciplinary stretch of territory imposed by evolutionary psychology's concerns with universality, modularity, and the adaptedness of our cognitive faculties. For this reason, if for this reason alone, their findings may weaken evolutionary psychology's paradigmatic outlook but they cannot make it topple over. As Thomas Kuhn pointed out old paradigms persist and anomalies are submerged and ignored until new paradigms are formulated and installed in their place, new paradigms that can account adequately for new and unusual data (1962). 
Therefore, what I hope to show is that by pulling together the findings from these three distinct social sciences we can see evidence of a new paradigm's contours emerging. That new paradigm whose incipient structure is becoming more and more apparent might be called 'Developmental-Evolutionary Psychology.' It is implied by and grounded in 'Evolutionary Developmental Biology.' Advocates of Evolutionary Developmental Biology (EVO-DEVO) are concerned to forge links in the relationship between development and evolution that have gone unnoticed due to the different directions the disciplines of developmental biology and genetics have taken (Burian, et al., 2000). Certainly, these links have implications for psychology.

I seek to emphasize the reciprocal interrelation of development and evolution implicit in the name 'Developmental-Evolutionary Psychology' because the data show that the study of development and the study of the evolutionary histories of organisms bear upon one another. Neither study can be successfully completed without drawing upon the others' information and concepts. ${ }^{23}$ The implied equivalence in their relation is also justified by the need to overturn the "explanatory hegemony of neo-Darwinian theory" which defines evolution as change in the genetic makeup of populations of organisms, and eschews the broader understanding of evolution as concerned with the origins of phenotypic variations themselves (Johnston and Gottlieb, 1990). Needless to say, EVO-DEVO advocates find that until evolutionary theory puts the problem of biological form on a par with genes and complexes of genes, it will not be able to integrate important findings on developmental processes.

What is compelling about the Developmental-Evolutionary Perspective (aside from its ability to integrate research findings on the developmental process itself) is that its intellectual reach is so vast that it is able to integrate evolutionary theory and remain close to the empirical

\footnotetext{
${ }^{23}$ As Susan Oyama puts it: "Evolution is...the derivational history of developmental systems' (1989, p. 5); and Dick Burian points out evolution is more likely to be understood in terms of changes in developmental processes, not gene frequencies (2000).
} 
data, much closer than has evolutionary psychology whose tendency is towards becoming more theoretical at the expense of the empirical warrant. Also, enticing about DEP is that it does not carry any blueprint mandating a particular relation of the cognate fields to one another. Rather, DEP (1) accepts the core tenets evolutionary psychology defines as focal issues and then (2) allows on-the-ground determinations of where cooperation among researchers is required to settle those issues. It does not stipulate the terms for their cooperation in top-down hierarchical fashion. Evolutionary psychology makes a contribution unmatched by the other disciplines, in any event, through highlighting these focal issues.

How the on-going tug of war between the evolutionary psychologists and outside researchers plays itself out is still up in the air. Therefore, the foremost reason for interceding in the context of current practice is to facilitate a disciplinary interchange among them and work to ensure that the most promising outcomes are promulgated widely among all scientific professionals. This is important when it comes to scientific facts still in the making and when new scientific paradigms are still breaking ground. Ultimately, the breadth of acceptance of new facts and approaches will decide the direction of future research.

\section{CHAPTER 3. BIOLOGICAL ANTHROPOLOGY}

Evolutionary psychology has the greatest quarrel with anthropology. Their tug of war is a battle over which discipline gets to claim the right to generate knowledge; which discipline gets to make the contentful claims that define human nature. The appearance is that knowledge changes depending upon who owns the subject. Both disciplines claim to synthesize biological and sociological elements; both deny setting biology and culture up as mutually exclusive objects of study. 
Evolutionary psychologists tend to present the assumptions that hold sway in anthropology in caricature form, however. To paraphrase Pinker, ever since Franz Boas (who got the field going in America) anthropologists have been arguing that the human mind is like a lump of Silly Putty passively molded by 'culture.' To be clear, Pinker admits this was not Boas' position. One thing he fails to point out, of some relevance, though, is that Boas was founder "of a large and productive school of linguistic research under the aegis of the Smithsonian Institution" and that Boas believed (as Pinker's mentor Chomsky believed), that language was key to other aspects of culture. The reason language was key, according to Boas, was that "people are normally unconscious of the principles on which their language operates, while when it comes to other aspects of their culture they commonly have their own erroneous but firmlybelieved rationalizations which hinder rather than help the anthropologist who seeks to understand how the system hangs together (cf. Boas 1911, section iv, especially p. 63)" (Sampson, 1980, pgs. 57-58).

Pinker notes that Boas was neither a relativist nor an advocate of the Blank Slate. What mattered to Boas was the idea that all ethnic groups are endowed with the same basic mental abilities. "Boas was right about this" Pinker continues, "and today it is accepted by virtually all scholars and scientists" (2002, p. 23). Boas' recognition of the role of heredity reinforced his emphasis upon the individual - the same 'individual' who disappears from anthropology in the hands of subsequent thinkers in anthropology like Clifford Geertz.

It is not true, though, as Pinker claims, that since Boas anthropologists have thought like Geertz - believing that only the collective mind belonging to culture, not individual minds, count. For Pinker this tendency of thought is significant because it sets the stage for the elimination of mental entities like beliefs and desires from the social sciences (2002, pgs. 14-29). In his account 
of anthropology's development, Pinker singles out Alfred Kroeber (one of Boas' students) as responsible for this intellectual gaffe. According to Pinker, Kroeber used culture to explain not only differences among ethnic groups but also all aspects of life. Notably, while Degler agrees with Pinker that many anthropologists following Boas did come to hold this position, he explicitly denies that Kroeber is guilty of seeing individuals as products of culture alone. ${ }^{24}$ So here again Pinker appears to error in his interpretation of anthropology and its tradition.

The most important error Pinker makes is quite substantial: Pinker overlooks another major tradition in anthropology also traceable to Boas; namely, the structuralist tradition of Claude Levi-Strauss. ${ }^{25}$

Levi-Strauss sought to discover the nature of the mind in its most pure and primitive state (Gardner, 1987, p. 238). He believed, as do the evolutionary psychologists, that certain properties of the mind determine the way language operates. These properties of the mind (properties which Tooby and Cosmides call frames) may not be immediately evident to us because they are so natural, according to Levi-Strauss. However, once specified they allow us to make sense of how we take in, classify and interpret information about the world. So it happened that at an anthropology conference Levi-Strauss alluded to the human mind as an uninvited guest seated among the conferees (1963, p. 7). Surely Pinker knows this about Levi-Strauss, given his linguistics background.

The concept of mind Levi-Strauss provides anthropology with has the resources for integrating mind with evolutionary theory and thus for answering the question of "how culture is

\footnotetext{
${ }^{24}$ Degler states: "To believe that the individual is 'the result of his mouldings by the society that encompasses him,' Kroeber warned, is an assumption, and an extreme one at that, and quite at variance with observation...Modern conception of socialization, which perceives individuals as products of culture alone would not have been any more acceptable to Kroeber than to Boas" (1991, p. 100).

${ }^{25}$ Howard Gardner points out that the structuralist tradition is traceable back to Boas in The Mind's New Science (1985, p. 235).
} 
possible, how it is constituted, and how it is acquired" (Gardner, 1985, p. 256). These are precisely the questions Tooby and Cosmides raise in their constitutional piece "The Foundations of Culture" (1992). Significantly, the structuralist tradition of anthropology has not escaped the notice of evolutionary psychology's opponents, Gould and Lewontin, who are well-informed as to the bearing of formal, structural relations on the development of organisms as their famous "Spandrels of San Marco" (1979) article shows. As a consequence, they see the need to consider organisms as totalities, not as aggregates of atomic functional parts whose relation to the external world is all that is important. Indeed, evolutionary psychologists must explain their preference for functionalist explanations, particularly, when they insist on the presence of invariant structures in organisms.

In summary, anthropology has a rich and diverse tradition. The metaphor of the Mind as Silly Putty never permeated the understanding of all its practitioners. What seems to have happened in the instances where the metaphor applies is that the need to leave space for individual biological and psychological realities led to bracketing these phenomena, which in turn led to (became confused with), denying them. As the writer Andrew Brown points out: "To argue that anthropology must be conducted as if there were no such thing as human nature is not the same as arguing that no such nature actually exists" (1999, p. 120). Yet, it is easy to see how such a conclusion might be drawn if the very point of bracketing gets somehow lost in the process. So, Pinker himself points out, Clifford Geertz propounded that: "Our ideas, our values, our acts, our emotions, are, like our nervous system itself, cultural products...." (Geertz, 1973, p. 50 quoted in Pinker, 2002, p. 25), to which one need simply add 'our ideas, our values, our acts, our emotions, are, like our nervous system equally biological products...' to get the slogan back on track and recast in evolutionarily informed terms. 
Still, there is a difference between bracketing bio-psychological realities from cultural ones and viewing the later as emergent phenomena with feed-downward influences upon these realities to boot. The evolutionary biologist Richard Lewontin describes what such a position would look like, arguing that it offers a more reasonable perspective on the relation between human psychology and culture than evolutionary psychology does. "Far from being constrained by lower-level limitations," Lewontin argues, "culture transcends them and feeds back to lower levels to relieve the constraints. Social organization and human culture... are best understood as negating constraints rather than being limited by them" (Lewontin, 1981, p. 244). This is an advance, then, even over the bracketing view, which does not deny evolution since it tries to explain that relation. Barbara King and her colleagues would grant there is much truth in what Lewontin says.

Yet, evolutionary psychologists suggest Lewontin's position is anti-evolutionary. And they appear to be totally unfamiliar with King's views, although she shares many of their commitments. King accepts evolutionary psychology's fundamental premise, namely, that human nature shall be revealed through evolutionary theory. King and her colleagues also agree that culture is an evolved phenomenon, not something sui generis as older proponents claimed, which means that human nature can't be malleable in the manner evolutionary psychologists have found most objectionable. The reason, King would say, is that human nature must reflect its evolutionary history as well as its unique psychosocial development. Stephen Rose may therefore be correct in complaining that, "the work of those Pinker derides...suggests that he has scarcely read, still less attempted to understand anything we have ever written" (1998). King and her colleagues are not the Blank Slate proponents from anthropology against whom evolutionary psychology directs its animus. Evolutionary psychology's critique is outdated 
because it is out of touch with what practitioners in the anthropological community are saying about mind and cognition now.

Anthropologists have since splintered off into groups - some following evolutionary psychology's lead, others attempting to wrest control of cognitive science from evolutionary psychology by proposing their own transdisciplinary terms for research. Both approaches are evolutionarily informed. Tim Ingold, a colleague of Barbara King's, falls into the latter group. He states that his aim is to lay out the foundations for an "adequate integration of anthropology within the wider field of biology." Employing what I have referred to as 'historical reason,' Ingold presents a view that is fundamentally relational. "In place of the kind of 'population thinking' (Mayr, 1982, pgs. 45-47) that is the hallmark of Darwinian biology, it is necessary to substitute a kind of 'relationship thinking,' which locates the organism or person as a creative agent within a total field of relations whose transformations describe a process of evolution" (Ingold, 1990, p. 208). For Ingold anthropology falls within the wider domain of biology and biology itself is fundamentally redefined.

Evolutionary psychology does not get the history of anthropology right. Indeed, it may be an understatement to say that evolutionary theory is (and has been) as central to anthropology as it currently is (and has been) to the field of psychology all things told. This is, in an ironic way, reinforced by the observation of one anthropologist, Susan Cachel, who stated in 1993 that, "any impact of evolutionary theory on anthropology now affects only physical anthropology" (Cachel, 1993, p. 188, quoted in Ingold, 1993). Its increasing centrality with respect to both disciplines is not always perceived or appreciated by practitioners in either field of study. 


\section{Continuity Versus Discontinuity - Divergent Paradigms}

Barbara King is a biological anthropologist who has been teaching at the College of William and Mary since 1988. She specializes in primate behavior and human evolution and has also written extensively on the origins of language. King studied the social learning of baboons in Kenya for her doctoral research project and has recently been engaged in observing the gestural communication of gorillas living at the Smithsonian National Zoo for her latest book titled, The Dynamic Dance: Nonvocal Communication in African Great Apes (2004).

King's arguments are largely directed at Pinker who regards language as a genetically specialized capacity unique to the human species. King sees Pinker's failure to be impressed with the "cognitive or communicational abilities of free-ranging nonhuman primates or their relevance for understanding how language evolved" as a major flaw in his position (1999a, p. 27). She notes that Pinker's stance requires him to find "chimps," whom he describes as "strong, vicious, wild animals," as languageless. Reflected in King's thinking is her appealing opposition to Pinker's top-down, anthropocentric approach to language. By contrast, King affirms that the bulk of evidence points to language being, in significant part, socially constructed which, she emphasizes, is not to deny a role for innate processes or to polarize innate processes to learned ones (1999, p. 18).

Significantly, King directly engages evolutionary psychology in her arguments. King states unequivocally that she is a continuity theorist. This means she believes that language evolved from language-like precursors in non-human primates and that there is only a quantitative not a qualitative difference between human and non-human primate communication. This is the real crux of their differences. ${ }^{26}$ In the anthropological literature the terms

\footnotetext{
${ }^{26}$ Arguably, different images of man are located at the core of these dichotomies since different metaphysical posits ground each of them. Discontinuity theorists regard humans as unique among all other species - due to their
} 
'continuity' and 'discontinuity' are entrenched. That is to say, they are standardly used to describe the relation of humans to other animals, particularly, other primates. These terms are virtually absent in the literature on evolutionary psychology; perhaps, an indication of how little cross-talk there is between these research communities; perhaps, an indication that the issue is one that evolutionary psychologists would sooner avoid. As it turns out, though, continuity thinkers like Barbara King are in the minority in her discipline as well (1994a, p.131) - this lopsidedness exacerbated by the preference of even fellow biological anthropologists for focusing on controversies that revolve around hominids and that rely on fossil and artifactual analysis to the exclusion of behavioral research on monkeys and apes (1999, p.7).

Discontinuity theorists "posit sharp breaks or discontinuities" in the capabilities of humans versus animals (King, 1994a, p.131). Thus, Harvey Sarles remarks that the discontinuity thinker Gregory Bateson, who persists in doing research on animals, persists for no reason whatsoever since he accepts Chomsky's narrow notion of language as syntax, that is, as a specific aspect of verbal behavior biologically tied to human brains (in the form of a Universal

linguistic prowess - and this uniqueness justifies the ascription of dignity to humans. Along with dignity, comes human superiority and along with superiority comes the right to exploit nature at will, or so it has been argued. Eugene Linden states: "Our notions of human nature and language are not just dry textbook ideas; they are our excuse for plundering the planet" (Linden, 1974, p. 213).

Linden sees the competing paradigms as Platonic versus Darwinian with the advocates of ape language research being faithful to the Darwinian worldview and the discontinuity theorists subscribing to the Platonic conception, which sees man as autonomous and hence separate from the rest of nature. There are a couple of problems with Linden's understanding and juxtaposition of these paradigms, however. First, it is incongruous, if not unfair to contrast a philosophical paradigm with a scientific one for there is a difference. Secondly, Plato held a reverent attitude towards nature. Man had his place between animals and the gods and even animal sacrifice had a chthonic justification. Animal sacrifice was the gaining of life and strength from the killing and consuming of something that had greater life and strength. The Greeks believed that hubris, their word for 'violent assault,' for stepping beyond boundaries, portended their downfall. Accordingly, the Greek goddess Artemis punished those who waged war too much on nature or who took more than their fair share of the kill. Thus, the Greeks saw checks and balances in the world order; they had a fundamental understanding of the intrinsic limits of things. And Aristotle, as is well-known, considered man a part of nature. To my mind, it is not our Greek heritage but our Christian heritage that sanctions man's special place in the universe and his dominion over the rest of creation (Genesis 1:26). It is the Christian doctrine that sees man as fundamentally distinct from the balance of the animal kingdom - being created in God's image for fellowship with him - and at the same time being continuous with creation - for man is made of "dust from the ground" (Genesis 2:7). See also Leslie Stevenson, Seven Theories of Human Nature, (New York: Oxford University Press, 1974, pgs. 41-52). 
Grammar) (1969, p. 219). So defined, it follows logically that language can have no precursor forms locatable in the animal kingdom. It is exclusive to humans (King, 1996, p. 194). Bateson takes for granted, as do the evolutionary psychologists, a hard and fast distinction between verbal and non-verbal behavior, which disallows the search not only for linguistic but also syntactic behavioral precursors in non-human primates, including those found in their structured visible gestures (King, 1996).

King, on the other hand, finds field studies devoted to identifying syntactic precursors in gesture worthwhile. While she is willing to accept even the definition of language as syntax to engage discontinuity theorists, she denies that the "evident limitations on animal syntactic production and comprehension necessarily rule out the existence of precursors to human syntax." "After all," she states, "if there is strong evidence for syntactic precursors, then factors seen as responsible for syntax such as sudden mutations or uniquely human biological structuresincluding Chomsky's language acquisition device in the brain - could be neatly ruled out"(1996, p. 195). While this is too strong a conclusion to draw on the basis of the data (Hardcastle, personal communication) it does not detract from King's proposition that there is good reason to pursue the possibility that "syntax is derivable within incrementalist, continuity framework" (1996, p. 195). Indeed, as we shall see, this is where King finds her way to communicating with evolutionary psychologists.

Evolutionary psychology is not a pure discontinuity perspective. King notes the nuances in its viewpoint and so describes a third approach, and considers it evolutionary psychology's approach. According to this middle view the human form of linguistic behavior sets the standard. It is the qualitatively superior form of communication; animal forms are inferior and defective versions of the standard (Sarles, 1969, p., 212). While language emerged gradually in 
accordance with evolutionary theory, it emerged gradually in the hominid line after humans and apes separated from the common ancestor. Thus, the evidence shows a disjuncture between humans and all other living creatures. Humans do not fall neatly along the primate continuum.

In fact, Pinker favors the metaphor of a 'bush' over a 'ladder' as more appropriately descriptive of the evolutionary process because a bush images breaks as well as continuities. Humans may be continuous with some non-extant species, but it is erroneous Pinker thinks to assume continuity characterizes the relation between humans and the modern chimpanzees and apes that biological anthropologists study today. The fact that they are "'the living species closest to us has no special status"' (Pinker, 1994, p. 346). The species that is closest to us depends on the accidents of extinction. Pinker drives this point home effectively. Imagine he says, "that in the past some extraterrestrials developed a craze for primate fur coats, and hunted and trapped all the primates to extinction except the hairless us. Would insectivores like anteaters have to shoulder the proto-language burden?" (1994, p. 346).

The categories of continuity and discontinuity expose evolutionary psychology's anthropocentrism. King would even say that discontinuity thinking is anti-evolutionary. She precisely turns evolutionary psychology's arguments against anthropologists about face on its proponents. For King an evolutionary perspective - as it pertains to language specifically - is one that "achieves a comparative description of the properties of animal communication versus human language." It involves studying a "variety of species of diverse social and ecological contexts...in order to identify and model (1) potential continuities or discontinuities between the behaviors of humans and other primates, and (2) selection pressures for change over time in those behaviors" (1994, p. 2). In short, King believes that: "An evolutionary perspective compels 
us to understand that language emerged gradually, with no major Rubicon crossed at the starting point of the hominid lineage" (2002a, p. 20, emphasis added).

King is unyielding in her commitment to the idea that for a "full evolutionary picture to emerge; primates must be closely analyzed." She thinks that unless we do so "we cannot know what communicational abilities evolved only in the hominid line and which have longer histories" (1999a, p. 22). Inasmuch as evolutionary psychology's proponents insist that, "the ancestor to language first appeared after the branch leading to humans split off from the branch leading to chimps" (Pinker, 1994, p. 349) this question never gets raised. In fact, the definition of evolutionary psychology as the study of humans alone disallows this question by fiat.

To be truly Darwinian, in King's opinion, evolutionary psychologists must surrender the equation of language with syntax, and take a broader view of what language is. Other questions worthy of pursuit then become possible: "What does language have in common with the communication systems of nonhuman primates and even with their nonlinguistic behavior? How is language different?" "Surely," King surmises, "only by approaching these questions with data from behavioral primatology can we even know the full range of questions to ask about language evolution" (1999, p. 7).

King posits that taking a full evolutionary picture allows us to see continuity and discontinuity approaches as orthogonal, and not as conflicting and contradictory. Broadening our viewpoint encourages us to understand continuity thinkers as really asking questions about the origins of linguistic behavior, i.e., what monkeys, apes, and hominids do, how they structure their communicative behavior, while discontinuity thinkers inquire into the origins of language per se (1997, pgs. 93-94). This broadening also seems King's best hope for confronting the one evolutionary possibility which her own perspective forecloses: the possibility that human 
language is a spandrel, a by-product of some naturally selected-for feature, not a selected-for feature itself.

Theoretically speaking, only by relaxing the imperative to see selective pressures everywhere, and looking just at what monkeys, apes, and human do, can human linguistic ability be recognized as an emergent property of other adaptive cognitive features. More than that, from an enlarged perspective biological anthropologists are better poised (and motivated) to identify the cognitive powers that underlie linguistic ability, not merely linguistic precursors, such as the ability of primates (and other animals) to parse the world conceptually and to make generalizations about it instinctively (as animals clearly come equipped with these abilities without the benefit of instruction). At the present time, however, due perhaps to evolutionary psychology's over-emphasis on contentful instinctive capacities, King and her colleagues concentrate their focus strictly on what is overlooked in that analysis, namely, social learning.

\section{Pinker's Synthesis - King's Persistence}

The charge that evolutionary psychology is anthropocentric is easily made but not so easily made to stick. Above all, Pinker eschews the metaphysical assumption about man's centrality in all of nature and the ethical implications of this view that lie behind discontinuity theorists' uniqueness claims. He believes that many scientists have been "captivated" by the research with great apes just because they see the projects as a "healthy deflation of our species' arrogant chauvinism." Pinker's response is to query: "Is it really 'humility' for us to save species from extinction because we think they are like us? Or because they seem like a bunch of nice guys? What about all the creepy, nasty, selfish animals who do not remind us of ourselves, or our image of what we would like to be - can we go ahead and wipe them out?" (1994, p. 336). 
The irony Pinker discerns is that the attempt to "bring Homo sapiens down a few notches in the natural order has taken the form of us humans hectoring another species into emulating our instinctive form of communication, or some artificial form we have invented, as if that were the measure of biological worth...the idea that some species needs our intervention before its members can display a useful skill, like some bird could not fly until given a human education, is far from humble" (1994, p. 342). So Pinker rebukes the human standard as applied to primates and for exactly the same reasons as does King: that to impose such a standard is not only chauvinistic, it forces a distortion of the unique abilities other creatures have which should be appreciated and understood in their own terms.

Accordingly, Pinker plays out our relation to other animals in a polysemous way. "Though language is a magnificent ability unique to Homo sapiens among living species, it does not call for sequestering the study of humans from the domain of biology, for a magnificent ability unique to a particular kind of human species is far from unique in the animal kingdom.... In nature's talent show we are simply a species of primate with our own act, a knack for communicating information about who did what to whom by modulating the sounds we make when we exhale" (Pinker, 1994, p. 19).

As effective as Pinker's pronouncements are, there is an ambivalence apparent in the relation he sees evolutionary psychology as having towards 'animal.' Pinker's ambivalence is shown in his determination to avoid direct, or referential identifications with other creatures, particularly primates, in favor of analogical identifications, which depreciates the special relation humans have to primates. Effectively, Pinker manages to meld polysemy and semantic replacement or restriction together. Polysemy is born out by the ambivalence just mentioned; the semantic restriction shows itself in Pinker's refusal to grant consideration to human under the 
aspect of 'animal' in its most robust sense, the sense to which biological anthropologists subscribe. Pinker clearly favors a more generalized and more anemic sense of 'animal', one that sees human as bearing no special relation at all to any other particular creature.

Evolutionary psychologists prefer to reveal the 'human' through comparison with the computer; and the process of disclosure they prefer, called reverse engineering, substitutes for (and is thought to constitute a superior substitute for) animal study. Evolutionary psychologists seek to reverse engineer the mind. They aim to figure out how it was constructed in the same way that engineers reverse engineer modern gadgets, by taking them apart to see if they can duplicate how they were originally put together.

Pinker presses his case for difference. Although "we evolved from apes...that does not mean we have the same minds as apes" (1998). Of course, the idea that we have ape minds is not exactly King's view either. Continuity theorists also acknowledge the unique properties of language. "Only human language relies on large vocabularies comprised of words with specific, widely understood meanings. These words are used in ways that not only convey information in the present, but reflect on the past and plan for the future" (King, 2002a, p. 21). King concedes the uniqueness of human language, then, but with the caveat that evolutionary theory can help explain the various language differences between humans and non-humans. This renders the human species-specific form of language neither mysterious nor unexplained, as is the language gap, King would say, discerned by evolutionary psychology.

Pinker works hard to upgrade our understanding of what evolution can accomplish in order to identify humans up with the modern computer rather than down with apes and animal minds. In "A Mind to Love" published in The Guardian Newspaper (London) $1998,{ }^{27}$ Pinker claims it is wrong to believe that evolution can only fashion as it has done for the animals

${ }^{27}$ Listed under "Pinker, Steven" in the References Section of this paper. 
"stupid instincts and fixed action patterns: a sex drive, an aggression drive, a territorial imperative, hens sitting on eggs and ducklings following hulks." "Everything changes" Pinker concludes once it is granted that evolution equipped humans with a "neural computer" (emphasis added).

In another agile turn of phrase, Pinker states: although "thinking is computation...that does not mean that the computer is a good metaphor for the mind." Nevertheless, he indulges the metaphor. "Artificial computer programs - from simulations of the weather to programs that recognize speech and answer questions in English - give us a hint of the finesse and power of which computation is capable. The outsize brain of Homo sapiens is, by any standard, an extraordinary adaptation" (1998; 1997, pgs. 23-24).

When Pinker does bring in animals and compare them with humans, it is never primates, and it is never to show similarity per se but to demonstrate similarity in human responsiveness to evolution's selective pressures. Pinker argues, for instance, that language and Darwinian gradualism are just as compatible as is the emergence of the elephant's trunk with Darwinian gradualism despite the fact that it, too, is unique to elephants among all creatures. "Elephants are the only living animals that possess this extraordinary organ," says Pinker...and "no biologist has made a fuss about it." He goes on in some fun: "But now imagine what might happen if some biologists were elephants. Obsessed with the unique place of the trunk in nature, they might ask how it could have evolved given that no other organism has a trunk or anything like it" (1994, p. 333, emphasis added).

But that is just the issue: there is no given, and Pinker simply begs the question of whether language is locatable in other species. Pinker's polysemous construal of the term 'unique' does not help matters. If humans are a priori no more or less unique than other 
creatures then it should not be permissible to invoke a human standard for what counts as language.

Yet, Pinker does so when he describes the evidence brought forward for language precursors in monkeys and apes as testimony to the very "impoverished" nature of their abilities. He concurs with E.O. Wilson that animal communication is "repetitious to the point of inanity" (1994, p. 340). “Chimps just don’t get it.” Still, Pinker insists, “the chimpanzees' resistance is no shame on them; a human would surely do no better if trained to hoot and shriek like a chimp, a symmetrical project that makes about as much scientific sense" (1994, p. 342). But, even with this proclamation, which takes back what it gives at the same time, 'uniqueness' reinforces evolutionary psychology's considered focus on human language as definitive.

Pinker's remarks about chimpanzees stand in striking contrast to King's description of their communicative behaviors as co-regulated activities that create 'meaning' as interaction unfolds. For King communicative events between human as well as non-human primates are unpredictable and contingent occurrences. It is always possible that the meaning that ultimately emerges between social animals that are partners in an exchange might have turned out differently. King thinks that too much focus has been laid on the evolution of speech - even in the case of human evolution - and not enough on the evolution of information transfer of all types through behaviors, material culture as well as vocal productions (1991, p. 98).

In turn, King stands to evolutionary psychology, then, as a constant reminder of the Rylean-type notion that vocal productions are not logically distinct sorts of communicative occurrences of a higher order than those expressed in the social exchanges she describes. They are not the special effects of occult linguistic principles that inhere in human minds alone, but are as ineliminably social at their source as other forms of communicative behaviors. Therefore, the 
sharp distinction evolutionary psychologists draw between linguistic and non-linguistic forms of behavior is, on King's view, illegitimate. Contrasting them is to confuse them. They are of the same logical type.

Clearly, King's choice of the word 'meaning,' as that which is created in social interaction, is deliberate. 'Meaning' is an important aspect of language, which along with other features, such as, grammar and phonemes constitute a system. What linguists do is precisely to study the structured relations among these various components in the system (Gardner, 1985, p. 236). That meaning can be teased out strongly insinuates that language is occurring. As well, it helps King create the picture of language as a mosaic of various critical components. Most importantly, a wholly different method for studying language becomes appropriate if language is understood in the social terms King prefers. "If we accept that meaning is constructed socially and does not reside in an innate rule-based system, then the most valuable place to look for linguistic precursors are social behavior, social interaction, and the comprehension and coordination of activities, perhaps in developmental contexts most critically of all" (1999, p. 15). We might even say that for King it is not accidental that meaning emerges in social interactions in much the same way as many developmental thinkers believe that biological form emerges in biological interactions: through unpredictable, co-constructivist exchanges between organism and environment.

Two completely divergent, internally consistent paradigms confront us. Their starting points are incompatible and the choice between them seems essentially metaphysical, not scientific. However, the standard scientific objection to the existence of a language instinct remains. Evolutionary psychologists add nothing to mollify their critics' qualms on the issue. The objection is that the language acquisition device (LAD) requires all of the neurophysiology 
implied by the deep structure to be frozen and fixed in place all at once. These elements range from details of brain anatomy and circuitry bringing the three parts of language's structure together - the syntactical, phonological, and semantic components - to the positioning of various organs in the hominid vocal tract and the reshaping of the human skull. From an evolutionary perspective, this is regarded an extremely implausible view (Burian, personal communication). Richard Lewontin makes the point through analogy: "The explanatory reconstruction of the origin of the camera eye by natural selection requires a particular ordering of light receptor and enervation first, followed by lens, followed by focusing distortion of the lens and iris diaphragm. The reverse order would not work, if every stage was to be an improvement in vision. Is there an unambiguous ordering for the elements of natural language? Did we have to have them all at once, in which case the selective theory is in deep trouble?" (1990, p. 741).

King even tries to help the evolutionary psychologists out. In her opinion, now that we have Gould's theory of punctuated equilibrium ${ }^{28}$ both a gradualist argument for the evolution of language as well as the argument that language evolved as a consequence of some cataclysmic event are both reconcilable with evolutionary theory. But Pinker does not accept the help King offers for an all of a sudden and out of the blue language mutation. Like Dawkins, Pinker downplays the revolutionary nature of Gould's theory. Instead, he hypothesizes that Wernicke's and Broca's areas, which are found in monkeys and apes but are not wired to produce language, gave evolution "some parts it could tinker with to produce human language circuitry." Evolution revamped "primate brain circuits that originally had no role in vocal communication and added some new ones" (1994, p. 350).

\footnotetext{
${ }^{28}$ Gould's theory of punctuated equilibrium argues that the occasional transformation of small, local populations into species occurs as the result of the isolation of these tiny populations for long periods. The isolation is due to rare, climactic, geographic or geological events - and the entrenched local changes allow natural selection to work. Thus, he maintains, that the stability of the fossil record reflects reality and is not an imperfection as generally thought.
} 
The professor of linguistics Philip Lieberman concurs with Pinker. Employing 'theorythinking' after the fashion of the evolutionary psychologists, Lieberman maintains that Broca's area must have some unique neural circuitry that accounts for our linguistic capacity (Lieberman, 1991). However, other developmental scientists contest this point, particularly, Kathleen Gibson (1994) and the neurologist/anthropologist Terrence Deacon $(1988 ; 1989)$. They maintain, to the contrary, that no such differences in neural circuitry have been identified after a comparison of monkeys with humans and that Lieberman's hypothesis is in fact a logical deduction from the data (Gibson, 1994, p. 98).

Pinker has not shown any awareness of Gibson and Deacon's findings. However, it is unlikely he would give their data much credence since he goes into the argument, like Lieberman, convinced that humans have a LAD. In this instance, it would make sense for Pinker to make the call for on-going investigation in order to keep his presupposition about the LAD out and in front thereby forestalling pro tempore consideration of the available evidence in favor of Gibson and Deacon's alternative view. Indeed, since the search for a LAD will prove propitious only if he is right, he could conceivably employ this strategy indefinitely if he is wrong.

\section{Finessing The Impasse}

Barbara King is important because she addresses the question of how theorists on both sides of the continuity-discontinuity divide can begin speaking to each other. While King stands firmly with the continuity theorists, her obvious commitment to realizing the Habermasian conditions of undistorted communication, ${ }^{29}$ particularly the condition of sincerity, that everyone means what they say, is another very good reason for taking seriously what she says. For

\footnotetext{
${ }^{29}$ The four conditions that must be met to achieve undistorted communication are: the symmetry condition (everyone has an equal chance to speak and listen); the sincerity condition (everyone means what they say); the truth condition (everyone discloses what they believe to be true); and the normative condition (everyone attempts to say what is right morally).
} 
instance, in her critical review of Gesture, and the Nature of Language (1995), in which the authors (D.F. Armstrong, W.C. Stokoe and S.E. Wilcox), argue that the essence of language is bodily activity and that the origins of syntax can be found in gesture, she urges that the book be given a "deeper response than being quickly embraced by continuity theorists and quickly dismissed by discontinuity theorists. It merits close critical examination on its own rather than instant alignment with one camp versus another, for GNL does something entirely new: it derives syntax incrementally, without reducing it to something so diluted that linguists will not recognize it as a property of language" (1996, p. 201). Elsewhere she points out that "despite a strong motivation to show that there are no major gaps across the primate continuum, but rather gradual incremental shifts in features of communicative ability," it is impossible to conclude from the primatological data on the communication of wild apes that their communicative utterances indicate sensitivity to syntactic sequencing patterns (1996, p. 195).

A perusal of the literature shows King has not had many direct exchanges with evolutionary psychologists. Because evolutionary psychologists regard animal communication systems as unrelatable to human linguistic behavior, they have made few, if any, overtures to biological anthropologists studying primates. Consequently, the inter-textual relationships that we do find are mainly one-way. Barbara King is very familiar with Stephen Pinker's work; Pinker seems totally unfamiliar with King's researches. In his classic article written with Paul Bloom published in Brain Sciences (1990) and republished in Tooby and Cosmides' Adapted Mind (1992) Pinker presents the Chomsky-Gould position as the main evolutionary alternative to their own. The Chomsky-Gould position is that language is a spandrel, a by-product not a selected-for feature of evolutionary processes. Pinker and Bloom never mention the primatological data that also sees language as having emerged gradually without any major 
Rubicon being crossed at the starting point of the hominid lineage. They resort to dichotomous, either/or terms of reasoning (referred to earlier as one of their main rhetorical ploys).

King recommends that researchers 'ditch the dichotomy' - the one that says there are only two types of theories, continuity and discontinuity - which are posed as polar opposites. (As King has already shown, evolutionary psychologists are really both at once.) She proposes that theorists "get away from simple labels" and break the cycle of claim and counterclaim by analyzing "each theory's elements and conclusions using a clear set of questions." In something of a rebuttal to the philosopher of science Helen Longino, King finds the debates that have taken place between discontinuity and continuity theorists on language origins not to be very productive at all. Longino, by contrast, maintains that many of the debates between practitioners operating in different paradigms are productive and that their productivity is testimony to the ability of the theorists involved to communicate effectively and negotiate past their differences (1990).

As far as King is concerned the debate has gone round and round (1994, p. 3; 1996) seeming to resolve nothing $(1996$, p. 194) as theorists talk past, rather than to each other (1996, p. 201) just as one would expect to happen when researchers adhere to incommensurable concepts and standards of evidence. The only way to ensure a productive debate is to flatten the viewpoints down; to show that there are not just two extreme views locked in struggle, and that there is no natural solidarity among the proponents at either end. King's antidote is to begin with a more realistic assessment of the situation, to begin by acknowledging the diversity of views that theorists actually hold. She calls for practitioners to accept that their positions do not really break down along stark disciplinary lines; that they fall on a continuum like everything else, and that there exists a middle range of views that cannot be neatly pigeonholed into either camp. 
Some theorists resist being labeled as discontinuity or continuity theorists altogether, according to King, and the most interesting ones commingle elements from both, as is the case with evolutionary psychology, (yet another reason why they may avoid such terminology).

Nevertheless, King is as locked in struggle with the evolutionary psychologists as she could be with any polar opposite view, even though their theory exemplifies, on her own accounting, a theory that falls in the middle. She does make headway but not as a consequence of any give on the evolutionary psychologists part. Instead, King decides to meet Pinker's gambit. He claims biological anthropologists need to provide evidence that the traits or behaviors that they claim are homologous with linguistic traits or skills are not merely analogous, but show the stuff of 'true language.' "To check for homology" Pinker says, "one would have to find some signature trait that reliably emerges both in ape symbol systems and in human language, and that is not so indispensable to communication that it was likely to have emerged twice, once in the course of human evolution and once in the lab meetings of the psychologists as they contrived to teach their apes" human languages (1994, p. 348).

Presumably, Pinker focuses on enculturated apes, that is, apes enculturated to a natural or artificial human language, because language requires the appropriate social circumstances in which to develop. King also indicates that "Pinker might have pointed out one of the greatest gaps in the primatological data: very little is known about the communicational behavior, either vocal or gestural, of wild apes" (1999a, p. 29). Accordingly, Pinker and King are agreed that enculturated apes are the best, if not the only source for acquiring the relevant data. Unfortunately, however, both theorists also overlook the fact that "the enculturated ape can't be sufficient to determine whether there is a fixed underlying grammar that apes and humans share. If an ape is successfully enculturated, this shows only that it had the capacity to acquire the 
relevant syntax and terms, not whether it did so because it already had the depth grammar of human language somehow wired into its brain (as humans are supposed to)" (Burian, personal communication).

Obviously complicating matters is the fact that Pinker and King disagree on what the ape's successful enculturation means. For Pinker the successfully enculturated ape proves the ape has a LAD. For King the successfully enculturated ape proves that humans do not have a LAD. Their differing background assumptions cause them to interpret the hard evidence in contradictory ways. Consequently, the possibility looms that Pinker and King may continue to go round in circles and talk past one another because of the potential for misunderstanding that attends their differing interpretations of the evidence and what they think the evidence shows.

Still, Pinker suggests that one could check to see if enculturated apes "echo some of the standard human sequence from syllable babbling to jargon babbling to first words to two-word sequences to a grammar explosion. One could look at the developed grammar, seeing if apes invent or favor some specimen of nouns and verbs, inflections, X-bar syntax, roots and stems, auxiliaries in second position inverting to form questions, or other distinctive aspects of universal human grammar." Notably, though, Pinker leaves an opening for locating these factors in the language of signing apes; for he remarks that these abstract structures "leapt out of the data when linguists first looked at American Sign Language and Creoles, for example” (1994, p. 349).

The kinds of studies that would convince Pinker, then, need not to be limited to ape vocal communication, but can be extended to apply to investigation of the signing of language by apes as well. Pinker concluded in 1994 that, although, this line of questioning "has never been applied to chimp signing one could make a good prediction of what the answers would be” (1994, p. 349). Ironically, at that very time the interdisciplinary team of Armstrong, et al., (1995) 
was engaged in analyzing data of the sort Pinker would have approved to show homology. Their work is the focus of King's discussion in, "Syntax and Language Origins" (1996).

Armstrong et al., go for a lesser conclusion, however, namely, that the evidence supports the existence of syntactical precursors (not full-blown syntax) in the visible signing of apes. They claim, in other words, that syntactic patterns can be discerned that show apes understand relationships among concepts, such as noun-verb combinations (1995, p. 159). This conclusion is almost as problematic for evolutionary psychology as a finding that apes make full-fledged use of syntax, for it suggests that syntax is derivable within a continuity framework and, hence, is not tied solely to the human brain (King, 1996). King, of course, wishes to interpret the evidence as casting doubt on the existence of a LAD entirely, either in humans or apes, but an alternative, albeit (equally) inconclusive possibility (given the lack of data) is that apes possess (rudiments of) a LAD, too.

Armstrong, et al., proceed in the light of a different conception of the essence of language, namely that, "the essence of language is bodily activity," (1995, p. 37) not syntax or Universal Grammar. For Armstrong, et al., sign language is not a special subset of language, sign language and speech are a subset of gesture and gesture is language. In short, they reject that speech and gesture are dualisms and they invert our customary understanding of these notions. But this does not alter the potential significance of their findings for evolutionary psychology. So the ball is now in evolutionary psychology's court. It would be helpful for its exponents to respond.

\section{Analysis}

One conclusion to be drawn is that the evolutionary psychologists obstruct objectivity by denigrating many of the research questions biological anthropologists wish to investigate. Their 
determination to prematurely close off questions by deeming them a priori of no relevance at all to the study of human cognition seems unscientific. Evolutionary psychology's short-sightedness appears to be a product of the decision to focus exclusively on the human species as sole object of study. The reality may be that this way of defining their interest is more arbitrary than justifiable.

The wariness evolutionary psychologists feel regarding the knowledge that might be gleaned from comparative data with other primates is evident in their failure to keep abreast of new research. Tooby and Cosmides cite few primatological studies and in those cases where they do, it is not to derive any insight about humans from them, but rather to buttress their argument in some way where animals figure in tangentially, not centrally, and always as a foil, never as a direct reflection of what human beings are (e.g., 1994, p. 73). King criticizes Pinker for being unaware of the latest primatological research (1996, p. 198). She and her colleagues are still waiting for a response to Armstrong, Stokie and Wilcox's findings.

Biological anthropologists rarely mention that humans did not descend from the other primates but that all primates descended from a common ancestor. When they do raise the subject, it is to make the point that gaps in behavior between monkeys and apes and humans is not unbridgeable as born out by their close anatomical and genetic relationship (King, 1994a, p. 131). Of course the very opposite point can be drawn, i.e., that a qualitative difference exists and this difference justifies doubts about the certainty of extrapolating from primates to humans. Kathleen Gibson's empirical data suggests that this is not the case, however (1994). In any event, it is a claim that should be the subject of ongoing investigation.

Regardless, it is not adequate merely to trumpet assertively, as Steven Pinker has that, "language is obviously as different from other animals' communication systems as the elephant's 
trunk is different from other animals' nostrils" (1994, p. 334, emphasis added); nor is it enough to proclaim that the debate over what qualifies as 'True Language' is a debate for dictionary writers, not scientists (1994, p. 347). Pinker can’t really mean this. If he does reconciliation between the evolutionary psychologists and biological anthropologists is not far to seek and their apparently intense opposition can be dismissed as subterfuge. It is the very fact that evolutionary psychologists wish to legislate what True Language is, not that they do not care what it is, that indicates a corrective is needed in the way that they do science. King and her colleagues would be happy to speak of language more broadly and see it in family resemblance terms, not essentialist ones.

The disposition of anthropologists to report what they see and take the imaginative leaps that are scientifically required to make sense of their data is far more in keeping with the spirit of the works of Darwin and William James to whom evolutionary psychologists appeal to justify their lineage and bolster the authority of their view. Darwin, after all, projected 'beauty' in the co-adaptations that manifested the principle of natural selection everywhere in the organic world (1859/1964, pgs. 60-61). He believed that "when we no longer look at an organic being as a savage looks at a ship, as at something wholly beyond comprehension; when we regard every production of nature as one which has had a history...when we thus view each organic being, how far more interesting, I speak from experience, will the study of natural history become!" (1859/1964, pgs. 485-486)

For Darwin the scientific temperament did not exclude empathy for other creatures and the experiences we have with them. Darwin impresses this point by adopting in Descent of Man the subjective perspective of the ape and employing narrative from the point of view of this bestial creature details what it is they know and feel and what is simply beyond their 
comprehension (1859/1964, p. 289). And James considered any science objectionable that would deflate or distort real experiences to force-fit them to science's preconceptions. This is the point of James' radical empiricism. Both Darwin and James would have been more prone to side with the empathetic anthropologists than with their skeptical counterparts in evolutionary psychology.

Evolutionary psychology's willingness to engage other scientists in discussions about the nature of human as 'animal' would signal their effort to contribute to empirical research of the sort that extends knowledge. Helen Longino puts forward the mission of knowledge-extension as an important goal of scientific inquiry and one that is separate from and independent of the pursuit of truth which is another goal (1990, pgs. 32-37). Biological anthropologists constantly promote knowledge-extension through the questions that they raise that lead them to new investigations. It is debatable whether they are better at advancing this goal than are the evolutionary psychologists for Artificial Intelligence research in which evolutionary psychologists are invested provides an avenue for knowledge-extension of a different sort. Any scientific theory, Longino points out, can be measured against both criteria, faring well in one area, less well in the other. One thing for certain is that evolutionary psychology would at least gain on the knowledge-extension score if they acknowledged the relevance of primatological research to human understanding, too.

Biological anthropologists take a lead affirming the progressive character of science when they refuse to admit that any stage in the development of their theorizing is final. As in the natural sciences, they recognize that it is anti-scientific to take anything but a provisional and tentative attitude towards current findings. Attempting to distance their field from other fields for the purpose of defining it in some original fashion may be necessary to achieve evolutionary 
psychology's goal of getting established but doing so for long also runs the risk of alienating cognate fields with which it shares an obvious interest. This seems to be evolutionary psychology’s Achilles heel.

The cognitive archeologist Steven Mithen even shows that the choice can be made the other way round, that is, to give priority to knowledge-extension at the (possible) expense of correctness or truth. ${ }^{30}$ He does this when he invokes the controversial notion of recapitulation to model the mind's evolution. Mithen appeals to the concept of recapitulation because it is needed to facilitate his study providing "a means to establish the framework of hypothetical architectural phases" of the mind, whether correct or not. Mithen states: "Indeed, it would seem a missed opportunity verging on academic negligence if I were to ignore the idea of recapitulation" (1996, p. 63) for the prospect that it affords is enticing: by adopting the notion of recapitulation the possibility looms that we will see developmental stages of the minds of children today paralleled in the evolution of human ancestral minds" (1996, p. 64). One can never be sure what one will find.

The knowledge-extension mission provides the fuel for reworking, re-thinking, and ultimately, realizing true and objective knowledge. King and her colleagues give the evolutionary psychologists something worth having: a way to further open up the subject that concerns them both to continuing interpretation in one additional venue. Evolutionary psychology's defensive posture regarding the definition of their subject compromises their claims to objectivity in this regard.

\footnotetext{
${ }^{30}$ The empirical linguists, Lakoff and Johnson, would not find this surprising. They would see the priority Mithen gives to knowledge-extension over truth in line with their dictum that truth takes second place to understanding (see Metaphors We Live By, 1980).
} 


\section{CHAPTER 4. EMPIRICAL LINGUISTICS}

Since the nineteenth century linguists have been making conscious moves to get their field accepted as a scientific discipline. Although today linguists mainly study features of languages as communicative systems, virtually ignoring the route by which different languages have taken on the form in which we find them today (synchronic linguistics), in the nineteenth century they studied the history of languages and their relationships (diachronic linguistics). In the opinion of one contemporary linguist, Geoffrey Sampson, the history-centered outlook of nineteenth century linguistics was related to the general state of science at the time. Linguistics had available "two outstandingly successful scientific paradigms" from which to select a model, Sampson claims, Newton's mechanistic physics and Darwin's theory of evolution. The latter biological model was by far more influential (1980, pgs. 14-15). The science of linguistics intersects evolutionary theory at its inception, then, and in a highly conspicuous way.

Languages were viewed as organisms - specifically, organisms of speech - not unlike any of the other organisms found in the natural world. "Languages are organisms of nature; they have never been directed by the will of man; they rose, and developed themselves according to definite laws; they grew old, and died out" (Schleicher, 1869/1983, p. 21). The linguist August Schleicher unabashedly considered linguistics to be a branch of biology, and it was an important branch because it reflected human nature. According to Schleicher "the history of the formation of the progress of speech" constituted "the main aspect of the development of mankind" (1869/1983, p. 18).

The boost Schleicher gets for linguistics from Darwinism cannot be underestimated. Schleicher sees Darwin's conclusions as "a necessity." Schleicher follows Darwin deep into the details. Noting Darwin's position on the lack of a clear line of demarcation between species and 
sub-species or well-marked varieties, Schleicher says: "Well, if for the terms species, subspecies, variety, we substitute the words language, dialect, patois, as used by the glossologist, Darwin's statement holds perfectly good with regard to those divergences of speech in the bosom of one family, of which we have already illustrated the gradual process of development" (1869/1983, pgs. 47-48).

While the historical approach of evolutionary biology seemed the natural approach for linguists, filled with promise for making new discoveries, applying the model became problematic as the nineteenth century ended. The first problem, according to Sampson, had to do with the directionality of evolutionary change for languages.

It is central to the evolutionary view of biology that the replacement of old species by new is not merely a process of random changes (even if the individual mutations on which evolution depends are random), but rather is a movement from lower to higher - mutations which succeed in spreading are those which give their possessor an advantage in the struggle for survival, while disadvantageous traits are eliminated. This notion that different forms of life occupy different points on a scale of degrees of development is by no means an original feature of Darwin's theory of descent with modification, of course; it had been familiar since Aristotle as the philosophical and theological doctrine of the Great Chain of Being, a concept which became particularly influential in the eighteenth century (1980, p. 21).

Sampson concludes his discussion of the nineteenth century linguists with the observation that despite the fact that they could not find an analogue to survival of the fittest for the causes and changes of languages, the Darwinian paradigm was probably abandoned prematurely. Its abandonment, he says, was "less well motivated than may have appeared at the time" (1980, p. 33). Sampson reasons that just as Darwin was forced to treat the occurrences of modifications in offspring as an unexplained axiom, so too linguists might have treated linguistic change as unexplained axiom - one that would eventually be addressed (1980, p. 32).

Of course, except for the opinion of Robert Richards (1932), the general consensus among evolutionary-minded thinkers today is that Darwin never meant for his theory to be understood in progressivist terms, as Sampson understands it; hence, the notion of 'directionality 
of change,' to which Sampson refers (1980, p. 32), should not have posed a problem for linguists in their concern to comprehend the ebb and flow of languages. So Sampson may draw the right conclusion - that the Darwinian model was abandoned prematurely - but for the wrong reason progress from lower to higher life forms was not a 'problem' in need of explanation. Gould captures the prevailing opinion. He states that: "Ironically...the father of evolutionary theory stood almost alone in insisting that organic change led only to increasing adaptation between organisms and their own environment and not to an abstract ideal of progress defined by structural complexity or increasing heterogeneity - never say higher or lower." Darwin mused that "if an amoeba is as well adapted to its environment as we are to ours, who is to say that we are higher creatures" (Gould, 1977, p. 36). ${ }^{31}$ One might surmise that had linguists understood Darwin in these terms, their investigation into the mechanism responsible for the ebb and flow of language might have led them deeper into historical reality to find the explanation.

While Schleicher dismisses the idea of a proto-language as impossible, the idea that there existed some one common primitive form of language from which all other languages descended, he does consider that "all the languages of a higher organization - as for instance the Indo-Germanic parent which we are able to examine - show by their construction, in a striking manner, that they have arisen from simpler forms, through a process of gradual development. The construction of all languages points to this, that the eldest forms were in reality alike or similar; and those less complex forms are preserved in some idioms of the simplest kind as, for example, Chinese" (1869/1983, p. 50, emphasis added).

Schleicher's misconstrual of Darwin lends some support to Peter Bowler's thesis that the Darwinian Revolution did not occur until the neo-Darwinian synthesis of the 1940s (when

\footnotetext{
${ }^{31}$ Yet this advice Darwin did fail to heed, particularly in Descent of Man (1871) where his reference to lower life forms is frequent, so Schliecher's misreading of Darwin is understandable.
} 
natural selection was linked to the theory of heredity) because nineteenth century thinkers influenced by Darwin preserved a teleological view of things (Bowler, 1988, p. 5). So too, it would appear does Sampson for he never abandons his claim that Darwin rightfully saw the natural world progressing from lower to higher forms. His misreading bears out Gould's observation that "had we heeded Darwin's warning" and resisted equating organic complexity with progress we would have been spared much of the confusion and misunderstanding that exists between scientists and laymen today" (Gould, 1977, p. 37) - or between scientists and other scientists as in the present case.

What is more, if Noam Chomsky is correct - that the form of all human languages is the same - then ranking languages in terms of their complexity is certainly misguided.

\section{Noam Chomsky: Architect Of Evolutionary Psychology's Deep Structure}

To continue this disciplinary history, I jump from the nineteenth century to the twentieth where descriptivists and structuralistists have predominated. The twentieth century saw the works of Ferdinand de Saussure, moved through the anthropological linguistic studies of Franz Boas and Edward Sapir, and culminated in the transformational-generative phase of linguistics inaugurated by Noam Chomsky, who deeply influenced evolutionary psychology.

Chomsky's approach marks a difference because, unlike the descriptivists who "tended to think of abstract linguistic theorizing as a means to the end of successful practical description of particular languages," he tended to think of individual languages "as sources of data for the construction of a general theory of language" (Sampson, 1980, p. 59). Further, the subject matter of linguists for Chomsky was not, as it was for the structuralists, some set of sentences selected randomly from the corpus of a language. Rather the appropriate subject matter was the speaker's underlying knowledge of its abstract rules and principles, which enabled the speaker to formulate 
novel sentences. Chomsky sought to get at the innate knowledge that accounted for a speaker's ability to produce and understand sentences. In the view of many of his contemporaries, Chomsky's alteration “enabled linguistics to cross the line from a descriptive pre-science to an axiomatic science" (Gardner, 1985, p. 189).

Chomsky had his own agenda for linguistics. He proposed that all languages were composed of a deep syntactical structure of Universal Grammar. Studying this structure is what made linguistics interesting for Chomsky. The reason he gave was that this deep structure provided insights into the structure of the human mind. Evolutionary psychologists follow Chomsky in making this assumption. Chomsky recurs to the scientific paradigm of mechanics, not biology, describing language in terms of laws and universals, which apply across a whole range of linguistic phenomena. He chooses this approach over examining individual words and particular languages on a case-by-case basis or the particular historical sequence that describes the current distribution of languages.

According to Chomsky the complete grammar of a language is composed of three parts: its syntactical, phonological, and semantic components. The syntax, or heart of the grammar, generates and describes the internal structure of the sentences of a language. The phonological and semantic components describe the sound and meaning structures, respectively, and on Chomsky's view the latter two are purely interpretative elements. That is to say, the phonological and semantic components do not generate sentences. Rather they merely describe the sound and meaning produced by the syntax that generates the sentences and, hence, does the main work.

Among Chomsky's insights is that sentences are not unordered strings of words; sentences cannot be haphazardly generated by, what Pinker calls a word-chain device, i.e., “a 
bunch of lists of words and a set of directions for going from list to list" (Pinker, 1994, p. 91). Chomsky refutes the relevant application of the word-chain device to human languages with his famous phrase "colorless green ideas sleep furiously." This nonsense sentence, which we recognize as grammatically correct, is intended to show that when people learn a language, they learn how to put words in an order by the proper category they fall into, noun phrase, verb phrase and the like, not merely by recording the sequence of words and remembering only the most recent list that one has picked words from.

Chomsky showed that grammatical relations and dependencies abound in human languages and that linguistic competence involves a complicated process of rule application. $\mathrm{He}$ did not mean to suggest that people go through the application of such rules either consciously or unconsciously, however. He meant that in some sense individuals have tacit knowledge of the rules that the linguist represents in his grammatical constructions. These grammatical constructions show that language, with all its dependencies, is hierarchically arranged.

As Pinker puts it in his popular rendering of Chomsky, language is not like a chain; it is more like a tree (1994, p. 97). One of the special consequences of this is that it would be extremely difficult to teach a child to acquire a language no matter how simple that is nonhierarchical in structure. Simply put, children are born with minds designed to acquire hierarchical languages, something which they are able to do on "relatively slight exposure and without specific training" (Chomsky, 1975, p. 4). "Powerful constraints" are "operative restricting the variety of languages" people can learn even though they are "obviously, not designed to learn one 'human' language rather than another" (Chomsky, 1975, p. 11). "Thus, language is a mirror of mind in a deep and significant sense" (Chomsky, 1975, p. 5). 
Chomsky calls the rules that define which part-of-speech category a particular word belongs to its 'phrase structure grammar' (Pinker, 1994, p. 99). The super-rules that enable people to construct the phrase structure grammar of a sentence, on the other hand, is called the deep structure or Universal Grammar. Chomsky calls the deep structure the Universal Grammar because he believes it is the same for all natural languages. It is the essence of language. The grammar is generative because it is capable of kicking out all the sentences of a language that are grammatically correct and only those sentences that are grammatically correct.

A sentence containing an unambiguous set of words can have several different underlying deep structures. The surface structure is conveyed in the utterance, it is what we read or hear, but the surface structure may conceal several different syntactical deep structures. It is by parsing these deep structures that we get at the precise meaning that was intended for the sentence by the speaker.

While these fundamentals of Chomsky's theory are widely known, misunderstandings about their implications are prevalent among his readers. This is evidenced at a minimum by Chomsky's repeated defense of his ideas on this basis. Chomsky's readers include the likes of John Searle and Hilary Putnam to whose particular misunderstandings he responds in Reflections on Language (1975). I am certain they would also include the thinkers whose voices I bring into the conversation in this chapter, George Lakoff and Mark Johnson. (I address the misunderstandings they have in a succeeding section.)

Lakoff and Johnson's representations of Chomsky conflict with what he says. Nevertheless, John Searle tells us, that Lakoff was one of Chomsky's best students, one who found Chomsky's general theoretical notion that the syntactical structure of sentences determines their meaning implausible. Before getting to Lakoff and Johnson's theory of cognitive 
semantics, which they develop in response to their perceived inadequacies of Chomsky's view, I wish to show how Chomsky's ideas are echoed in evolutionary psychology.

\section{Evolutionary Psychology: The Surface Structure}

John Searle believes that “one of the merits of Chomsky's work has been that he has persistently tried to call attention to the puzzling character of facts that are so familiar that we all tend to take them for granted as not requiring explanation" (1972). Evolutionary psychologists endorse this effort, which (following William James) they describe as the effort to make the natural seem strange. Tooby and Cosmides attribute the source of the difficulty involved in conceiving our inability to put our finger on and identify what seems natural and intuitively obvious as "instinct blindness" (Cosmides and Tooby, 1994). "Our minds are always automatically applying a rich variety of frames to guide us through the world. Implicitly these frames appear to be part of the world. For precisely this reason we have difficulty appreciating their magnitude, or even the existence of the frame problem" (Tooby and Cosmides, 1992, p. 107). Hence, the one way to overcome instinct blindness is by studying grammars derived from minds much different from our own. ((For Tooby and Cosmides, but not for Pinker who rebukes the value of comparative data across the board, this includes animal minds) (Cosmides and Tooby, 1994, p. 73)).

So evolutionary psychologists approach their task in the same intellectual fashion as Chomsky. Like Chomsky, they bristle at the idea that human nature is entirely a social product. As Chomsky puts it: "The principle that human nature, in its psychological aspects is nothing more than a product of history and given social relations removes all barriers to coercion and manipulation by the powerful. This...may be the reason for its appeal to intellectual ideologues" (1975, p. 132). As evolutionary psychologists put it from another politically motivated angle: 
"The most risible pretexts for bad behavior in recent decades have come not from biological determinism but from environmental determinism: the abuse excuse, the Twinkie defense, black rage, pornography poisoning, societal sickness, media violence, rock lyrics, and different cultural mores (recently used by one lawyer to defend a Gypsy con artist and by another to defend a Canadian Indian woman who murdered her boyfriend)" (Pinker, 2002, p. 178).

More than this, though, Chomsky is originator of evolutionary psychology's key insight that "language falls naturally within the sphere of human biology" (1975, p. 123). They accept the idea that the human species possesses a Universal Grammar that is "a rich structure of pre-determined form" vastly underdetermined by the triggering effects of experience, which prompts it to grow and develop in the manner of any other biological organ, say, the liver or heart. For evolutionary psychologists as for Chomsky, learning as conventionally understood, is an inappropriate, even misleading metaphor for the competence that is achieved by the mature genetically-preprogrammed language faculty. Language mastery is so extraordinarily complicated that human beings, regardless of intelligence, could not do it at a young age even if they were deliberately taught.

Evolutionary psychologists also echo Chomsky on this corollary to the notion that language is biological; namely that, our cognitive faculties should be treated on a par with other biological or physiological organs. Like any other biological or physiological organ, language matures according to its own timetable. Chomsky is insistent: "I think we might ... say that language isn't even learned... We begin our interchange with the world with our minds in a certain genetically-determined state, and through interaction with an environment, with experience, this state changes until it reaches a fairly steady mature state, in which we possess 
what we call knowledge of language" (Chomsky, 1978, p. 176). ${ }^{32}$ Environmental factors serve as 'triggers' that activate the development of the language module among others. Learning strategies are entities "too formless compared to the exacting phenomena they are meant to explain that they must be granted near magical powers" (Pinker, 1997, p. 27). The ease with which language is learned is a consequence of the pre-existent cognitive capacity.

The evolutionary psychologists follow Chomsky in believing that language is only one among many of the various capacities humans possess innately. As Pinker puts it, evolutionary psychology "takes many of the lessons of human language and applies them to the rest of the psyche." "Just as language is an improbable feat requiring intricate mental software, the other accomplishments of mental life that we take for granted, like perceiving, reasoning and acting, require their own well-engineered mental software. Just as there is a universal design to the computations of grammar, there is a universal design to the rest of the human mind - an assumption that is not just a hopeful wish for human unity and brotherhood, but an actual discovery about the human species that is well motivated by evolutionary biology and genetics" (Pinker, 1994, p. 410).

Chomsky, before Pinker, makes his point as follows: "Investigating the cognitive capacity of humans, we might consider, say, the ability to recognize and identify faces on exposure to a few presentations, to determine the personality structure of another person on brief contact (thus to be able to guess pretty well, how that person will react under a variety of conditions), to recognize a melody under transposition and other modifications, to handle those branches of mathematics that build on numerical or spatial intuition, to create art forms resting on certain principles of structure and organization and so on" (Chomsky, 1975, p. 21). Chomsky

\footnotetext{
32 These are Chomsky's words from an interview conducted by Brian Magee which can be found in Chapter 11 of Magee's book, Talking Philosophy (1978), titled: The Ideas of Chomsky: Dialogue with Noam Chomsky. The citation appears in the References Section of this paper under "Chomsky."
} 
also speaks of our capacity to formulate scientific theories (1975, p. 58-59) and our capacity for common sense understanding (1975, p. 133). He concludes: "Humans appear to have characteristic and remarkable abilities in these domains, in that they construct a complex and intricate intellectual system, rapidly and uniformly, on the basis of degenerate evidence" (1975, pgs. 21-22).

Finally, one other commanding idea of Chomsky's echoed in evolutionary psychology, intimated in the foregoing but not made explicit, is the idea that our biological instincts provide the basis for the achievement of creativity as well as the basis for its limitations. Without rules and constraints our behavior would be aimless in character. "Creativity is predicated on a system of rules and forms, in part determined by intrinsic human capacities. Without such constraints we have arbitrary and random behavior, not creative acts" (1975, p. 133).

Tooby and Cosmides take offense at the use of the term "constraint" (1992, p. 36) in this context. But the reason they do is precisely because they accept Chomsky's point: that the psychological mechanisms that inhere in people's heads do not limit, rather they serve as conditions of possibility. The specific generative programs people possess create and enable them to do all the things they can do. Tooby and Comsides concur with Chomsky that an empty or plastic organism is an unreasonable construct. "The notion that inherited psychological structure constrains is the notion that without it we would be even more flexible or malleable or environmentally responsive than we are. This is not only false, but absurd," declare Tooby and Cosmides. Without this evolved architecture we would have no competences or contingent environmental responsiveness whatsoever" (1992, p. 38). Chomsky reinforces the point: "If we really were plastic organisms, without an extensive preprogramming, then the states our minds 
achieved would simply be a reflection of the individual's environment and therefore would be extraordinarily impoverished" (1978, p. 184)

Unlike Tooby and Cosmides, Chomsky and Pinker openly concede the cognitive limitations that follow from their view. Assuming one of our mental organs is a science-forming capacity Chomsky muses: “A Martian scientist looking at us and observing our successes and errors from the standpoint of a higher intelligence might be amazed to discover that whereas in some domains we seem to be able to make substantial scientific progress, in other domains we always seem to be running up against a blank wall, perhaps, because our minds are constructed that we can't make the intellectual leap required - we can't formulate the concepts, we don't have the categories required to gain insight into that domain" (1978, p. 187). Pinker concurs: "Humanly thinkable thoughts are closed under the workings of our cognitive faculties, and may never embrace the solutions to the mysteries of philosophy... We should be thankful that the problems of science are close enough in structure to the problems of our foraging ancestors that we have made the progress that we have" $(1997$, p. 563).

\section{Pinker's Synthesis: Take Two}

Although they agree on much, Chomsky and evolutionary psychologists disagree on what is perhaps the most important thing. Causing Pinker some consternation, Chomsky finds it unlikely that the language acquisition device (LAD) evolved by natural selection. Even granting that the needs of communication influenced the evolution of language, Chomsky claims we can conclude little from this. "The needs of locomotion influenced the fact that humans developed legs and birds wings. This observation is not very helpful to the physiologist concerned with the nature of the human body. Like physical structures, cognitive systems have undoubtedly evolved in certain ways, though in neither case can we seriously claim to understand the factors 
that entered into a particular course of evolution and determined or even significantly influenced its outcome" (Chomsky, 1975, p. 58). He goes on:

Among the systems that humans have developed in the course of evolution are the scienceforming capacity and the capacity to deal intuitively with rather deep properties of the number system. As far as we know, these capacities have no selectional value, though it is quite possible that they developed as part of other systems that did have such value. We know very little about what happens when $10^{10}$ neurons are crammed into something the size of a basketball, with further conditions imposed $b$ the specific manner in which this system developed over time. It would be a serious error to suppose that all properties, or the interesting properties of the structures that have evolved can be "explained" in terms of natural selection. Surely there is no warrant for such an assumption in the case of physical structure (1975, pgs. 58-59).

Chomsky takes the contrary view that "if we hope to understand human language and the psychological capacities on which it rests, we must first ask what human language is, not how or for what purposes it is used" (1972, p. 70). He states: "there is no doubt that the physiologist, studying the heart, will pay attention to the fact that it pumps blood. But he will also study the structure of the heart and the origin of this structure in the individual and the species, making no dogmatic assumptions about the possibility of "explaining" the structure in functional terms" (1975, p. 57).

Chomsky stands firmly by his position. Structure and function are distinctly separate issues - a distinction that will not do for Pinker who assumes that function determines structure; that in order to get at the mind's hidden mechanisms one must determine first what purposes are served by the behaviors they prompt people to exhibit, what problems our ancestors faced in the past that caused them to be selected for. ${ }^{33}$ Pinker's answer to the question: 'what is the language structure that harbors the Universal Grammar for?' is “to convey news” (1994, p. 83). Pinker adopts the common sense view that language was selected for the purposes of communication. He then commingles it with Chomsky's not so commonsensical view that the generative

\footnotetext{
${ }^{33}$ The inference from behavior to psychological mechanism on which evolutionary psychologists rely is criticized by Lawrence Shapiro in "Presence of Mind" in Where Biology Meets Psychology, edited by Valerie Hardcastle (1999, MIT Press).
} 
component of language is the syntax. For Pinker, too, the deep syntactical structure, contained in the Universal Grammar, is autonomous from the rest of cognition, sharply divided off from all other cognitive sources of meaning. This is not to say that form and function, syntax and semantics do not interact, however. They do. Rather it is to say that the Universal Grammar is not influenced by meanings and the needs of communication. This leads Chomsky to answer the question: 'What is language for?' with the declaration: 'Language is for the expression of thought, not the communication of ideas to another' (1966; 1975, pgs. 57-61).

The notion that language is expressive is thoroughly developed by Chomsky in his book, Cartesian Linguistics (1966). It bears out the Cartesian notion that human language differs from animal communication in that it is not a response to external stimuli or internal physiological states. Instead language serves as "a general instrument of thought and self-expression rather than a communicative device to report, request, or command" (1966, p. 12). As far as Chomsky is concerned, a person can use language with no intent at all to communicate. In such cases, although one's utterances have "a definite meaning, their normal meaning," nevertheless one's "intentions with regard to an audience may shed no light on this meaning" (1975, p. 61).

Chomsky provides the following example:

As a graduate student, I spent two years writing a lengthy manuscript, assuming throughout that it would never be published or read by anyone. I meant everything I wrote, intending nothing as to what anyone would believe about my beliefs, in fact taking it for granted there would be no audience. Once a year, along with many others, I write a letter to the Bureau of Internal Revenue explaining, with as much eloquence as I can muster, why I am not paying part of my income tax. I mean what I say in explaining this. I do not, however, have the intention of communicating to the reader, or getting him to believe or do something, for the simple reason that I know perfectly well that the "reader" (probably some computer) couldn't care less. What my statements in the letter mean, what I mean - in one sense - in making these statements, is not explicable in terms of what I mean, what I intend, in writing the letter, namely to express support for people undertaking resistance to the criminal violence of the state in more meaningful ways (1975, p. 61). 
Chomsky is consistent. There is no tension in affirming that the essential structure of language is syntax; that this structure works autonomously from the rest of cognition; and that the main purpose of language is expressive. But how does Pinker account for the primacy and autonomy of the syntactical deep structure and the communicative function that this deep structure serves? Once communication as a function is brought in, it becomes necessary to explain how that function shaped the structure in question. While the primacy Pinker ascribes to syntax, which is a formal and abstract symbolism, fits nicely with his view of the mind as a computational mechanism, another formal and abstract symbolism, the attention he must now pay to functionality and hence to the particularities of the real world creates a tension in their conjunction. ${ }^{34}$

Pinker's answer has three parts: he posits first that grammatical devices alone are extremely useful. "Without recursion you can't say the man's hat or I think he left. Recall that all you need for recursion is an ability to embed a noun phrase inside another noun phrase or a clause within a clause... With this ability a speaker can pick out an object to an arbitrarily fine level of precision. These abilities can make a big difference. It makes a difference whether a far off region is reached by taking a trail that is in front of the large tree or a trail that the large tree is in front of. It makes a difference whether the region has animals that you can eat or animals that can eat you. It makes a difference whether it has fruit that is ripe or fruit that was ripe or fruit that will be ripe. It makes a difference whether you can get there in three days or whether you can get there and walk for three days" (1994, p. 368).

\footnotetext{
${ }^{34}$ Pinker says specifically that he embraces the computational metaphor for its ability to transform mental phenomena "formerly considered too airy-fairy to study scientifically" into a device that trades in signals, data structures, information, and feedback ("Mind, Morality, and Evolution: An Interview with Steven Pinker," Free Inquiry, Spring 2000, 1997, p. 78). Citation appears under "Pinker" in the References Section of this paper.
} 
Secondly, Pinker addresses the question, "why was one universal language not selected for if syntax and semantics, structure and function obviously interact? Why wasn't the whole interaction hard-wired into the brain?" Pinker's answer is that the things we have to learn about language may be easily learned by a simple mechanism so that with the basic grammar of language in place evolution "may have seen no need to replace every bit of learned information with innate wiring." A second reason Pinker gives for the fact that language is partly learned is that it involves "sharing a code with other people...An innate grammar is useless if you are the only one possessing it: it is a tango of one, the sound of one hand clapping. But the genomes of other people mutate and drift and recombine when they have children. Rather than selecting for a completely innate grammar, which would soon fall out of register with everyone else's, evolution may have given children an ability to learn the variable parts of language as a way of synchronizing their grammars with that of the community" (1994, p. 243).

The third reason Pinker provides to show that the Universal Grammar's autonomy is consistent with its selection for communication has to do with the functionality of the classical concepts generated by its formal rules. The rules that produce these concepts are basically responsible for our ability to cognize law-governed generalities. Our ability to cognize lawgoverned generalities accounts for our ability to make practical, every-day inferences about the world in which we live. At the same time, our ability to cognize law-governed generalities enables us, derivatively, to do science. In this manner, Pinker rebukes Chomsky's claim that people's ability to perceive regularities has no selectional value. As well, he puts his own twist on our 'science-forming capacity' as being something more along the lines of a spandrel, a byproduct of the UG module and its capacities, not a separate modular domain unto itself as Chomsky suggests. 
How Pinker's account fares against that of his linguistic contemporaries George Lakoff and Mark Johnson follows in the next two sections. Lakoff and Johnson take the argument of how the mind works to the other extreme from Chomsky denying the autonomy of syntax altogether (and any abstract, formal system of rules inherent in the mind) while granting that our cognitive traits have evolved and that they are adaptive. Lakoff and Johnson, in other words, see our mind's structure and its functions as wholly interactive and intertwined.

\section{Two Views Of Reality - Two Views Of Cognition: Divergent Paradigms Again?}

George Lakoff and Mark Johnson represent the student generation of critics of Chomsky who call themselves second-generation cognitive scientists. Lakoff's degree is in linguistics. He taught at Harvard, the University of Michigan, conducted research at the Center for Advanced Study in the Behavioral Sciences at Stanford and is presently ensconced at Berkeley. Johnson's background is in philosophy. He is currently Knight Professor of Liberal Arts and Sciences in the Department of Philosophy at the University of Oregon and claims a special interest in the aesthetic dimensions of experience, meaning and human action. Lakoff and Johnson have coauthored two books: Metaphors We Live By (1980) as well as Philosophy in the Flesh: The Embodied Mind and Its Challenge to Western Thought (1999) as well as having other books (separately composed) to their credit on subject matters ranging from concepts, reason and metaphor to their bearing on politics and morality.

Lakoff and Johnson speak of "two views of cognition" which correspond to "two views of what reality can be known" (Lakoff, 1987; 1988; Lakoff and Johnson, 1999). They attempt to exploit this dichotomy. They oppose Western metaphysical ways of thinking which they believe have been unreflectively and universally accepted for thousands of years to their own empirically responsible ways of looking at the world which are grounded in the facts of lived experiences 
and informed by science. Their philosophy, which they call 'experiential realism,' proceeds on the assumption that meaningful concepts and categories of thought are realized in neural structures. These neural structures are formed automatically and unconsciously through our sensory-motor interaction with the world. They are inseparable from experience (hence the name) arising from and understood through our bodies and brains.

Accordingly, Lakoff and Johnson claim that “we evolved to categorize; if we hadn't we would not have survived" (1999, p. 18). To wit, "reason is evolutionary, in that abstract reason builds on and makes use of forms of perceptual and motor inference present in 'lower' animals. The result is a Darwinism of reason." "Reason," they continue, "even in its most abstract form, makes use of, rather than transcends our animal nature." Like the biological anthropologists discussed in the previous chapter, Lakoff and Johnson believe that "the discovery that reason is evolutionary utterly changes our relation to other animals and changes our conception of humans beings as uniquely rational. Reason is not an essence that separates us from other animals; rather, it places us on a continuum with them" (Lakoff and Johnson, 1999, p. 4).

Casting Western metaphysics as a paradigm that diverges sharply from (is even diametrically opposed to) Lakoff and Johnson's own experiential view of reality is a problem in the making. Taking our cue from Barbara King we know that either/or ways of thinking of this sort (also employed by the evolutionary psychologists) encourage point and counter-point exchanges that often fail to be communicative. Such exchanges tend to overshadow the many plausible, intermediate views that fall in-between force-fitting recalcitrant positions towards one extreme pole of the dichotomy or the other. Lakoff and Johnson's treatment of evolutionary psychology, I shall argue, is a case in point. Moreover, it is glaringly contrary to the way of 'thinking about thinking' that they consider most plausible. For Lakoff and Johnson wish to 
emphasize that the concepts we use to think with are largely comprised of fuzzy categories and family resemblance type similarities, not by clear conceptual boundaries as either/or thinking suggests, not by necessary and sufficient conditions for membership as the classical theory of the Western philosophical tradition presupposes.

Lakoff and Johnson's strategy for undermining the Western tradition is shrewd, but it is also suspect. They tie a whole bunch of theories or posits, which they associate with all the errors of Western thinking, to one key theme: the classical theory of categories just mentioned. This is the idea that the world comes parsed into natural kinds - where all members of the kind have ' $\mathrm{x}$ ' and only members of the category or kind have ' $\mathrm{x}$. ' ' $\mathrm{X}$ ' is the essence of the thing. ' $\mathrm{X}$ ' is what Socrates was looking for - an 'every' and 'only' definition. One of the arguments Lakoff and Johnson give to undermine the propriety of these categories comes straight from evolutionary biology. They claim that evolutionary biology contradicts the idea that natural kinds of living things can be defined by their shared essential properties. Lakoff and Johnson point out that the world that evolutionary processes have constructed is a fuzzy world, one best understood by experiential realists like themselves, not metaphysical realists like Plato, and along with Plato they place Chomsky. Species are not natural kinds. Species do not have necessary conditions, clear boundaries, or homogeneous internal structures. Species are delimited relative to other groups and relative to geography (Lakoff, 1987, p. 192; Lakoff, 1988, p. 125).

Lakoff and Johnson maintain that the classical theory of concepts is also tied to the correspondence theory of truth, to the idea of meaning as reference, to the idea that grammar is a matter of pure form, that all people think using the same conceptual system, that the mind is independent of the body, that emotion has no conceptual content, that reason is transcendental, 
and that there is a correct, God's eye view of the world. Boldly, they state: "when that concept [of classical categories] is left behind, all these others will be too" (Lakoff, 1987, p. 9).

To these posits, Lakoff and Johnson counterpose their own: that truth is "always relative to a conceptual scheme that is defined in large part by metaphor" (Lakoff and Johnson, 1980, p. 159); that meanings are metaphorical and depend wholly on context and the speakers' attitudes, not independently of them (1980, pgs. 11-12); that people think using conceptual systems that depend upon their experiences; that grammar depends upon understanding; that the mind is embodied and emotion a part of our embodied experiences; (Lakoff and Johnson, 1999, p. 327, p. 404); and that reason is evolutionary - no God's eye view is possible. In fact Lakoff and Johnson contend that the very notion that people can assume a transcendental perspective is a socially and politically dangerous doctrine (1980, p. 159).

So it is all for one, one for all. These various epistemological posits stand or fall together as one scheme. In Philosophy in the Flesh (1999), Lakoff and Johnson quite explicitly connect Chomsky to all these ideas - not just to grammar as pure form or that all people utilize the same conceptual system as one might expect but also to dualism, to an objectivist metaphysics, and to a view of the transcendence of reason (1999, pgs. 469-512).

What they ascribe to Chomsky and his transformational grammar, they also ascribe to evolutionary psychology, which relies on Chomsky's transformational grammar. By the same token, though, establishing that any one of these claims does not apply to Chomsky or to the evolutionary psychologists, casts doubt on the applicability of any one of the others with which Lakoff and Johnson associate it. (And this notwithstanding the further distortion implied by their view; namely, that there is really only one interpretation of these various theoretical posits that 
can be given). ${ }^{35}$ In this section, I shall show that Chomsky and the evolutionary psychologists make it quite plain that dualism, a priorism, and the transcendence of reason are not any part of their science. In the next section, I consider more specifically the terms in which the evolutionary psychologists accept the classical theory and how it circumvents the worst parts of the rest of the metaphysical claims Lakoff and Johnson attribute to them.

Lakoff and Johnson, acknowledge that their view of experiential realism shares many features in common with the metaphysical realism they eschew: both are committed to the existence of a real world and both are committed to the existence of conceptual links between human ways of thinking that match up with the real world. Both affirm the possibility of stable knowledge, both commit to standards of objectivity in science, and hence, both reject the notion that "anything goes" in science, i.e., that all conceptual systems are of equal value (Lakoff, 1988, p. 123).

Since they share so much in common, Lakoff and Johnson face problems demarcating their position from the metaphysical one they criticize. For example, Lakoff and Johnson suggest that metaphysical realists are committed to the centuries old distinction between primary and secondary qualities. They argue against this distinction that colors are neither purely one nor the other, neither purely subjective (secondary qualities) nor purely objective (primary qualities). Since colors are natural kind categories, but we know the world doesn't come parsed in terms of color categories at all, Lakoff and Johnson conclude: metaphysical realism fails. It fails because colors must be substances that inhere in the real world, according to metaphysical realism, but

\footnotetext{
${ }^{35}$ Ruth Millikan endorses a correspondence view of truth and a theory of meaning as reference but she combines these views, associated by Lakoff and Johnson with metaphysical realism only, with a naturalized epistemology. Millikan argues that there are 'facts of the matter' as to meaning but these facts are not contained in language or in the speaker's head; rather, reference is fixed, on her view, by sentences mapping onto, (linking up with), states of affairs in the world in a posteriori ways that have biological, evolutionary explanations. Hers is a causal theory of reference that involves a normative dimension. For Millikan reference is not fixed by its initial or canonical use nor does Millikan assume a picturing, mirroring relation between word and object (1989; also see Post, 1991).
} 
they do not. "An adequate theory of the conceptual structure of red...cannot be constructed solely from the spectral properties of surfaces. It must make reference to color cones and neural circuitry. Since the cones and neural circuitry are embodied, the internal conceptual properties of red are correspondingly embodied... color is a function of the world and our biology interacting" (Lakoff and Johnson, 1999, pgs. 24-25).

Nonetheless, it is simply not the case that metaphysical realism commits one to the belief that 'colors must be substances that inhere in the real world.' Nor does metaphysical realism stand or fall on the fact that our perceptions and investigations of the world are relative to the kinds of beings we are, embodied beings, socially situated beings, beings subject to all sorts of physical limitations and intellectual imperfections. The philosopher John Searle affirms the truth of metaphysical realism ${ }^{36}$ but in no sense wishes to deny that "all investigations are relative to investigators," that our epistemological efforts are affected by our sensory motor apparatus.

Searle states: "Real human investigators have to discover that water is made of hydrogen and oxygen, but the fact that water is made of hydrogen and oxygen is not relative to any investigators" (1990, p. 40). Indeed, Searle comes very close to sounding like an embodied realist when he explains:

What counts as reality - what counts as a glass of water or a different book or two tables - is a matter of the categories we impose on the world; and those categories are for the most part linguistic. And furthermore when we experience the world we experience it through linguistic categories that help to shape the experiences themselves. The world doesn't come to us already sliced up into experiences: what counts as an object is already a function of our system of representation, and how we perceive the world in our experiences is influenced by that system of

\footnotetext{
${ }^{36}$ Searle affirms metaphysical realism in his New York Review of Books article "Storm Over the University" (July 3 , 1989). He states: "Many arguments have been made against metaphysical realism, all of them inadequate in my view." And further: "Are there convincing arguments for metaphysical realism? The demand for a proof of the existence of a reality that is independent of our representations of reality is a puzzling one, because it looks like making the demand itself already presupposes what is demanded to be proved" (p. 40).
} 
representation...The world divides the way we divide it, and our main way of dividing things up is in language (Interview with Searle, 1978, p. 156). ${ }^{37}$

All Searle needs to add to the aforementioned statement is that our linguistic categories are a function of our sensory-motor system (not merely a matter of the system of representation we learn in social settings) to meet Lakoff and Johnson all the way. Surely, this is something that Searle, who is an advocate for "science and common sense" (1999, p. 12), who says that philosophy starts with the fact that we are "embodied brains" and who speaks about the "logical structure of intentionality of biological brains encased in biological bodies," (1999, p. 14)would be inclined to do. "A sane philosophy starts with atomic theory and evolutionary biology" says Searle "and with the fact that we are identical to our living bodies, and goes from there" (1999, p. 13).

Lakoff and Johnson challenge a version of metaphysical realism that is no longer held by many philosophers. The version they describe is wholly out of step with developments in science and ascribing it the whole Western philosophical tradition in one fell swoop makes their charges against this tradition too easy. Lakoff and Johnson are insensitive to the many varieties of realism that philosophers now put forward, and these many versions grant the impossibility of getting outside one's own conceptual scheme. Yet Lakoff and Johnson countenance this one version only. Lakoff and Johnson ignore the fact that one can be a realist about the findings of science, for instance, and an anti-realist about common sense truths or vice versa. One can even claim to adopt a position somewhere in between as the philosopher of science, Arthur Fine does. Fine tells us that he accepts the findings of science and the evidence from the senses as being on

\footnotetext{
${ }^{37}$ The interview was conducted by Brian Magee and is found in Chapter 10 of his book, Talking Philosophy, titled "The Philosophy of Language: Dialogue with John Searle" (1978.) The citation appears in the References Section of this paper under "Searle."
} 
a par with one another. Fine resolves to resist the urge to expound upon reality one way or the other. This is to abide what he calls "The Natural Ontological Attitude"(1996). ${ }^{38}$

In his famous essay, "Philosophy and the Scientific Image of Man" (1963/1992) Wilfrid

Sellars covers how we might resolve conflicts between our common sense understandings and the judgments that we get from science. Sellars concludes that "the conceptual framework of persons is not something that needs to be reconciled with the scientific image, but rather something to be joined to it...so that...we directly relate the world as conceived by scientific theory to our purposes, and make it our world and no longer an alien appendage to the world in which we do our living" (1963/1992, p. 78).

There are differences too between realists like Searle and realists like Lakoff and Johnson, who continue to want to speak about the relation between language and the world, and post-modern realists like Sellars who restrict their use of words like 'real' and 'exists' to the linguistic framework. Having so restricted their application Sellars defines the existence of theoretical entities that science displays in terms of correspondence rules and support for theories. Sellars' correspondence view gets more complicated still. While he seeks to retain the desired relation of correspondence to the world that modernists prize so highly he does so in terms of relations built into social practices, not in terms of representations (1963/1992). ${ }^{39}$

\footnotetext{
${ }^{38}$ Granting the difficulties inherent in the attempt to assimilate these different kinds of knowledge - scientific and commonsense - some philosophers have espoused a perspectival realism, one that involves embracing different criteria for the different purposes or perspectives one adopts. For the Sicilian realist Joseph Pitt, the scientist's interests dictate which theory of the aggregate sizes of matter will take priority in his researches (2000). The philosopher John Post fleshes out this pluralistic approach by factoring in the subjective perspective of common sense experience. He says that the subjective life-world perspective takes priority when people are concerned with their inner selves, the natural world when people's scientific interests take over. To wit, reality has many levels and there are priorities of all kinds; but these priorities are always 'in a certain respect' (1991). These priorities can also live side by side without necessarily being derivable from one another.

${ }^{39}$ This is yet another interpretation for correspondence theory and meaning as reference not countenanced by Lakoff and Johnson.
} 
In sum, just as Lakoff and Johnson acknowledge the need for more sophisticated accounts of realism - they say we need a better way of explaining the relation between our embodied conceptual systems and the external world - so too have philosophers of science today acknowledged the same. The problem is that Lakoff and Johnson do not acknowledge them. In a very real sense, by attacking a two-world metaphysical view of reality, Lakoff and Johnson attack a strawman version of realism - one that is plagued by taboo words and other-worldly entities rejected by philosophy as well as science. ${ }^{40}$

The only other influential thinker besides Plato to whom it may be fair to impute the metaphysical views Lakoff and Johnson attack is Descartes. Importantly, Chomsky acknowledges the influence of Descartes' on his conception of both mind and language, so it is easy for Lakoff and Johnson to insist that Descartes' ideas carry over. These ideas include not only a view of the mind as separate from the body and of reason as transcendent and autonomous, but also the idea that all things have essences that makes them what they are, that rationality defines human nature, that mathematics constitutes human reason in its ideal form, that reason is therefore formal, that thought can be conceptualized as language, and that the methods of introspection are sufficient for understanding the mind's innate contents; hence, no empirical study is necessary (Lakoff and Johnson, 1999, p. 471).

Lakoff and Johnson believe Chomsky substitutes language for reason, which is given primacy on Descartes view. Language stands in for reason as the essence of human nature. They say that Chomsky sees language as an innate, universal and autonomous capacity of the mind, "independent of any connection to things in the external world" (1999, p. 472). Lakoff and Johnson claim that according to Chomsky, "language does not arise from anything bodily. It can

\footnotetext{
${ }^{40}$ One possible explanation for their indiscretion is that like the evolutionary psychologists, they, too, seek to distance their new field of empirical linguistics from other fields in order to underscore the originality of their contributions and facilitate their academic acceptance.
} 
be studied adequately through introspective methods. "Studying the brain and body" on their account of Chomsky's position "can give us no additional insight into language" (Lakoff and Johnson, 1999, p. 472).

The problem is that most of these ideas are distortions of what Chomsky says. To start with Chomsky disavows being a dualist; he disavows being committed to the idea that the contents of the mind are in principle open to introspection. He states:

In the British Platonists...there is a rich mine of insight into the organizing principles of the mind by which experiences are structured - some of the richest psychological insights I know. It's this tradition that I think can be fleshed out, made more explicit, modified and advanced by the kinds of empirical inquiry now possible. Of course, I think we have to diverge from that tradition in a number of respects. I've mentioned one - the fairly general (though not universal) commitment to the belief that the contents of the mind are in principle open to introspection. And there's no reason to accept the metaphysics of much of that tradition either, the belief in a dualism of mind and body. One can see why the Cartesians were led to that - it was a rational move on their part, but it's not a move we have to follow. We have other ways of approaching the same questions (Chomsky, 1978, p. 191, emphasis added).

And again:

There is no reason to believe that the mental representations and principles of mental computation that enter so intimately into our action, or our interaction with the world or with others, or our understanding, or our speech, are accessible to introspection any more than the analyzing mechanisms of our visual system, or for that matter the workings of our liver (Chomsky, 1978, p. 190).

More importantly, Lakoff and Johnson do not appreciate Chomsky’s

scientific-mindedness. They unabashedly dismiss his claim regarding the autonomy of the language faculty in the following cursory way: "syntax cannot be autonomous, that is, affected by no syntactic input" for "there is no part of the brain, no module or subnetwork of neurons, that has no neural input! That is a physical impossibility" (Lakoff and Johnson, 1999, p. 495). But clearly Chomsky does not mean to suggest that the language faculty is structurally and neurophysiologically isolated from other organs in the body, any more than the heart or liver to which he likens the language organ. Chomsky considers the neural basis for language a mystery, but he does not deny it has a neural basis (though he does deny that the way to find it is by 
studying other primates (Chomsky, 1975, p. 40)). Chomsky is as evolutionary-minded as any

thinker. He acknowledges the debate over how the language faculty evolved, and clarifies his position accordingly:

One has to make a sharp distinction between notions like "inexplicable" and notions like "unexplained." At the moment there is no explanation, in terms of the biological structure of the organism, for the genetic program for this particular human language, and of course that is true of any other organ as well. To say that there is no explanation at the moment means, to me, that there is no set of principles by which we can deductively conclude this or that. There is no explanation at the moment for the fact that the heart is what it is, or the liver. That is not to say that it is inexplicable. It is possible that the principles are actually known but we don't know how to draw the conclusions because it is too complicated (1980, p. 125. ${ }^{41}$

Chomsky is not even dogmatic about "how the language faculty fits into the system of cognitive capacity." While he believes it is a rich structure of predetermined form, which grows as a result of the triggering effect of experience, he is not averse to considering other views about its relation to other cognitive capacities. Nor does Chomsky feel that such consideration disrupts the language faculty's autonomy one iota. He state: "I have been assuming that UG suffices to determine particular grammars (where, again, a grammar is a system of rules and principles that generates an infinite class of sentences with their formal and semantic properties). But this might not be the case. It is a coherent and perhaps correct proposal that the language faculty constructs a grammar only in conjunction with other faculties of mind. If so, the language faculty itself provides only an abstract framework, an idealization that does not suffice to determine a grammar." Yet, he goes on: "Note that this conclusion if correct, does not imply that the language faculty does not exist as an autonomous component of the mental structure. Rather, the position we are considering postulates that this faculty does exist with a physical realization yet

\footnotetext{
${ }^{41}$ Chomsky uses the words "particular human language" to refer generally to human languages and to distinguish human languages from languages that may have no problems about communication but are still essentially different, i.e., in possession of different grammars. Chomsky will call these languages governed by alternative grammars languages but not human languages. Chomsky says, for instance that "one could conceive of an organism exactly like humans, but minus the specific subject condition, and it would talk with a fine language which it could use for all possible purposes" ("Initial States and Steady States" in Piatelli-Palmarini, Language and Learning: The Debate Between Chomsky and Piaget, 1980, p. 123). Human languages do not violate the subject condition, however.
} 
to be discovered, and places it within the system of mental faculties in a fixed way." In all, the place of the language faculty within human cognition is a "matter for discovery, not stipulation" (Chomsky, 1975, pgs. 42-43).

In point of fact, Chomsky is probably most accurately characterized as a Kantian, a suggestion he is not opposed to (1978, p. 191). Transporting Kantian ideas into linguistics with a biological twist, we might understand Chomsky to be saying that a Universal Grammar inheres in the mind and this grammar represents a fixed operating characteristic of our evolved neurological system. This Universal Grammar is on a par with the a priori categories of understanding about which Kant spoke. Without a Universal Grammar it would be impossible to organize the semantic and phonological components of language in a meaningful way. The universal grammar also sets limits to our understanding. What it cannot accommodate is, by that very fact, unintelligible and inexpressible. Just as we bring to bear automatically a priori concepts of understanding, concepts, like substance and causality (as well as the pure forms of intuition space and time) to make our experiences possible, in similar vein, the thoughts we express in language also come already organized with an intellectual structure.

For Chomsky, as for Lakoff and Johnson, organizing experience does not happen after experience occurs as if it were primarily an intellectual matter (Lakoff and Johnson, 1999, p. 19). Rather Universal Grammar is part of our experience; concepts are not formed merely by our embodiment, they structure our experience prior to and independently of our embodiment, for all three thinkers, and in doing so become parts of our experience (Lakoff, 1987, p. 271). For Lakoff and Johnson our basic level concepts - concepts that correspond to natural kinds in the physical domain - correspond to the 'preconceptual structure.' It is precisely for this reason, they say, that naïve realism and objectivism seem true. In addition to these basic level concepts we also 
impose kinesthetic image schemas onto experience. These schemata - the container schema, the part-whole schema, the link schema, the center-periphery schema and so on - also structure our experiences preconceptually and provide the basis for our metaphorically mapping image schemas into other domains. These schemata are not arbitrary because they are "motivated by structures inhering in everyday bodily experience" (1999, p. 275).

For Chomsky as well as Lakoff and Johnson, reality as it is in itself - that which the metaphysical realist believes can be captured by disembodied thought - is beyond human understanding. Objects of knowledge relate to the capacities of the knower. This was Kant's great insight. It prompted his famous dictum: concepts without percepts are empty and percepts without concepts are blind. Transcendental reason, what Kant called pure reason, is helpless to advance beyond given concepts to substantial truths about things-in-themselves which are independent of human perception. For Lakoff and Johnson this means that there is no such thing as pure reason and so it makes no sense to speak of the separation of percepts and concepts. For Kant it meant that what we know of the world comes to us from the appearances the world presents to our point of view only.

Chomsky is no more a Cartesian dualist than are Lakoff and Johnson. Thought is not transcendent on his view. Thought is constrained by categories and concepts in the mind. Chomsky is an embodied realist and evolutionary psychologists are embodied realists too. They would concur with Lakoff and Johnson's central thesis that our understanding of the world is crucially shaped by the kind of biological beings that we are. ${ }^{42}$ It therefore seems no accident that in their foundational book, Philosophy in the Flesh (1999), Lakoff and Johnson fatally

\footnotetext{
${ }^{42}$ According to the philosophical psychologist, Daniel Robinson, Kant even considered the idea that the concepts and categories of our understanding might be explained in biological terms. Robinson states that Kant rejected it, however, on the grounds that this would render the concepts and categories of our understanding contingent rather than necessary (The Enlightened Machine, 1980, p. 153)
} 
ignore Kant's epistemology in favor of discussing his theory of morality, which lends itself more readily to their manner of critique.

Indeed, Pinker agrees with Lakoff and Johnson that reality is neither directly available nor completely socially constructed. Taking as his key opponent the social constructivists of the postmodern era, not the metaphysical realists of the past, Pinker declares: "But just because the world we know is a construct of the brain, that does not mean it is an arbitrary construct - a phantasm created by expectations or the social context. Our perceptual systems are designed to register aspects of the external world that were important to our survival, like the sizes, shapes, and materials of objects...The mechanisms of perception go to a lot of trouble to ensure that what we see corresponds to what is usually out there" (Pinker, 2002, p. 199). He concludes: "The demonstrations that refute naïve realism most decisively also refute the idea that the mind is disconnected from reality. There is a third alternative: that the brain evolved fallible yet intelligent mechanisms that work to keep us in touch with aspects of reality that were relevant to the survival and reproduction of our ancestors" (Pinker, 2002, pgs. 200-201). This view is what I have previously referred to as evolutionary psychology's naturalized essentialism.

Lakoff and Johnson make the same sort of contention. While embodied realism does treat knowledge as "relative to the nature of our bodies, brains, and interactions with our environment, it is not a form of extreme relativism, because it has an account of how real, stable knowledge...is possible. That account has two aspects. First there are the directly embodied concepts... These concepts have an evolutionary origin and enable us to function extremely successfully in our everyday interactions with the world." Secondly, there are the primary metaphors - metaphors that extend the embodied concepts into abstract theoretical domains. "The primary metaphors are anything but arbitrary social constructs," Lakoff and Johnson add, 
"since they are highly constrained both by the nature of our bodies and brains and by the reality of our daily interactions" (1999, pgs. 95-96). To wit, Lakoff and Johnson also endorse a naturalized essentialism.

This brings us to one notable discrepancy in their respective views; namely that, for the evolutionary psychologists metaphor does not play the same crucial role in our daily living or scientific theory building as it does for the empirical linguists. It is merely considered one among many of our mental tricks. According to Pinker, metaphors provide an alternative way of expressing our thoughts, but they are not always the best means of expressing them. Humor is a superior form. "The complete process of understanding is better characterized by the joke about the two psychoanalysts who meet on the street. One says, "Good morning"; the other thinks, "I wonder what he meant by that" (Pinker, 1994, p. 230).

More significantly, Lakoff and Johnson disagree with the evolutionary psychologists on how our cognitive architecture has been shaped by the processes of natural selection and the embodied experiences it undergoes. This difference is reflected in their theory of cognitive semantics which is the counter to evolutionary psychology's theory of the Universal Grammar. The theory of cognitive semantics presupposes that language makes use of our general cognitive capacities; hence, linguistic categories "are the same type as other categories in our conceptual system"; they are not independent of the rest of cognition and contained in a separate module in the mind (Lakoff, 1987, p. 58). This is the crucial consequence of their difference. Nevertheless, Lakoff and Johnson develop their theory of cognitive semantics by exaggerating, if not misrepresenting the sorts of considerations that evolutionary psychology's account of our cognitive abilities can handle. The upshot is a stand-off on whose view is stronger, on whose view provides the best support for the claim that mind is modular or that it is not, though 
neurobiological findings enter in as before as an important venue for achieving the desired understanding.

\section{Lakoff And Johnson's Cognitive Semantics}

Lakoff and Johnson believe that semantics (meaningful categories of thought) is the generative component of language and that syntax (formal, hierarchical rules) to which Chomsky gives priority is the incidental component. Semantics governs syntax, then, not the other way around, and the two cannot be sharply demarcated. Syntax is symbolization - "the pairing of meaning with linguistic expressions" - the linking of a concept with a phonological form. More controversially, Lakoff and Johnson say that: "symbolization is just a way of discussing neural connectivity... "The grammar of a language consists of the highly structured neural connections linking the conceptual and expressive (phonological) aspects of the brain" (Lakoff and Johnson, 1999, p. 498). The conceptual aspects are not cut off from, but intimately tied with, the rest of our general cognitive system.

These insights lead Lakoff and Johnson to the view that concepts have mainly family resemblance relations - evincing prototype and other basic-level effects as our other cognitive categories do - not classical ones (Lakoff, 1987, p. 58). ${ }^{43}$ Accordingly, Lakoff and Johnson describe family resemblance categories that have central members whose boundaries are fuzzy and whose membership can be graded in degrees. They also describe categories that have prototypical members where the prototype stands as an ideal and its boundaries from other

\footnotetext{
${ }^{43}$ While George Lakoff is the one who originally formulated the theory of cognitive semantics in Women, Fire and Dangerous Things (1987), major elements of the view are located throughout Philosophy in the Flesh (1999) since, of course, the philosophy of experiential realism (described in the latter book) is integrally connected up with it. Thus, in Philosophy and the Flesh, Lakoff and Johnson conjointly endorse cognitive semantics (p. 497, p. 544) as well as discuss prototypes, polysemy, primary metaphors, radial categories, image schemas, and so on. For this reason, it is reasonable to describe, as I do, specific claims Lakoff makes and which are found in Women, Fire and Dangerous Things, as ones that Johnson stands behind also.
} 
objects is also clear and sharp. ${ }^{44}$ Family resemblance concepts of these sorts are heterogeneous in origin. They fail to share defining features, although various sets of the family members will overlap and have features in common. Lakoff shows that even the classical category 'mother' has a family resemblance structure since surrogate mothers, eggdoner mothers, working mothers as well as adoptive mothers all cluster around the housewife stereotype 'mother' (Lakoff, 1987).

Lakoff and Johnson also maintain that thought is characterized by cognitive models that yield categories of various sorts: scalar cognitive models, metonymic models that allow a part of a category to stand for the category as a whole, and radial categories, the most radical of all, that "involve many models organized around a center, with links to the center...characterized by the other cognitive models" as well as classical models. So classical models are included. The difference is that all these models, including the classical, derive from human properties because they depend on the interaction of our bodies and brains with the environment. ${ }^{45}$

Lakoff and Johnson believe that evolutionary psychologists presuppose that the meaning of concepts is bound to fixed sets of terms. They think that evolutionary psychologists are only in a position to grant the meaningfulness of classical categories and cognitive models (Lakoff, 1987, p. 58). They contend that family resemblance categories create havoc for evolutionary psychologists, particularly, because the existence of natural kinds is disproven by evolutionary

\footnotetext{
${ }^{44}$ Pinker's witticism is "the members of a category are not created equal" (1997, p. 272).

${ }^{45}$ In philosophical terms, Lakoff and Johnson here identify the mind with the senses and affirm them that the mind has only a sensitive faculty, just as the empiricists before them did. To wit, there is nothing in the mind that does not get there except through the senses. To this, the rationalists retort a la Leibniz: "Nothing expect the intellect itself" (New Essays, Book II). To the sensitive faculty, rationalists add the intellectual faculty, the organizing principle of our experiences without which we could have no experiences. It is the intellect that has reflexive power, enables us to perform abstractions, group things into kinds, among other things. Chomksy and the evolutionary psychologists are our modern rationalists. They make the intellect, material; they take what the rationalists before them described as an a priori cognitive capacity and ground it in science. And just like the rationalists who maintained that the intellect was the foundation of all our knowledge they too are saying that these frames, these organizing principles of the information we take in from our senses, these Platonic forms incarnate that have evolved as products of the evolutionary process, serve as the foundation of all of our knowledge-claims.
} 
biology. Species are not defined by common essential properties at all (Lakoff, 1987). Clearly, there could be no more devastating objection to evolutionary psychology were it committed solely to classical categories since it presents itself as a merger of the disciplines of cognitive psychology with evolutionary biology. But Pinker accounts for our reliance on natural kind concepts simply by reaffirming the facts: species start off populating local, homogeneous environments and so start off with a relatively uniform morphology. They constitute natural kinds. With subsequent geographical dispersal and the influence of processes that destroy their homogeneity (genetic drift, local extinctions, climatic changes imposing new selection pressures) the descendents of species take on family resemblance forms. Linguistic evolution and biological evolution thus mimic each other (Pinker, 1997a, pgs. 282-283; 1996, p. 341). For Pinker, the parallel extends to irregular verbs because they were originally generated by rules, too, "but the rules died long ago and the families have been disintegrating ever since" accumulating idiosyncrasies till they must memorized individually (1997a, pgs. 279-283).

Evolutionary psychologists concede that there are inherent limitations imposed by the cognitive architecture that humans have evolved; what they do not concede is that family resemblance theory with its emphasis on variation and degrees of membership rather than necessary and sufficient conditions for membership undermines their view. As far as Pinker is concerned, discovery of family resemblance categories has mainly served to generate interesting questions for research. For example, he believes that the distinction between classical and prototypical categories raises the following questions: "Is one type of category psychologically real, the other an artifact (of formal schooling, or of the experimental methodologies used to study them)? If both are psychologically real, do they serve different functions in cognition? Are 
they processed by the same architecture? And do they correspond to fundamentally different kinds of things in the world" (Pinker, 1996, p. 307).

More interesting still is that Pinker finds his way to answers to the aforementioned questions through an "unusual source": through discovery of a parallel between the structure of regular and irregular verbs and the structure of classical and family resemblance categories (Pinker, 1996; 1997a). Basically, what Pinker discovers is that subclasses of irregular verbs in English, which have also traditionally been thought of as all or none operations, turn out to have the characteristic features of family resemblance categories as well, including, gradations of membership, prototype members, unclear and fuzzy cases, and so on. Regular verbs, on the other hand, provide instances of classical categories having necessary and sufficient conditions for membership.

Pinker has no problem taking the facts as he finds them. The fact that our concepts conform to family resemblance categories as well as classical categories is simply not the problem for evolutionary psychology that Lakoff and Johnson make it out to be. In Words and Rules (1997a), Pinker remarks in, perhaps, his only direct reference to George Lakoff:

In his book Women, Fire, and Dangerous Things (a family resemblance category in an Australian aboriginal language), the linguist George Lakoff called attention to the fuzziness that lies at the heart of that traditional bastion of rules, grammar. He cited irregular verbs as the ultimate proof of the bankruptcy of the two-thousand-year old Aristotelian tradition in Western thought that seeks precise definitions for everything in sight.

But Lakoff did not notice that right next door to the irregulars are regular verbs, and they pass all the tests of classical categories. Other than verbs with an irregular form in memory, all verbs are members of the regular family in equal standing, simply by meeting the criterion "is a verb" (1997a, p. 277).

Pinker and Lakoff's positions diverge fundamentally on the origination of regular verbs and hence, on the place of classical categories in cognition. For Pinker, regular past-tense forms are not the upshot of exchanges between the environment and us as Lakoff insists that they are. 
In contrast to irregular past tense forms, which do have a history, and so are the result of such exchanges (although they did not start out that way), regular past-tense forms have no history. Regular past-tense forms do not reflect the influence, to paraphrase Pinker, of vowels drifting, consonants being swallowed, words losing their popularity, or dialects breaking apart or coalescing. "In fact," Pinker points out, "they barely have an existence. Only the past-tense rule exists. Children don't have to cope with learning the quirks of regular forms, because they don't have to learn regular forms at all. The rule creates them when they are needed, and then can be thrown away, because the rule is always around to create them again the next time" (Pinker, 1997a, p. 280).

Thus, for Pinker it is not the content of classical categories that is pre-given in the manner of an essentialist metaphysic. Rather, it is the abstract, formal, system of rules that is pre-given and these rules that have evolved have the capacity to generate the classical concepts through idealizing real-world particularities and contingencies away in their formulation. Here again, the evolutionary psychologists 'naturalize' essences.

So Pinker urges that we ask about family resemblance concepts the same sorts of questions that we ask about classical ones. He strengthens his hand when he distinguishes psychological reality from ontological reality too. For this gives him another place from which to counter those critics who would insist that since (it is manifestly the case that) the world does not come pre-parsed into classical categories of thought, evolutionary psychology must be wrong. In the light of his distinction, Pinker can say that people may use classical categories to understand the world, though their best epistemological efforts show that the world is not as they presume it to be. Pinker is able to say that both kinds of concepts play a role in human thinking. 
Ultimately, Pinker finds the evidence indicates that our ability to formulate classical categories required the evolution of a specialized neural structure suitable to performing the task of idealization that it involves, whereas family resemblance categories are grounded in a more general cognitive ability, namely, memory. All this stands as one more superlative Pinkercompromise. Pinker concludes just as Lakoff and Johnson do, that both classes of categories are psychologically real (Pinker, 1996, p. 322); and both have similar psychological functions, that of identifying and classifying entities (1996, p. 323).

Classical and family resemblance categories differ, then, in that different kinds of mental processes produce them. They also arise under distinctive conditions. The classical concepts are generated by a formal system of rules that attempts to capture the world's regularities even though it applies to idealizations of objects, not to real things. The formal system is useful because it facilitates the ability to make non-trivial inferences about entities in a law-governed way. What is more, the neural mechanism that evolved that accomplishes this feat, which crucially depends on selectively ignoring salient properties of objects to apprehend the correct formal rule that applies, was "a critical event in the evolution of human intelligence" (Pinker, 1996, p. 341).

Family resemblance concepts record correlations among sets of objects as they are given in experience and that appear to be similar (Pinker, 1996, p. 325). ${ }^{46}$ Family resemblance categories allow us to make inferences about actual things that possess properties that warrant their visible correlation, even when this correlation is (as it generally is) less than perfect. Family resemblance categories rely on, and are limited by, human memory capabilities, which

\footnotetext{
${ }^{46}$ Pinker understands Lakoff to suggest that classical categories have never existed; that all categories have a family resemblance structure. This is not quite right. Lakoff concedes along with Johnson that, "the classical view that categories are based on shared properties is not entirely wrong. We often do categorize things on that basis" Women, Fire, and Dangerous Things (1987) p. 5.
} 
structure the exemplars falling into the categories. These concepts have a parasitic relation to the classical ones requiring general cognitive abilities only for their formulation. In sum, "we evolved a taste for family resemblance categories because they really do exist in the world and we evolved a taste for classical categories because they are by-products of rules in the mind that allow us to exploit laws in the world. The rules thereby allow us to deduce predictions about how things in the world work" (Pinker, 1997a, p. 284).

So while Lakoff and Johnson disagree with Pinker that classical categories are generated by formal rules that required the evolution of a special neural structure (no such 'critical event in the evolution of human intelligence' ever took place on their account) they do concur that classical concepts are central and psychologically real. They also agree that variants of classical concepts, i.e., family resemblance concepts, must be learned one by one; and hence, rely on memory. Lakoff and Johnson contend that classical concepts are extended by convention albeit not randomly or arbitrarily (Lakoff, 1987, p. 91). Pinker concurs (1997a, pgs. 282-284). He states explicitly that concepts are extended through superimposing cognitive patterns that reflect the "accumulated effects of the analogizing and forgetting tendencies of previous generations of learners" (Pinker, 1996, p. 336; 1997a). Lakoff and Johnson acknowledge that classical categories play a significant role in human understanding and therefore in structuring many of our cognitive models. They grant that some classical categories really exist in nature. What they deny is that we can assume all of nature is structured by these concepts. But evolutionary psychologists also deny this.

Lakoff and Johnson come to a position very similar to Pinker's on the ontological and psychological reality of classical concepts, their manner of extension, and their significance, except as they reflect on how the mind works and how it is constituted. Perhaps, the most 
interesting consequence of their difference of opinion is that the conditions of our Pleistocene past do not play the important role for the empirical linguists as they do for the evolutionary psychologists. Concepts and cognitive models have evolved that are perforce adaptive, on the empirical linguists' view, but they are highly general and abstract concepts and cognitive models since they are based upon the universal experiences of people (and hence, presumably not tied to any particular social configuration or other). This raises the question, though, whether concepts and cognitive models that dilute could be content rich enough to aid the species in its struggle to survive and therefore be selected, or alternatively, whether, given their particularity, they really reflect the biases and prejudices of the experiences of people under certain social conditions (and, hence, are not really universal).

Great as their differences are, Lakoff and Johnson are not justified in setting their prototype theory apart as a radical departure from evolutionary psychology's alternative view. Evolutionary psychologists basically put prototype theory forward as an elaboration of classical theory. Prototype theory is not antithetical to it in any way. As a consequence, evolutionary psychologists are nonplussed about Lakoff and Johnson's contention that since species are not natural kinds 'in the technical objective sense' evolutionary biology refutes their commitment to an objectivist metaphysics (which they do not endorse, in any event) and their formalist view of language (which they do endorse) too.

\section{Analysis}

While Lakoff and Johnson's negative critique of western philosophy, its tradition and its heirs, is far too superficial, their own positive contribution to psychology and linguistic study in the form of their theory of cognitive semantics - which is based on the critique of this tradition is not. Evolutionary psychologists ought not ignore their contributions in this area. Lakoff and 
Johnson perform a valuable role in showing that an issue evolutionary psychologists regard as settled has not been settled at all. It has another side. Theorists must continue their search to resolve the issue of whether our linguistic concepts are a product of our general cognitive capacities or whether they are specially formed. As previously mentioned, their best hope for answers comes from neurobiology.

Interestingly, the conflict between evolutionary psychologists and empirical linguists also comes to a head on the question of the relevance of considerations of neurobiology to their respective theories and claims. Indeed, the findings of neurobiology may play the same decisive role in adjudicating their conflicting positions, as we found was the case with evolutionary psychology's debate with biological anthropology. Tooby and Cosmides are intent on carrying on their investigations, however, in abstraction from findings of neuroscience, and, hence, in denial of their relevance. They distinguish the upper-level information processes and mechanisms of interest and concern to them from the "the interaction of neurons, hormones, neurotransmitters, and other organic aspects" which instantiate those processes and mechanisms at the physical level (1992). This is basically the distinction Artificial Intelligence (AI) researchers make between cognitive software and cognitive hardware.

Tooby and Cosmides maintain that knowledge of these neurophysiological processes is not necessary for understanding how human minds work (Tooby and Cosmides, 1992, pgs. 65-66). This pretty much leaves Pinker, who does not share Tooby and Cosmides' conviction that neurobiology is irrelevant to their project, on his own to defend evolutionary psychology against the unflattering implications of much recent neuroscience research. Pinker devotes a whole chapter in his most recent book The Blank Slate (2002) to discussing neuroscience and to showing, among other things, that constructivist interpretations of human 
neurophysiology do not tell against the innate, modular structure of the mind. Tooby and Cosmides feel their decision to by-pass neuroscience is justified because natural selection functionally organized the psychological mechanisms, "and the neurophysiology has been organized insofar as it physically realized this cognitive organization" (Tooby and Cosmides, 1992, p. 66). For Lakoff and Johnson, by contrast, concepts are neural structures. ${ }^{47}$

So we have evolutionary psychologists drawing a sharp distinction between the facts of neurophysiology and their bearing on the facts of neuropsychology, on the one hand, and the identification of the facts of neurophysiology and neuropsychology, on the other hand, by Lakoff and Johnson. The evolutionary psychologists back into the problem of having to explain how the psychological mechanisms they describe can be confirmed or disconfirmed when no empirical criticism is possible (Hardcastle and Buller, 2000, p. 20). The empirical linguists back into the problem of having to explain how their identification of psychological concepts with neurons and cells shows how neurons and cells treat the concepts they embody (and with which they are identified) as embodied concepts. Indeed, there is some question as to whether we can really get at the reality of many folk psychological concepts, including such concepts as the 'self,' 'ethics,' and even 'experience' - so important on the empirical linguists' view - when we are asked to understand these concepts in terms of neuron firings and brain wave patterns.

Confronting these questions is of the essence. Fortunately, for empirical linguists, Gerald Edelman has come forward to fill the gap in their argument. He tries to show precisely how it is that concepts become embodied, and in the process suggests how the folk psychological concepts mentioned above can be plumped up through a form of emergentism (i.e., Edelman's identification of higher-order consciousness) not found in their theory. Edelman recognizes that

\footnotetext{
${ }^{47}$ In Philosophy in the Flesh (1999) Lakoff and Johnson emphasize that "contrary to long-standing opinion about metaphor, primary metaphor is not the result of a conscious multistage process of interpretation. Rather it is a matter of immediate conceptual mapping via neural connections" (p. 57).
} 
Lakoff and Johnson's theory of cognitive semantics lacks a description of the mechanisms of embodiment, "it does not specify how such embodiment takes place" (Edelman, 1992, p. 251). Edelman supplements Lakoff and Johnson's work by providing the deep biology, or more specifically, the bridge between psychology and physiology, their proposals on language and cognition need. Essentially, Edelman's own theory, the theory of neuronal group selection, called TNGS, constitutes his answer. The theory describes how the brain is set up to start and how it changes over the course of a person's developmental experiences which results in certain maps of the brain taking shape that are associated with important behavioral functions (Edelman, 1992, p. 83).

Edelman elaborates Lakoff and Johnson's neural account of primary metaphors too. Lakoff and Johnson seek to convey foremost that primary metaphors are not arbitrarily created (Johnson, 1987, p. xvi). To this end, Edelman posits that particular objects and events in the environment get neuronally mapped onto the brain in light of internal criteria of value that define their appropriateness for the species (1992, p. 90). He maintains that the driving forces of human and animal behavior are evolutionarily selected value patterns that help the brain and body maintain the conditions necessary for continued life (1992, p. 94). Qualia - the congeries of subjective experiences, feelings and sensations that people have - are therefore not mere epiphenomena for Edelman as many of the original evolutionary theorists maintained, e.g., Thomas Henry Huxley especially, as well as the long list of those singled out by William James in his Principles of Psychology (1890, ch.4). Rather, qualia - which evolutionary psychologists relegate to the no-man's land of imponderables - are understandable and efficacious on Edelman's view. They are testimony to the value-laden condition of human perception and thought processes. 
According to the philosopher, Daniel Dennett, by contrast, a backer of evolutionary psychology, internal, subjective, sentient experiences are cognitive illusions (1991). Pinker even confesses that "we have no scientific purchase on the special extra ingredient that gives rise to sentience"(1997, p. 147). He contradicts Edelman accordingly: “As far as scientific explanation goes, it might as well not exist. It's not just that claims about sentience are perversely untestable; it's that testing them would make no difference to anything anyway. Our incomprehension of sentience does not impede our understanding of how the mind works in the least" (1997, p. 147). Therefore, evolutionary psychologists prefer to speak simply about 'emotions' which they view as well-designed adaptations that work harmoniously with the mind to ensure its smooth functioning (Pinker, 1997, p. 370). The emotions set the brain's highestlevel goals (1997, p. 373). The emotions are mechanisms that can be reverse-engineered and so are subject to empirical analysis. Empirical analysis shows how they trigger "the cascade of subgoals and sub-subgoals that we call thinking and acting” (Pinker, 1997, p. 373).

By eliminating the need to account for qualia, evolutionary psychologists un-complicate their theory. It means that thought can be considered computational without remainder and that human experience can be explained (away) in reductive and mechanistic terms while denying that the very essence of what it is to have an experience (and the value of that experience for people) has been purged from their account. ${ }^{48}$

Buttressed by the neuroscientific work of Edelman, Lakoff and Johnson are poised to argue that the missing link that evolutionary psychologists claim to have discovered is not the mind's psychological mechanisms, after all, but morphology which is a consequence of

\footnotetext{
${ }^{48}$ Accordingly, Pinker makes the ingenious remark that if we speeded up John Searle's Chinese Room Argument, which Searle himself has slowed down so that the mental computations involved seem laborious and trite - and if we considered that the person manipulating the symbols was "deploying millions of memorized rules in fractions of a second, it is not so clear that we would deny that he understood Chinese" (1997, p. 95).
} 
constructivist developmental processes. The missing link - the largest single basis of behavior is "the shape of cells, tissues, organs, and finally the whole animal" (Edelman, 1992, p. 49). There is a tension, then, between the biology Lakoff and Johnson support and the sociobiology evolutionary psychologists support, which opposes epi-genetics to genetics (or morphological causation to genetic causation). Following Edelman, Lakoff and Johnson want to say that genes are not determinative (Lakoff and Johnson, 1999, p. 507). Rather, other factors like neurons and cells have priority over genes - for the principles governing neurons and cells determine how genes affect an animal's form throughout its development. In short, other factors enter into an animals' morphology besides its genes.

The principles that govern the influence of these factors are epigenetic in nature. This means that "key events occur only if certain previous events have taken place." As a result the "connections among the cells in an animal are not precisely prespecified in its genes" (Edelman, 1992, p. 23). The actual fate of a cell depends on an organism's unique developmental history. The mappings of neurons with the concepts that comprise basic-level categories in human individuals are unique processes. Categorization is an "epigenetic developmental event," for Edelman, "and no amount of value-based circuitry leads to its selection without experiential selection of neuronal groups" (1992, p. 94). Environmental interaction is critical; human cognition is the result of an enriching developmental process. It is not a specialized part of our genetic constitution that merely needs to be triggered by the environment in order to unfold.

Most importantly, the anatomical diversity and structural variety that individual brains exhibit is absolutely essential for evolution to work (Edelman, 1992, p. 82). According to Edelman, evolution requires differential reproduction as well as differential amplification of synaptic strengths for neuronal groups (1992, p. 94). Evolutionary psychologists completely 
overlook individual biological diversity - whereas Edelman considers it one of the most important features of the morphology of animals that gives rise to mind (1992, p. 64).

In sum, the morphological development of an animal's brain matters, as do the dynamic processes that bring it about. The brain is, in this sense, a self-organizing holistic system "created by cellular movement during development and by the extension and connection of increasing numbers of neurons" (Edelman, 1992, p. 25), not a functional unit of human anatomy whose vital capacities are preprogrammed to emerge all at once at some future time. A series of developmental events must occur for language and many of our other capacities (such as higherorder consciousness upon which the capacity for language is based) to emerge. So it is because chimpanzees (with whom humans share $99 \%$ of their genes) lack higher-order consciousness, Edelman tells us, that they also lack true language.

Higher order consciousness involves the ability to construct a sense of the self as a social creature. This cannot take place, however, without the ability to symbolically retain in memory ideas of the past, present, and future and the meanings associated with these ideational symbols. While chimpanzees can think, and while they have some elements of a self-concept, the capacity for symbolic memory eludes them. Consequently, Edelman resists (as did the biological anthropologists) taking an anthropocentric approach to both language and the mind. Instead, he shows that higher-order consciousness (which distinguishes human beings) lies along the same continuum that covers all animal life, and can, therefore be regarded as an extension and enlargement, an epigenetic development of animal nature and anatomy.

The real irony, then, is that evolutionary psychology, which presents itself as a biologically informed view, turns out not to be as biologically informed as it could be. Even Pinker, the lone advocate prone to seriously attend developments in neuroscience, is forced to 
align them with a conception of the mind as a thinking machine. The metaphor imposes powerful constraints (which of course may seem to some as liberations) the most important being the body's dispensability. It doesn't matter what the brain's hardware is for evolutionary psychology; the hardware is not key to understanding how the software works.

Any physical system at all will do so long as it can support the implementation of symbolic computational processes. Accordingly, in How the Mind Works (1997) Pinker dutifully denies that the human brain is a Turing machine ${ }^{49}$ while he simultaneously affirms that information processing - using physical symbols to generate new symbols - is precisely what the human brain does. He makes it quite clear that a "chain of physical events accomplished by a pointless contraption" can mimic human information processes (1997, p. 66). He has only technical reservations - in practice, not in principle reservations - about our eventual ability to construct human psychology on a computer with the right knowledge and sufficient computing power. This is what the information processing metaphor adds to evolutionary psychology's starting point in Chomsky while changing evolutionary psychology's end-point completely. For Chomsky never set out to devalue the body or its fundamental role in shaping human (cognitive) experiences.

\section{Pinker states:}

Some things just may not be practical. There may be some aspects of the psyche that require having a body. We may have to wait for some genius to be born to give us the key insights about how a particular mental faculty is organized, and those geniuses may turn up once a century and you may need eight of them to know how to do it. It may require more parallel computing than we can fabricate on silicon. The parallelism of the brain, where each neuron can synapse with up to 10,000 others, is easy to grow molecule by molecule in a fetus, but may be difficult to fabricate out of little wires and silicon traces, and that might stop us in our tracks. And there may be other roadblocks that we can't imagine (2002a).

\footnotetext{
${ }^{49} \mathrm{He}$ also denies that the computational theory of the mind which evolutionary psychology supports "is the same thing as the despised computer metaphor" (Pinker, 1997, p. 26).
} 
Again, experience on evolutionary psychology's view is neither self-evident nor sui generis bur virtually dispensable (inasmuch as the brain is enough, inasmuch as meaning can be generated from a purely physical system). ${ }^{50}$ They take the traditional view that people derive meaning by accurately representing the world, not by representing and attempting to describe their own formative experiences. By contrast, Lakoff and Johnson take experience as the ontological basis of reality. Nature (i.e., the external world) does not come first in their philosophy. Nor does the individual, as subject, for that matter. Rather, Lakoff and Johnson tie linguistic expressions to human experiences in the world, not to the world itself. Their philosophy starts in the middle.

Epigenetic development - development that relies on constructivist experiences occupies an important space between the facts of neurophysiology and the facts of neuropsychology. In their current form, neither evolutionary psychology nor empirical linguistics makes room for these facts, although Edelman shows how the linguists might overcome this shortcoming. The real issue is whether Edelman's theorizing adequately answers the question of how concepts become embodied or whether he merely re-locates the problem (and accompanying narrative explanation) to a higher (neuronal) level. As their theory stands, the empirical linguists' identification of concepts with neural structures seems inadequate, however, just as evolutionary psychology's modular thesis does since each precludes epigenesis. Furthermore, while acknowledging a space for constructivist development calls into question the mind's modularity to start with, it does not rule out the mind's gradual modularization over time any more than it rules in the possibility that the mind completely lacks

\footnotetext{
${ }^{50}$ The dispensability of actual lived experience raises important questions on a moral compass concerning what the good life is and how it should be pursued. If the good life can be synthetically induced through direct activation of the brain, what reason would evolutionary psychologists have for saying that the it should not be accepted on such terms? The experience of acting for the sake of something or someone beside oneself may be essential to the good life.
} 
a modular structure - Lakoff and Johnson's supposition - when development is fully completed.

Another look at the relation between evolution and development, this time from the perspective

of developmental psychology, should tell us more, particularly, whether evolutionary psychology

has the resources to integrate developmental facts, as has empirical linguistics, without

fundamentally altering its point of view.

\section{CHAPTER 5. DEVELOPMENTAL PSYCHOLOGY}

Evolutionary psychologists and developmental psychologists appear destined to be at

loggerheads. The nature-nurture conflict that erupts when these particular orientations clash may

be represented by the bitter altercation that has took place in full public view between Steven

Pinker and the British psychologist Oliver James. "Both are openly abusive about each other's

stance" report the journalists Robin McKie and Vanessa Thorpe of The Observer (2002).

"Hence the accusation of one of Pinker's allies that James is 'fucked up" ${ }^{51}$ while he has retorted

in turn that his opponent is telling lies." McKie and Thorpe write in their piece captioned,

"Raging Boffins":

Pinker says violent roots are deep and innate, and quotes Winston Churchill's maxim that 'long before history, murderous strife was universal and unending'. He is dismissive of those who claim violent tendencies are learnt from others.

'Aggressive parents often have aggressive children, but people who conclude that aggression is learnt from parents in a "cycle of violence" never consider the possibility that violent tendencies could be inherited,' he says.

And he dismisses agencies such as the United Nations, which claim that 'violence is part of an historical process and is not natural or born of biological determinism'. According to Pinker, violence is 'part of our design.'

"On the other side" explain McKie and Thorpe, "are traditional psychologists and

psychoanalysts who say that children's aggressive behavior is picked up from violent parents.

The family is the root of all troubles. Genes have only a limited role in the birth of criminal,

${ }^{51}$ Oliver James is author of They F*** You Up: How to Survive Family Life (2003). 
violent behavior. Learning from parents is key." According to Pinker, however, "James is out on his own. He is at the end of a declining field and he is desperately trying to prop it up." The fundamental fact is that evolutionary psychologists, like Pinker, agree with the philosopher Jerry Fodor that cognitive development does not really exist (Fodor, 1985, p. 35).

These different socio-psychological positions undergird different understandings of developmental processes. While Pinker proclaims that James is on the side of a dying, minority view in psychology, as it turns out that traditional view coheres better than Pinker's with the more dynamic perspective on human development supported by recent work in the fields of genetics and neurobiology. Psychology's original emphasis on the importance of constructivism and learning is also more consistent with current focus on the mediating processes that are involved in the growth of organisms from genetic inheritance to phenotypic traits. And, pace Pinker, evolutionary psychology is really the minority view in the academic community today.

\section{Development, Evolution And Jean Piaget - Against Risky Darwinism}

In an article titled, "Evolution of Human Behavioral Development" (1981) the biological anthropologist Melvin Konner argues that biology has played little, if any, role in the way psychologists in the $20^{\text {th }}$ century have chosen to approach cognitive development. In fact, as Konner explains it, developmentalists swore off biology due to the biological form of determinism implicit in the understanding they inherited from their teachers $(1981$, p. 3$)$. This resulted from overapplication of Ernst Haeckel's "biogenetic law" (still controversial, still taught and still vehemently challenged today), which says that the ontogenetic developmental processes of organisms recapitulates their phylogenic history - a position Darwin also espoused in Origin of Species (1859). 
Konner downplays the works of Jean Piaget to get his observation that developmental psychologists have shied away from biology to stick. His observation would also be gratuitous except for the fact that he wishes to encourage psychologists to integrate evolutionarily-informed ways of thinking into their analyses now and to draw attention to the ways that integration is currently being made. While Konner acknowledges Piaget's prominence in the field - as he must - he proposes that Piaget's biologizing "slipped by, perhaps, because he slyly refused to take a stand on the nature-nurture controversy." Konner states: "it became apparent that he was dealing with phenomena whose variance mostly was accounted for by maturation" (1981, p. 4). One of the things we shall find, however, is that the sharp distinction Konner draws between developmental (or maturational) processes and evolutionary processes is being called into question in the recent debates. This distinction becomes blurred once it is granted that the capacities of organisms depend upon the developmental context, and are not merely an expression of the genome. Most importantly, Piaget was on track to making this discovery.

Furthermore, it is untrue Piaget believed he was dealing with "phenomena whose variance mostly was accounted for by maturation." Piaget's publication of Behavior and Evolution (1978) is prima facie evidence against this interpretation of the focus and range of his work. Konner also never mentions in his overview of psychology the highly influential writings of the psychologist James Mark Baldwin (1861-1934), a man whose investigations stand out prominently in the line of evolutionarily informed psychologists writing early on in the $20^{\text {th }}$ century. Notably, too, Baldwin's influence upon Piaget was momentous as was Piaget's influence upon Annette Karmiloff-Smith whom Konner overlooks as well (along with all those who studied with Piaget at Geneva University). Karmiloff-Smiths first published works begin in the early 1970s. 
In his small but compact book, Behavior and Evolution, (1978) Piaget makes a compelling case for placing organic selection, which is attributed to Baldwin ${ }^{52}$ centrally in evolutionary theory, alongside natural selection, as a mechanism to explain evolutionary changes in the behaviors, and ultimately in the genetic constitution, of humans and other organisms. If natural selection is not the only principle at work in the biosphere, then telenomic behavior instigated by the organism itself can be understood to play a role in determining the evolutionary variations that we find among organisms, and of orienting the genetic and morphological changes that become manifest in the course of their development (Piaget, 1978, p. xii). Genetic mechanisms, on the strict neo-Darwinian view, are "radically independent of and alien to the retroactive effects of epigensis." Consequently, behavior is brought along by structures "created quite independently of behavior itself' (1978, p. xiv). Piaget finds this implausible.

Fundamental to the notion of organic selection is that "behavior is a determinant of selection as much as a result of it" (Piaget, 1978, p. xviii). Behavior is not passive, ineffectual activity. Piaget speculates about the "unknown process" (1978, p. 75) that must occur for behaviors to be copied onto a genotype. It is a process instigated by the disruptive effects of a disequilibrium created between the organism and its environment. The effects spread until they have been compensated for. Having so described the process, Piaget pronounces confidently that organic selection can be disassociated from the unwelcome spectre of Larmarckianism:

Where the disequilibrium is far-reaching, it eventually makes itself felt at the level of the regulatory genes, or at that of the genome's overall regulatory mechanisms...the genome's reaction here is to try out variations. These are semi-random owing to the genome's lack of information, but they are very likely canalized toward the areas of disequilibrium; if so, total randomness is ruled out, and the idea of "trials" is more appropriate for describing what happens. It is at this point that selection carried out by an environment comes into play, but in such circumstances the environment in question must initially, and essentially, be the internal and

\footnotetext{
52 The concept of "organic selection" as a new factor in evolution was apparently hit upon by two other thinkers at the same time James Mark Baldwin discovered it: C. Lloyd Morgan and Henry Osborn (see Robert J. Richards, Darwin and the Emergence of Evolutionary Theories of Mind and Behavior, University of Chicago Press, 1987, pages 480-496).
} 
epigenetic one. Now, this internal environment has clearly been somewhat modified by a new form of behavior that has precipitated the entire process and, thus, by extension, by the influences of the external environment which this behavior inevitably embodies... Next, as a consequence, come a series of selections, for the new genic variations can only become stabilized by submitting to the requirements of the modified internal environments. The necessity for genic variations to fit in with the framework which selects them but which is itself the outcome of the modifications provoked by the new behavior, or in a general way by a new phenotype, now inevitably entails a convergence between the new genic form and the characteristics of the phenotypical behavior responsible for the changes (1978, pgs. 80-81).

Several things are worth noting. Piaget calls the mechanism behind the process of organic selection he describes 'phenocopy.' He notes that phenocopy does not always culminate in the replacement of a phenotype by a genotype. Sometimes new behaviors generated by disequilibriums created between organisms and their environments do not rise to the level of phenocopy and become heritable traits, but must be learned anew with each generation. For Piaget human language and certain birds' songs fall into this category (Piaget, 1978, p. 77). Additionally, phenocopies generally account for specific forms of behavior that are elementary. Hence, phenocopy suggests behaviors whose simplicity "has been invented by the animal in the course of processes of learning or acquisition at the phenotypical level, and then reconstructed genetically thanks to phenocopy" (1978, p. 77$){ }^{53}$

The second point worth noting is that phenocopy involves adaptations to "highly differentiated aspects of the environment" (Piaget, 1978, p. xix). It presupposes "a detailed correspondence... between particular organs or movements of the organism and specific aspects of the environment” (1978, p. 28). Piaget calls this 'adequation' and argues that adequations involve a "much tighter link - indeed a necessary link - between the behavior in question" which

\footnotetext{
${ }^{53}$ Steven Pinker's proclamation that many social scientists believe that "learning is some pinnacle of evolution that humans have scaled from the lowlands of instinct, so that our ability to learn can be explained by our exalted braininess" (The Language Instinct, (1994), p. 242) is probably not accurate and is surely not held by Piaget as evidenced here.
} 
is designed as an accommodation to the specific environmental conditions of the organism "and its structural organ" (1978, p. 38).

Adequation, as an adaptation mechanism, is different, then, from adaptation by natural selection since it calls for "a structuring of the environment by the organism itself"; whereas natural selection, being concerned solely with the organism's survival, is not so particular about the behaviors it accepts or rejects so long as a posteriori they get the organism by. As examples Piaget mentions the "adequation of an insect's sting or probe to the integument of its victim or the morophological disposition of flowers; the adequation of a triton's instinctive movements as it folds a leaf around its legs, and so on" (Piaget, 1978, p. 28).

For Piaget, explanations of evolutionary change must be sought at a level other than that of reproduction and survival alone when such specific sorts of accommodations in the organic realm are observed (Piaget, 1978, p. 139). Evolutionary psychology's concern with practical and cognitive adaptations would, for all intents and purposes, be considered by Piaget adequations, too, not naturally selected-for features due to their highly specific character. This opens up the possibility, on Piaget's account, that these cognitive traits are not inherited traits at all but learned anew by each generation.

Thirdly, hard as Piaget tries to distinguish his position from neo-Darwinian orthodoxy even through employment of the concept of phenocopy in a sense that is non-standard among biologists $^{54}$ - it is still a concept which presupposes the airtight distinction neo-Darwinians draw, and which is so fundamental to their interpretation of evolutionary theory, between inherited and acquired characteristics. Phenocopy is the transition from behaviors that are acquired to their replacement in and control by the genome. Piaget, of course, sets limits to the degree to which

\footnotetext{
${ }^{54}$ According to Francois Jacob "the definition of a phenocopy is the phenotypic imitation of another genotype" (In Discussion with Piaget in "About the Fixed Nucleus and its Innateness," in Language and Learning: The Debate Between Jean Piaget and Noam Chomsky, edited by Massimo Piatelli-Palmarini, 1980a, p. 62).
} 
such behaviors can be 'controlled' by the genome - he states explicitly that behaviors brought to bear on the outside world "cannot be preformed in the genome, even if they are in some sense programmed by it" (Piaget, 1978, p. xxi). But he has not completely extricated himself from neo-Darwinian orthodoxy because, while he acknowledges phenotypic change that is not genetic, he does not place it on a par with genetic change as evolutionarily significant.

Genetic change, in other words, is not, on the new developmental view, more relevant to changes in phenotypic behaviors than other factors. Neophenogenesis is the new concept coined by proponents of a developmental theory of phenotypic evolution that sees all behavior as arising in development as the result of interactions between organisms and their environments, not that some phenotypic characteristics or behaviors are more directly determined by the genome than others (Johnston and Gottlieb, 1990). While Piaget does defer to the notion that some phenotypic traits are more directly determined by the genome than others, the gist of Piaget's project is towards laying the foundation for a theory of neophenogensis. Piaget was ahead of the game, but in making strides he stumbled, in precisely the way developmental thinkers today have expected when researchers are accustomed to apportioning cause and effect between genes and the environment (Oyama, 1985; Ingold, 2002).

Piaget's ideas on this topic contrast significantly with the ideas of evolutionary psychology's predecessor, Chomsky, as well as evolutionary psychology's principal founders, Tooby, Cosmides and Pinker. One, not entirely obvious from the foregoing, is that Piaget disagrees with Chomsky and the evolutionary psychologists who see no "qualitative difference between the evolution of anatomical structures and the evolution of behavioral structures" (1978, p. xxii). This lies behind Chomsky's claim that the best metaphor for the LAD is that it is like an organ that grows and terminates at puberty $(1980, \mathrm{p} .76)$. Piaget disagrees that the language 
organ should be likened to the human heart or to the liver and, hence, he calls into question Chomsky's denial that the brain is a much more complex organ than the liver despite the fact that, as Chomsky notes, "it has approximately the same number of cells" (1980, p. 126).

For Piaget and the developmentalists who come after, there is an important distinction to be drawn between variations occurring in the morphological structure of the brain or nervous system and that of the liver or any other type of anatomical organ (Piaget, 1978, pgs. xxi-xxii). In Piaget's view, behavioral adaptations go beyond the bounds of the organism and call into play actions, which because they involve the outside world, cannot be "preformed in the genome" (1978, p. xxi). Piaget commends to the reader's attention the close interaction between the development of the nervous system and the development of behavior (1978, p. 144), which although it emerges belatedly, after the nutritional, respiratory, circulatory and reproductive systems are in place, it emerges as a superior organ oriented outwards and extending its capacities in an ever-broadening environment as well as directing itself inward to coordinate diverse organs (1978, p. 145).

Thus, Piaget finds it legitimate to infer that "inasmuch as behavior plays a role in the formation of the nervous system, it helps generate the overall organization of which it is at the same time an expression" (Piaget, 1978, p. 145). This bi-directional process that illuminates the nervous system's participation in its own construction has no place in evolutionary psychology. Evolutionary psychology cannot explain novel behavior; it cannot account for what Piaget describes as the organism's intrinsic desire to "strive to improve and hence to transcend itself" (1978, p. 142). For Piaget, though, this striving is the essence of behavior. While evolutionary 
psychologists speak as if natural selection is capable of producing phenotypic variations, ${ }^{55}$ in fact, its role is inherently limited to filtering out the unsuccessful phenotypes generated by developmental processes (Lickliter, 2003, p. 827).

This has an obvious impact on the evolutionary psychologists conception of the nature of organisms overall and human nature in particular. Human organisms have really become increasingly less plastic and flexible with evolution, on evolutionary psychology's view. Unlike Piaget's conception of living organisms, humans are not essentially oriented outwards in search of progress and improvement. Human beings do possess rich and complex structures and these structures do make possible their greatest achievements, but these complex structures and the capacities to which they give rise cannot be transcended as Piaget suggests. There are limitations to our cognitive powers of understanding. ${ }^{56}$

For Piaget, by contrast, people are open systems forever attempting to transcend themselves through learning new behaviors (1978, p. 139). Learning new behaviors is an essential, vital capacity propelling them forward. Learning comes into play not merely when people are engaged in activities that fall outside their cognitive capacities; learning is a capacity that seeks out opportunities for expression and constitutes a part of normal human development. Our cognitive capacities are not a priori limited. Indeed, the ability to creatively re-represent knowledge over and over in the mind, a process Karmiloff-Smith describes, may best explain why final answers to philosophical questions are not to be had. Evolutionary psychologists may be wrong to suggest that our revisiting such questions stems from the fact that we were not shaped by natural selection to answer them conclusively, if at all.

\footnotetext{
${ }^{55}$ See Lickliter and Honeycutt for quotations from Tooby and Cosmides and others to the effect that natural selection is a creative force ("Developmental Dynamics: Towards A Biologically Plausible Evolutionary Psychology, 2003, p. 826).

${ }^{56}$ These limitations extend to what we can know about ourselves. Hence, Jerry Fodor, an extreme nativist claims that the "limits of modularity limit what we will know about the mind" (1983, p. 126).
} 
Piaget stands as evidence for a strong thread of continuity between the fields of psychology and evolutionary biology - predating the evolutionary psychologists and providing an exactly counter paradigmatic view - one that sees genetic change as the consequence, not always the cause of exogenous actions and processes. This makes it all the more significant that the psychologists Robert Lickliter and Hunter Honeycutt should find that today "few psychologists have the time or interest to keep pace with the insights and discoveries regarding developmental and evolutionary processes emerging from the biological sciences over the past few decades" (2003, p. 819). Their claim gives back some weight to Konner's efforts to draw attention to these matters. By contrast, though, Lickliter and Honeycutt seek to highlight findings that contradict those made by evolutionary psychology as illuminated by Konner.

Indeed, Lickliter and Honeycutt are concerned that psychologists will be "easily swayed" to understand human development as the expression of a genetic program in the manner of evolutionary psychology due to the deliberate positioning of its exponents to stand as translators of biology for their field and due to the disciplinary lag in communications that appears to characterize the relation between developmental biology and psychology. If those who clamor loudest are heard, Lickliter and Honeycutt predict that an anemic conception of learning may persist in the social sciences as well as a flawed conception of the environment and its influences upon development.

While the more biologically plausible view to which Lickliter and Honeycutt adhere is "not yet widely acknowledged or discussed within the psychological sciences" (2003, pgs. 819-821), psychology's future course depends upon it. Among its leaders, as I have mentioned, is Karmiloff-Smith. Karmiloff-Smith's researches counter evolutionary psychology's biological commitment to the triggering effect of the social and ecological environment in actualizing 
preformed innately possessed abilities and biases. Instead, Karmiloff-Smith, like Piaget before her, sees the environment as playing a crucial role in the epigenetic construction of these abilities and biases with new ones elaborating upon ones that have already been formed.

Karmiloff-Smith rejects the unspoken, though widely-shared assumption ${ }^{57}$ presupposed by evolutionary psychology that if species-behavior is patterned and predictable (or as Piaget puts it, if the behavior is stable and firmly rooted) it must be biologically specified and innate, otherwise not. The underlying thematic of her work is that development involves more dynamism with the environment than such nativist assumptions grant. Since developmental outcomes are not predetermined and ontogenetic circumstances sometimes affect the genes and what they do, the important question Karmiloff-Smith must address is how non-predetermined constructions of human characteristics come about. Accepting the "magnitude of the gap between genetic activity and phenotypic outcomes" (Lickliter and Honeycutt, 2003, p. 820), Karmiloff-Smith recognizes that an adequate account of ontogenetic development presupposes that "developmental information itself... has a developmental history. It neither preexists its operations nor arises from random disorder" (Oyama, 1985, p. 3). ${ }^{58}$ In what follows, it shall become clear that the outstanding defect of evolutionary psychology is that it cannot embrace this fundamental fact.

\section{On Behalf Of Pinker - Synthesis 3 - By Bjorklund And Pellegrini}

Two proponents of evolutionary psychology, F. Bjorklund and Anthony D. Pellegrini, have attempted to enfold a dynamic view of human development into their theory. This integration of views is presented in their article, "Child Development and Evolutionary

\footnotetext{
${ }^{57}$ Noted by Piaget (1980, p. 57) as well as the psychologist Susan Oyama (1985).

58 Thus, the crucial question discussed among developmental biologists is how individual ontogenetic development impacts the evolution of the species. If the circumstances of ontogenetic development affect the genes and what they do, then the factors that play a role in linking genotype with phenotype becomes important for evolutionary theory (Burian, 1986, 2000; Oyama, 1985; Ingold, 1998).
} 
Psychology" (2000). At a first pass, the article is notable for containing the key terminology of developmental thinking: epigenesis, behavioral plasticity, even developmental dynamism. I believe, however, that Bjorklund and Pellegrini bring into play very specific meanings for these terms while they never make clear, indeed, they may fail to recognize, that alternative robust understandings have been passed over. Ultimately, their semantic replacement is symptomatic of their inability to distinguish their version of interactionism from that of the developmental systems approach, which they also claim to support. But there is a difference in the older and newer senses of interactionism ${ }^{59}$ and this difference is reflected in the irresolvable tension that afflicts their theory.

Significantly, Bjorklund and Pellegrini do endeavor to crank up the role of the environment in their account of the evolution of our psychological mechanisms. They maintain that the genes that construct these mechanisms are differentially activated over the course of ontogeny depending upon the social and ecological contexts that trigger them off (2000, p.1690). "Over the course of evolution, natural selection has functioned to adapt organisms to their current environments, and the environments and selective pressures experienced by our ancestors early in their ontogeny differed from the environments and selective pressures experienced by our ancestors later in their lifespan" (Bjorklund and Pelligrini 2000, p. 1690). After all, Bjorklund and Pellegrini point out: "Before organisms can reproduce and get their genes into the next generation, they must first reach adulthood" (2000, p. 1704). At the same time, consistent with evolutionary psychology, age-related mal-adaptations to current conditions become a possibility as well.

\footnotetext{
${ }^{59}$ Even Lickliter and Honeycutt do not recognize that Bjorklund and Pellegrini abide the 'older interactionism' for they cite their work as an example of the potential for "a fuller and more useful integration of evolutionary and developmental psychology" (2003, p. 830).
} 
There are several things to note, not all of which are explicit from the foregoing. The first is that Bjorklund and Pellegrini endorse evolutionary psychology's gene-centered approach to cognition, an approach which - according to the new biological view - radically oversimplifies the regulatory dynamics involved in development. Bjorklund and Pellegrini affirm that species-wide behaviors and mental characteristics are passed onto future generations through genes that have been naturally selected-for over evolutionary time (2000, p. 1688). ${ }^{60}$

So for Bjorklund and Pellegrini it is still the case that human beings are pre-constituted genetically and that various behavioral outcomes are wholly predictable insofar as they are predicated upon a conception of how nature and nurture will interact. Epigenetic psychological mechanisms are still understood to have a content-rich and universal character. The only difference from evolutionary psychology as propounded by its founders (without the developmental addition) is an increased number of ready-made structures that the environment still also conceived as a triggering mechanism and poser of problems - can initiate. Our genetic inheritance has simply become more generalized and abstract, on Bjorklund and Pellegrini's account, for the psychological mechanisms lodged in our minds are now understood to be innately specified predispositions, not innately specified modules, and it is these predispositions that are set up to unfold in developmental contexts (Bjorklund, 2003, p. 822). ${ }^{61}$ The extra-modular conflicts about which evolutionary psychologists speak whose upshot determines

\footnotetext{
${ }^{60}$ Yet, Bjorklund and Pellegrini's claims about children's behaviors today being a consequence of the experiences that children faced under Pleistocene conditions, assume we have a grasp of the norm of reactions for genotypes that far exceeds our present state of knowledge. The norm of reaction "is a table of the correspondence between phenotype, on the one hand, and genotype-environment combinations on the other" (Levins and Lewontin, 1985, p. 114). In point of fact we do not have a norm of reaction for any genotype for any human mental or emotional trait (Griffiths, et al, 2000). And without knowing the norm of reaction for a distribution of environments for a genotype, it is impossible to correlate, let alone predict the adaptedness or maladaptedness of certain behaviors as being due to the change of circumstances.

${ }^{61}$ This point is amplified by Bjorklund in a commentary he wrote without Pellegrini on Lickliter and Honeycutt's piece, titled "Developmental Dynamics: Toward a Biologically Plausible Evolutionary Psychology" (2003) Psychological Bulletin 129 (6): 819-835. It is reasonable to assume that Pellegrini shares Bjorklund's stance since it is of piece with the unique 'Developmental Systems Perspective' which they develop.
} 
the behavior of adults facing problem situations, now occurs inter-modularly at critical times in ontogeny and helps shape the expressed form of the modules in their final states. ${ }^{62}$

In short, these predispositions imply genetic blueprints in the same way that innately specified modules containing content-rich representations do. Bjorklund and Pellegrini thus invite a charge Karmiloff-Smith works hard to rebuff. On Karmiloff-Smith's view (we shall see) the innately specified predispositions our minds start out with are merely skeletal predispositions capable of becoming a part of our biological potential only through rich constructivist interactions induced by the environments we are in (Karmiloff-Smith, 1992, p. 15). For Bjorklund and Pellegrini, by contrast, these innately specified predispositions are shaped by our ancestral past, and hence, not merely skeletal; nor are they sustained by environmental interactions as they occur in the here and now. On Bjorklund and Pellegrini's view, the essence of human remains something specifiable apart from the developmental contexts in which people actually become human, a core precept of evolutionary psychology. Bjorklund and Pellegrini just push the genetic starting point back a notch.

While Bjorklund and Pellegrini make it appear that Evolutionary Developmental Psychology presents a dynamic picture of the context-dependent formation of human capacities, the appearance is deceiving. For on a true developmental view, the genotype does not pre-exist since "there can be no specification of the characteristics of an organism, no design, that is independent of the context of development" (Ingold, 1998, p. 30). However, Bjorklund and Pellegrini's account implies that phenotypic end-results are pre-determined, linked to the genotype directly, albeit prompted by the conditions that cause their response. Once set off,

\footnotetext{
62 The question concerning how people know which mental module to invoke to handle the particular adaptive problem that they face at any given point in time is discussed by Daniel Cervone in "Evolutionary Psychology and Explanation in Personality Psychology, " American Behavioral Scientist, Vol. 43, No. 6, March 2000, pgs. 1001-1014.
} 
these traits unfold in a linear and automatic fashion. The main difference is that there are more characteristic manifestations with which the genotype is associated and which a unidirectional chain of processes must pass through once it starts off.

So there is still design. Consequently, there is no sense of real contingency in the developmental system itself, no sense that ontogenetic development is an open process of construction continually generating and regenerating behaviors in tune to the specific features of the contexts at hand. For evolutionary developmental psychologists constancy of form is a function of the psychological mechanisms our ancestors evolved and the experiences they had that shaped them. The developmental system has a final form and this final form is "encoded before its starting point and realized at maturity" (Oyama, 1985, p. 23) - or at significant age-related points in time - in stark opposition to the new developmental view which conceives the end-state of an organism as the upshot of mobile and contingent phenotypic processes (Oyama, 1985, p. 22). Thus, it is not really a part of Bjorklund and Pellegrini's understanding that "it is only within the context of the developmental system that we can say what any particular gene is for" (Ingold, 1998, p. 30).

Therefore, for Bjorklund and Pellegrini to speak of 'epigenetic programs' is really a contradiction in terms. Epigenetic processes are by definition not pre-programmed processes. For Bjorklund and Pellegrini to speak of behavioral plasticity that is pre-constituted is also a contradiction in terms. Plastic behaviors are generated and sustained in developmental contexts as interactions take place; the role played by any given factor cannot be predicted in advance. And for Bjorklund and Pellegrini to suggest that a developmental system is dynamic when its end-result is not really open negates that dynamism completely - another contradiction in terms. 
Yet Bjorklund specifically states, in his Commentary on Lickliter and Honeycut's piece, “Developmental Dynamics: Toward a Biologically Plausible Evolutionary Psychology" (2003), that integrating a developmental systems perspective into evolutionary psychology, would not "appreciably change its basic focus" (2003, p. 836). I disagree. As previously noted, Bjorklund and Pellegrini (who does not co-author the commentary but can be presumed to endorse the view presented therein since it amplifies evolutionary developmental psychology) want to take evolutionary psychology as the primary framework and superimpose it upon the developmental systems view. I believe, however, that the developmental perspective has to be accorded its rightful (and relevant) place in light of the evidence, and this means that developmental factors cannot be deemed a priori as secondary. Indeed, we find that evolutionary psychology unravels increasingly the more developmental factors are taken seriously.

At the same time, Bjorklund and Pellegrini clearly see development as the missing element evolutionary psychology needs to extricate itself from its problems. Bjorklund urges (on their behalf) that while most evolutionary psychologists are committed to the phylogeny fallacy that Lickliter and Honeycutt describe, they are not. This fallacy refers to the assumption that "evolutionary factors are somehow ontologically prior to and more fundamental than proximate factors in directing phenotypic outcomes" $(2003$, p. 822). Let us examine these issues in greater detail.

Bjorklund goes on to show that he and Pellegrini do not commit this fallacy since they affirms not representational innateness, as do the evolutionary psychologists, but rather the two types of innateness associated with the developmental systems perspective, architectural innateness and chronotopic innateness. Bjorklund explains that architectural innateness "refers to the way the brain is organized at birth, with some areas being biased to process some types of 
information more readily than others (e.g., because of differences in the distribution of neurons, presence of neurotransmitters, connections to other neurons). Thus, there is no innate knowledge, per se, but rather inherited dispositions that become solidified through experience." Chronotopic innateness refers to limitations in the timing of events such that certain areas of the brain must develop before others (Bjorklund, 2003, p. 822)

Like Bjorklund, Karmiloff-Smith accepts both these weaker forms of nativism. What Bjorklund does not acknowledge though, indeed he denies, is that a full-fledged developmental systems approach to the ontogeny of mental abilities and behaviors undermines evolutionary psychology's fundamental tenet that modern minds are adapted to an ancestral Pleistocene environment (Bjorklund and Pelligrini, 2000, p. 688; Bjorklund, 2003, p. 837). However, if the actual developmental context plays a constructive role in shaping minds and brains today then it follows that, to that extent, the particularities of the ancestral environment does not.

Bjorklund's support for evolutionary psychology's tenet that human minds are adapted to the Pleistocene past is also inconsistent with claims made by Jeffrey Elman and others (including Karmiloff-Smith) to whom he refers in documenting these varieties of innateness. In Rethinking Innateness (1996) Elman, Bates, et al., (Karmiloff-Smith included) write that "there is simply too much plasticity in the development of higher organisms to ignore the critical effect of experience" (1996, p. 8). Plasticity is the other side of these weaker forms of nativism. Granting plasticity undermines evolutionary psychology's modularity thesis, in other words, which Bjorklund supports (in modified form), since it means that people's mental modules are not preformed at birth - either with representations that unfold (as evolutionary psychology's founders argue) or with predispositions that unfold (as Bjorklund argues) - but that they often develop in a process of modularization. This is one of Karmiloff-Smith's main theses. Indeed, 
in granting bi-directional interactions between genes and environment "at all levels of biological organization" one is pushed closer to Karmiloff-Smith's view that humans are active constructors of their own cognition (1992, p. 11) a consideration missing from Bjorklund and Pellegrini's. Yet, it is in this manner that individual ontogenetic development connects up with and, hence, becomes important to, evolutionary theory.

In all, it is not the least surprising that Bjorklund, who describes himself as a proselytizer of both the developmental systems approach and evolutionary psychology, should declare that he has had to learn to live with contradictions. For his position is incoherent as a consequence. Were the modifications to evolutionary psychology he recommends granted, which bestows to the developmental perspective (he shares with Pellegrini) its relevant role, it would become possible to assimilate many of the ideas that follow from the alternative disciplinary approaches that conflict with evolutionary psychology that have been raised for consideration in the course of this dissertation.

The failure, if not reluctance, of theorists like Bjorklund and Pellegrini to follow through on the conceptual changes that the integration of the developmental perspective requires is of a piece with fully understanding what a truly interactionist approach means. While Bjorklund and Pellegrini may invoke the core concept of the developmental systems approach 'epigenesis' and claim to understand that it reflects a bi-directional relation between all levels of biological and experiential factors (such that genetic activity both influences and is influenced by structural maturation (2003, p. 1691)) they and other like-minded thinkers do not take the next required step. That step is to acknowledge that genes and behavior form a fully coactional system - being wholly biological and wholly environmental at once. If age-related ontogenetic behaviors are the result of interactive constructions then it makes no sense to talk about psychological mechanisms 
as genetically encoded programs or about human traits that are environmentally shaped. In both instances information pre-exists the processes that give rise to it (Oyama, 1985, p. 13).

Complementarity approaches are superseded on a truly developmental view (Ingold, 1998). ${ }^{63}$

Evolutionary developmental psychology is at root a complementary view, however, as is the foundational theory from which it originates.

One of the more interesting ideas central to evolutionary psychology and consistent with its commitment to neo-Darwinism is the idea that natural selection is the principal mechanism for generating novelty in the realm of organisms. Bjorklund rejects this idea (2003). Along with Gottlieb, Oyama and others, he accepts that "changes in developmental systems are responsible for generating the novel phenotypes that must then pass through the sieve of natural selection. Natural selection retains its role as the gatekeeper of evolutionary change, but its role is one of eliminating phenotypes that do not fit well with local environments, not as the generator of novelty. Rather, that role goes to changes in developmental systems, particularly changes in behavior influenced by novel responses to changing environments, with genetic changes sometimes following behavioral and morphological changes" (2003, p. 840).

Bjorklund only mentions this feature of the developmental systems perspective and then he drops it since his commentary is on Lickliter and Honeycutt's piece and, hence, is not the place "to expand on these approaches and convince skeptical readers that such views do not constitute Lamarckian inheritance of acquired characteristics" (2003, p. 840). What is clear, however, is that current developmentalists have fastened upon precisely the insight that Piaget fastened upon a generation earlier, namely, organic selection (also called the Baldwin effect),

\footnotetext{
${ }^{63}$ As Timothy Ingold explains: "Walking and talking are no more the operations of an enculturated mind than they are of a body designed by natural selection. They are rather the developmentally enhanced achievements of the whole organism-person, at once body and mind, positioned within an environment ("Evolving Skills" in Alas, Poor Darwin, 2000, edited by Hilary Rose and Steve Rose, New York, Random House pg. 294.)
} 
whose importance, we have also found, Piaget admirably describes in Behavior and Evolution (1978).

\section{Karmiloff-Smith: From Modularity To Creativity - The Ultimate Synthesis}

Annette Karmiloff-Smith was a student of Jean Piaget's at the University of Geneva for 13 years, thereafter a research collaborator. Karmiloff-Smith recognizes the need to give more play to the role of the environment in the mind's epigenetic interactions, in the processes of language acquisition, and other cognitive processes as well. Karmiloff-Smith also acknowledges the role of culture and sociocultural interaction patterns in cognitive development $(1992,122)$. Karmiloff-Smith is not by any means a carbon-copy of Piaget, however. In the Preface of her book, Beyond Modularity: A Developmental Perspective on Cognitive Science (1992), Karmiloff-Smith states that the "home grown Piagetians" at the University of Geneva "always considered me a heretic, both personally and theoretically." She goes on: "I refused to address Piaget as Patron, meaning 'Boss', as he expected everyone in his department to do; I dared to put in writing that Piaget had underestimated the role of language in cognitive development; and, worse, I argued that sensorimotor development alone could never explain how language acquisition got off the ground - that there had to be some innate component, even if more general processes might operate in subsequent development" (1992, p. xiv).

As a renegade student of Jean Piaget's, Karmiloff-Smith develops her thinking in contrast to his, effortlessly carrying forward and incorporating the best parts of Piaget's work and leaving behind just as effortlessly the parts that recent empirical research has undermined.

Karmiloff-Smith is well attuned to the debate between nativism and constructivism, particularly in the terms in which it raged between her mentor and evolutionary psychology's forerunner Noam Chomsky. However, she believes the debate has continued unconstructively with the 
growth of cognitive science. Karmiloff-Smith will not choose between these contrasting orientations. "I do not choose between these two epistemological stands, one arguing for predominantly built-in knowledge and the other for a minimum innate underpinning to subsequent domain-general learning. Rather, I submit that nativism and Piaget's constructivism are complementary in fundamental ways, and that the ultimate theory of human cognition will encompass both" (1992, xiii). For Karmiloff-Smith cognitive development is neither domain-specific nor domain-general in its entirety (1992, p. 9).

While development holds the key to understanding cognition on Karmiloff-Smith's view, (1992, p. 5) she takes a position which is not universally shared among developmentalists; namely, that the study of children is not an end-in-itself but a theoretical tool for understanding the workings of the human mind generally speaking. Karmiloff-Smith's believes that decades of research have been wasted on documenting the lowest age at which children could master a particular developmental task. Children, after all, do develop, Karmiloff-Smith points out (1992, p. 28). That in a nutshell encapsulates her conception of the child. While Karmiloff-Smith urges that the study of children is of instrumental, not intrinsic value, this is not intended to imply that children's experiences are any less valid than adult experiences. In fact, she seeks to discover how children really do experience their world through investigation of their knowledge and activities. She accepts, as did Piaget and Chomsky, the importance of understanding and getting at the initial state of a developing organism (Piaget, 1980a, p. 55; Chosmky, 1980, p. 109).

Syntheses of Chomsky and Piaget's views have been proffered before and rejected by their namesakes (Piatelli-Palmarini, 1980). Piaget has insisted that the hallmark of cognitive development in humans is their ability to construct unprecedented and novel behaviors and to be "open to further constructions" (1980a, p. 55). All knowledge proceeds from action for Piaget. 
Knowledge-making involves the active role of infant babies in transforming external noise into order in stepwise fashion. Piaget argues that infants possess, to start out, a general intelligence that enables them to do this (1980, p. 24) Language acquisition is therefore not a learned ability (in the behaviorist sense) but a result of this general intelligence or reason (1980a, p. 57).

Chomsky has insisted, on the other hand, that newborns enter the world biologically equipped with a complete system of rules for mapping their experiences onto their own internal states (1980, p. 130). The initial structure of children's minds is powerful - fully organized for projecting the order it contains onto experience - order that could not arise, in Chomsky's opinion, on the basis of the infant's experiences alone. For Chomsky, of course, Universal Grammar is a species-universal computational structure that is not learnable, it grows, which explains why evolutionary psychologists refer to it as an instinct. Common to both Chomsky and Piaget's view is a rejection of empiricism in the sense that cognitive development is a matter of passive perception alone. The problem with this idea is that it suggests infants lack a structuring faculty for imposing order onto their observations. Thus an important affinity of Piagetian theory and Chomsky's is that cognition is rudimentarily a biologically adaptive response of the organism that does not necessarily entail learning. The constructivist processes in which infants engage, according to Piaget, while dependent upon and responsive to the environment, are not the product of anything social or anything they were taught (by themselves or others) but a consequence of intrinsic, automatic capabilities. It is the empiricist view that the Blank Slate best emblematizes, not the view of evolutionary minded thinkers who support plasticity.

Karmiloff-Smith points out that whether development involves a process of gradual construction (which she believes culminates in modularization contra Piaget) or whether the 
human mind is innately-specified at birth in complete detail, while a speculative choice now, is an empirical matter. Future research using on-line brain activation studies with newborns and young infants should be able to distinguish the two hypotheses (1992, p. 5). If the mind is pre-specified and innate, Karmiloff-Smith argues, brain activation studies should show that, "from the very outset, specific brain circuits are activated in response to domain-specific inputs. By contrast, if the modularization thesis is correct, activation levels should initially be relatively distributed across the brain, and only with time (and this could be a short or relatively long time during infancy) would specific circuits always be activated in response to domain-specific inputs" (1992, p. 5). ${ }^{64}$

Piagetian developmentalists believe the child possesses neither innate structures nor built-in knowledge in its initial state. The child is a pure sensorimotor organism. Piagetian theorists grant only domain-general, biologically-specified learning processes to children for handling inputs. These processes (processes of assimilation, accommodation, and equilibration) apply indiscriminately to linguistic and non-linguistic data. The child's sensory transducers do not automatically transform inputs into formats that can be handled by innately-specified mental modules. Indeed, human development just is the active construction by the child "of domain-general changes in representational structures operating over all aspects of cognition in a similar way" (1992, p. 7). According to Piaget, this cognitive construction occurs in an epigenetic process that is stage-like, logical and spurred by the child's own interactions with its environment. At no point do these domain-general processes give way to the formation of

\footnotetext{
${ }^{64}$ Presumably, one would still need to determine the precise nature of the modules that innately exist or are being formed in the process of modularization in the light of these studies, e.g., those underwriting our capacity for language, for physics, for number, for psychology. Thus, Kathleen Gibson's failure to find special neural circuitry in Broca's area in monkeys and humans indicative of a LAD does not mean humans do not possess a LAD. Activation studies of the sort Karmiloff-Smith refers to may be indicative and even prove otherwise.
} 
modularized structures, however. The flexibility these mechanisms have to start is maintained throughout development.

Karmiloff-Smith has both theoretical and empirical reasons for rejecting Piaget's framework for understanding cognitive development. On the theoretical side, she finds that modularity theorists provide a compelling view of the child as "off to a very good start" rather than that of the child being assailed by "undifferentiated and chaotic" data from many competing information sources - a view that suggests the child is not well-suited to deal with the physical facts it confronts. ${ }^{65}$ On the empirical side, she is convinced by research in developmental (on adults as well as children) neuropsychology. This research substantiates the existence of very uneven cognitive systems. Autism, for example, involves a deficit in theory of mind cognition only, and with William's Syndome language, face recognition, and theory of mind are intact whereas number and spatial cognition are severely damaged. Additionally, in many instances of adult brain damage the damage typically turns out to be domain-specific (1992, p. 8).

Karmiloff-Smith appeals to the aforementioned research to lay the groundwork for what should be added to Piaget's view. What should be added, she believes, is not to postulate domain-specificity per se or modularity but "innate, knowledge-impregnated predispositions" existing in the mind (1992, p. 10). Karmiloff-Smith means to refer to our latent possession of the means for acquiring knowledge, not that we have the knowledge itself - she refers to our 'knowledge-how' capacity, not our 'knowledge-that' capacity. This postulate enables her to accept Piagetian constructivism while dropping its commitment to domain generality.

\footnotetext{
${ }^{65}$ Piagetian thinkers might respond that the child is actually quite well-equipped to deal with the confusion of the outside world so that the difference between their positions on the initial state of the organism is really a matter of perspective. Piagetian theorists may urge that while it is common to presuppose that an organism is more stable and biologically prepared to perform its behaviors if those behaviors are thought to be hereditary, rather than the consequence of "autoregulation," this presupposition is mistaken (1980a, p. 57). Therefore, it does not follow that modularity theorists provide a more compelling view of the child in terms of its overall biological preparation. Karmiloff-Smith may be too hasty here.
} 
Accordingly, Karmiloff-Smith explains that "domain" and "module" are not to be confused. A domain refers to a set of representations that sustains a specific knowledge area (language, number, physics and so on). It need not be informationally encapsulated, mandatory, or hardwired. A module, on the other hand, performs computations as well as being comprised of highly particular self-contained representations. Karmiloff-Smith does not grant either domain-specificity or modularity to the mind initially because to do so leaves no room for the rich, epigenetic, constructivist processes for which she finds ample evidence. Karmiloff-Smith holds to architectural nativism, the idea mentioned earlier, that the brain does not come pre-structured with content-rich representations, as evolutionary psychologists maintain, but that the brain comes prestructured to "progressively develop representations via interaction with both the external environment and its own internal environment" (1992, p. 10). ${ }^{66}$

Testimony to its reconstructive abilities is the brain's selective adaptation of inputs to alternative channels for processing when the proprietary module cannot do so due to damage (as in the case of a congenitally deaf person who processes auditory input to a language module) (1992, p. 10). In other words, the brain has more plasticity than evolutionary psychologists are prepared to admit. Indeed, current research shows it has even more plasticity than Karmiloff-Smith documented at the time of writing Beyond Modularity (1992), research to which she refers in her more recent book, Pathways of Language (2001). In Pathways of Language Karmiloff-Smith points out that the notion that language processing becomes progressively localized in the brain is being challenged (2001, p. 221).

\footnotetext{
${ }^{66}$ The anthropologist Christina Toren points out that the newborn human once conceived as a "self-regulating transformational system" a la Piaget, "is going to look like what cognitivists call a module. She believes this is an important point "because one of the main arguments for modularity theories is that the structured properties of mental processes can be a function only of an innately given 'set of evolved information processing mechanisms'..." Toren herself is of the opinion that "given the extraordinary complexity of the human nervous system, the infant's immersion in a world of highly differentiated sensation, and the rapid growth of interneuronal connections, a few months are surely ample time for the autopoietic development of complexly differentiated cognitive schemes out of much more primitive beginnings" ("What it is to be Human" in Anthropology Beyond Culture, 2002, p. 117).
} 
Instead, recent data indicate that language-processing circuits are widely distributed across the brain and that there is a great deal of individual variation (Karmiloff-Smith, 2001, p. 222). Karmiloff-Smith acknowledges that, "areas or regions once thought to be dedicated to one processing task are actually receiving inputs from more than one processing stream" (Hardcastle and Buller, 2000, p. 8). Accordingly, she amends the notion of domain-specificity, to which she gives credence in Beyond Modularity, in favor of the notion of domain-relevance somewhat parallel to Hardcastle and Buller's notion of domain-dominance - the idea that "our 'modules' are not so specialized that they deal only with restricted domains or types of input (2001, pgs 6-7). "Instead, they deal 'mostly' with particular domains" or environmental inputs (Hardcastle and Buller, 2000, p. 11; Karmiloff-Smith, 2001, pgs. 6-7). Thus, information overlap appears to be an inherent feature of our cognitive systems. The brain is in a continual process of reorganization in response to environmental demands such that by the end of our lives we have used regions entirely different from the regions originally used for the performance of the exact same tasks (Hardcastle and Buller, 2000, p. 8).

Karmiloff-Smith recognizes that by arguing for innately-specified predispositions instead of modules, she leaves herself open to the charge that these predispositions imply genetic blueprints in the same way that innately-specified modules do. Anticipating this criticism, she points out that the sense of innateness she invokes is not that of a static genetic blueprint unfolding. Unlike the triggering effect of the environment on an innate modular component, the environment acts as "much more than a trigger" when an innate predisposition is specified "merely as a bias or skeletal outline." In contrast, according to Karmiloff-Smith, the environment "actually influences the subsequent structure of the brain via a rich epigenetic interaction between mind and the physical/ sociocultural environment" (1992, p. 15). The innate 
predisposition "becomes a part of our biological potential only through interaction with the environment; it is latent until it receives input. And that input affects development in return" (1992, p. 10).

For Karmiloff-Smith innately-specified predispositions are what have been formed, and hence, selected-for by evolutionary processes. With respect to language, this means that grammar per se is not “evolution's gift to the human species, but rather the capacity for learning grammar" is evolution's gift (2001, p. 219). Unlike other animals "who need a vastly shorter postnatal period of development to reach maturity" the cost of which is "to render the organism relatively inflexible to changes in the environment," for humans the paradoxical fact is that "evolutionary specialization manifests itself by a relative lack of specialization at birth ... evolution's answer in the human case has not been to provide extensive prespecified linguistic knowledge. Rather evolution has provided humans with a wide variety of learning mechanisms and a very long developmental period in which to learn and shape our brains. That is what makes us special, because it gives us a greater capacity for adapting to, learning from, and ultimately changing our environment" (Karmiloff-Smith, 2001, p. 224).

Working, then, within a framework that embraces both nativism and constructivism, Karmiloff-Smith's principal interest is in providing an account of the mind's flexibility and creativity. She notes that whereas fixed constraints are initially adaptive, they are also relatively inflexible. This means that gradual modularization of the mind (if that occurs) implies gradual elimination of the mind's flexibility. As she sees it, the more capacities built into children's minds, the more compelling the need to explain the flexibility of their subsequent cognitive development. Karmiloff-Smith's answer to the question of where mental flexibility and creativity come from is encapsulated in her concept of representational redescription (RR). 
As she puts it, RR is a process whereby "information in the mind subsequently becomes explicit knowledge to the mind, first within a domain and sometimes across domains" (1992, p. 18). RR conveys the idea that once the knowledge relevant to a particular domain has been mastered, it "becomes applicable beyond the special purpose goals for which it is normally used and perceptual links across domains can be forged" (Karmiloff-Smith, 1994, p. 706). Thus, whereas with modularization information becomes less accessible to the cognitive system with RR information becomes more accessible (Karmiloff-Smith, 1992, p. 15). It is precisely the opposite process.

Furthermore, RR is a domain-general capacity (Karmiloff-Smith, 1994, p. 700) that is a part of normal cognitive development. It is not exceptional since it occurs repeatedly in childhood as well as in adulthood when new learning is involved. In a significant (and I believe erroneous) ${ }^{67}$ contrast to Piagetian theory, in which Karmiloff-Smith claims it is hypothesized that an organism in a state of stability will not act to spontaneously improve itself relative to its conditions, she calls hers a 'success- based view.' The reason RR is a success-based view is that it transpires frequently after a child has mastered a behavior and appropriates the knowledge involved in that behavior for other purposes. In all, development and learning for Karmiloff-Smith involve two complementary processes, one of gradual modularization and another of gradual "explicitation," that is, explicitly representing information that is implicit in knowledge that was in an earlier phase not consciously accessible (1994). RR accounts "for the

\footnotetext{
67 I am surprised at this contrast which Karmiloff-Smith makes distinguishing her position from Piaget's since the main thrust of Piaget's Behavior and Evolution is to impress the idea that it is of the essence of living organisms to be "forever attempting to transcend" themselves and their environments through new adaptive behaviors even when the "living organism's internal organization would have no reason of their own to change" (1978, pgs. 140, 141). Piaget is perfectly clear that this tendency applies throughout phylogeny and is not limited to humans. Indeed, I would have thought that Karmiloff-Smith's close association with Piaget is what accounts for the central place that the human desire to 'advance beyond success' has in her work.
} 
way in which children's representations become progressively more manipulable and flexible, for the emergence of conscious access to knowledge, and for theory-building" $\left(1992\right.$, p. 17). ${ }^{68}$

\section{Analysis}

Karmiloff-Smith singles out Jerry Fodor not any of the evolutionary psychologists as the principal nativist against whom she wishes to cast her views. It is of some use to bring Fodor into the analysis as his position sheds light on what evolutionary psychologists are up to. Fodor believes that our cognitive architecture consists of two parts: perception, which is the hard-wired 'stupid' system of our brains that channels input data in fast, mandatory ways and is only marginally influenced by cognition; and cognition, the slower, more cumbersome central system where 'thought,' 'problem-solving,' and 'intelligence' resides. The central system's fundamental character is that it is holistic in contrast to the input systems, which are like the blades of a Swiss army knife, comprised of discrete modules. The input systems govern the operations of sight, hearing and touch as well as language. In all, the human mind has two tiers that operate in contrasting fashions. Cognition is the puzzle, according to Fodor, impossible to

\footnotetext{
${ }^{68}$ As an example of RR Karmiloff-Smith provides that of the learning pathway involved in piano playing. "There is first a period during which a sequence of separates notes is laboriously practiced... There is a second period during which a chunk of several notes are played together as blocks, until finally the whole piece can be played more or less automatically... But the automaticity is constrained by the fact that the learner can neither start in the middle of the piece nor play variations on a theme...There is little flexibility...During a fourth period, the learner can interrupt the piece and start at, say, the third bar without having to go back to the beginning and repeat the entire procedure from the outset...I hypothesize that this fourth period cannot take place on the basis of the automatized procedural representations. Rather, it involves a process of representational redescription such that the knowledge of the different notes and chords (rather than simply their run-off sequence) becomes available as manipulable data" ( $\mathrm{p}$. 699). In sum, RR is basically a 4-phase process. In the Level E1 phase representations are bracketed and cannot be linked with others within the domain or without. At the E2 Level, "representations are available to conscious access... but not to verbal report (which is possible only at Level E3)... At Level E3 knowledge is recoded into a cross-system code...close enough to natural language for easy translation into stable, communicative form. It is possible that some knowledge learned directly in linguistic form is immediately stored at level E3" (1994, p. 701).
} 
study since its processes cannot be related to specific parts of the brain and it involves the integration of information from all the input systems (Fodor, 1983; 1985).

What evolutionary psychologists do is adopt the structure Fodor ascribes to the several modular input systems of perception and apply that structure liberally, extensively and exhaustively to the whole of our cognitive architecture expanding into the domain that Fodor calls 'cognition.' All cognitive processes are assimilated so as to produce the theoretical posit that the mind is massively modular. Accordingly, evolutionary psychologists argue that most all cognition is hard-wired to function in the fast, automatic, mandatory ('stupid') way delimited to modules - probably precisely the feature of these systems that led Fodor to reject them as an apt model for higher thought. Recall, though, that neurobiological research is disproving the idea that our basic cognitive processes function discretely and do not overlap.

Most importantly, neurobiological research is also disproving the idea that human cognition is hard-wired and functions in the mandatory ways that Fodor and the evolutionary psychologists claim. Rather development is best understood as the outcome of entities and processes that go on at different levels and that are interdependent and interact. On this new view of an organism's development, there is no preset plan for the orderly processes that take place to emerge, so that as a matter of principle, it is impossible to state definitionally the specific kinds of relations that shall constructively take shape among the constituent causal factors that are responsible (Oyama, et al., 2001; 1985). This undermines evolutionary psychology's posit that the mind's many modules are tightly coadapted to each other.

Consequently, evolutionary psychology's modular model of the reach and limitations of higher cognitive functions seems that much more suspect. To start, the secondary connections our brains contain for somatosensory inputs (indicative of overlap in the processing of perceptual 
information (Hardcastle and Buller, 2000, p. 10) coheres much better with Karmiloff-Smith's model of how higher thought processes function. The point is that to achieve cross-domain information, the neural system must forge connections that culminate in knowledge that overlaps different domains, in other words, by making connections that require representational redescription. And this is just to say that the functioning of our basic cognitive processes provides the resources Karmiloff-Smith needs to address what Fodor considers puzzling about cognition. Two dramatically different kinds of operations may not be needed, after all. The neurobiology that underpins somatosensory perception appears to be as creative as that which grounds our higher intelligence too.

Karmiloff-Smith's theorizing is estimable because she works with models of developmental biology that are current and she attempts to tackle cognitive creativity in scientifically robust, not reductive terms. However, even Karmiloff-Smith becomes forgetful of the space that must be left open for the will when she falters at the question: "Why do we not redescribe and link all of the knowledge we store?" (1993, p. 579). While automaticity is surely not a mandatory feature of higher cognition on any but the most deterministic account (even evolutionary psychologists claim to be complicated determinists, not simplistic ones), Karmiloff-Smith need only be reminded of the grand philosophical systems constructed by the eminent philosophers of the $16^{\text {th }}$ and $17^{\text {th }}$ centuries (Descartes, Hobbes, Spinoza, Leibniz) and in later centuries, the German philosophers such as Kant, Hegel and Schopenhauer. She need only be reminded of the erstwhile sway of the Coherence Theory of Truth, the String Theory of today's modern physicists, Chaos Theory, Marxism and all the many brands of reductionism (biological, cultural, economic) including evolutionary psychology's own architectonic ICM, a first-order exemplification of the reductive enterprise - whose viewpoint of compelling 
simplicity anchors the theory firmly in the popular imagination. All these theories are grand attempts to link all knowledge.

Developmental psychology makes worthwhile contributions as well to the other two disciplines, biological anthropology and empirical linguistics, which I have argued in this dissertation should be incorporated into a more workable theory of evolutionary psychology. Biological anthropologists draw the particular lesson, as noted by Barbara King (and developed extensively by Tim Ingold) that 'complementarity approaches', those that speak of 'biosocial influences,' fail to take into account that processes of development are at once wholly biological and wholly social (e.g., how a child learns to walk (King, 2000, p. 154; Ingold, 1998). Following Karmiloff-Smith and developmental psychologists like Lickliter and Honeycutt, King has become a systems thinker who appreciates that natural selection pressures are modified by complex interactive processes that themselves involve systematic feedback. Thus, King finds the tool-using behavior of West African chimpanzees is "co-constructed across the generations, and in so doing selection pressures are altered" (2000, p. 155). For King, as for Karmiloff-Smith, knowledge is often embedded in social interactions, contained in the structure of an infant's relations with conspecifics, and hence, neither exclusively inside the infant or outside in the situation (King, 2002, pgs. 86-87; Karmiloff-Smith, 1992, pgs. 123-124).

Furthermore, unlike the evolutionary psychologists, developmental psychologists in tune with Karmiloff-Smith place issues concerning cross-species similarities and differences centrally in their repertoire of what is important to study. The first line of the first chapter ("Taking Development Seriously") of Karmiloff-Smith's book, Beyond Modularity, chides those of her colleagues who overemphasize the disjuncture between humans and other animals. She queries: "Have you noticed how quite a large number of developmental psychologists are loathe to 
attribute any innate predispositions to the human infant? Yet they would not hesitate to do so with respect to the ant, spider, the bee, or the chimpanzee. Why would Nature have endowed every species except the human with some domain-specific predispositions? Yet, if it turns out that all species have such predispositions... what is special about human cognition? ... Is it language that makes humans special?" (1992, p. 1)

Karmiloff-Smith does not doubt that nonhuman primate studies will shed light on the evolutionary roots of human language. Unlike the evolutionary psychologists who unabashedly deprecate the value of comparative data, she believes the work of biological anthropologists shall remain a fascinating field of research of relevance to this line of questioning (2001, p. 219). For developmental psychologists the sense in which human beings are unique, or alternatively, the sense in which they lie on a continuum with other species, has pragmatic implications for the nature-nurture debate (2001, p. 211) as it does for biological anthropologists. To say that humans are unique with respect to the language faculty just as other species are unique in their own ways is not just meta-commentary, as it seems to be for evolutionary psychology.

Indeed, Karmiloff-Smith exudes enthusiasm in her commentary on David Premack's findings on the effects of language training on the mental abilities of chimpanzees (1983). One finds in her remarks the natural inclination to illuminate human cognition through comparisons of the chimpanzees' abilities with that demonstrated by human children. Whether chimpanzees are our closest relatives or not, they are the closest living relatives that we have for making comparisons and these comparisons turn out to be quite instructive. The comparative data generate deep and interesting questions for approbatory research. "Is the training that the chimpanzees received really linguistic?" Karmiloff-Smith asks. She goes on:

Is it not rather that the chimpanzees are taught some form of new representation that is indeed 'abstract' (arbitrary with respect to its relationships to the represented reality) but nonsystemic in nature and thus, in the deepest sense of the term, nonlinguistic? While Washoe (Gardner and 
Gardner 1969) for instance, at best learnt strings of lexical items, Sarah learnt to understand strings of lexically referential and relational terms. However, human language has the property that lexical and relational items not only convey what is said but also what is not said. Cognitive development seems, inter alia, to involve the gradual organization of language into systemic groups such that any lexical item used conveys simultaneously the nonuse of other items in the same systemic subsystem. But unlike the human child, the chimpanzee does not appear to go further and spontaneously work on the procedures to reorganize them into systemic groupings (1983, p. 150).

As Karmiloff-Smith concludes her book, Beyond Modularity, chimpanzees - with whom we share more than $98 \%$ of our genetic makeup - do not, as human children do, play with knowledge, the way they play with physical objects or conspecifics (1992, p. 191).

The broader reach of the developmental psychology perspective - and possibly, the less defensive posture taken by its proponents - places them in a position to elaborate upon those aspects of human cognition that are special as well as to make informed claims regarding the capacities of other species based upon comparative data. Barbara King is notably reticent about referring to the internal representational skills of the monkeys and apes she studies. She sticks firmly to the view that knowledge is best understood not in representational terms but in terms of social interaction, and grants that "testing hypotheses to prove or disprove whether and how non-human primates store information is "beyond the scope of her research" (King, 1999, p. 43). While this is not to say that she is unwilling to absorb information acquired from outside points of view, so far she has not.

Therefore, one might conclude that King lays excessive stress on experience and social learning in interpreting her observations of primates. Conceding some role to innate factors, she nevertheless, never addresses them. King is therefore not well positioned to appreciate Karmiloff-Smith's discovery of the human facility for RR, a domain-general capacity for which 
monkeys and apes show not the least potential. ${ }^{69}$ The main linguistic ability she does concede is that humans, not apes, are capable of complex narratives that refer to the past and the future, not only the present, but she emphasizes this is a difference in degree not in kind (2002).

Karmiloff-Smith's observation that humans, as apart from monkeys and apes also, "go beyond successful behavior and exploit the linguistic knowledge they have stored" (1992, p. 32), may be a difference of a different sort that King ought consider.

On the other hand, King might very well be disposed to accept Karmiloff-Smith's contention that "human language is 'new' in evolutionary terms only in that it makes novel uses of old capacities." Such capacities," Karmiloff-Smith says, “are described as old because they are the result of gradual evolutionary adaptation and have their roots in our common ancestry with other primates. The specialized, localized circuits for language found in the adult human brain are therefore not seen as innate, but as emerging from the brain's interaction with the linguistic environment during development. From this stance, language does indeed become a specialized function of the human brain, but it does not start out that way" (2001, p. 221). This possibility, which denies the language faculty and accepts evolutionary continuity, still manages to negotiate a place for that which is special about humans locating that quality in the processes of development, i.e., processes that account for changes in the human brain over time. This is a point King could never get at, not only because her focus is not on humans per se, but because she tends to equate developmental flexibility with social learning only.

Yet, the former does not necessarily entail the latter at all. Development also involves species-specific neurological changes that are not learned (Karmiloff-Smith, 1992). So for Karmiloff-Smith what is truly special about the human brain is the neurocomputational

\footnotetext{
${ }^{69}$ It is generally assumed that where there is no demonstration of a capacity, there $i s$ no capacity or supporting structure, (Premack, 1980, p. 181).
} 
properties it possesses so well-suited to processing the rapidly spoken sequences of language (Karmiloff-Smith, 2001, p. 222). Again, this point would likely remain hidden from King's view since biological anthropologists are not going to find useful (since their subjects do not acquire speech) many of the new experimental paradigms that developmental psychologists now have available for studying language acquisition, which enables them to go beyond purely observational research and chart brain activity (Karmiloff-Smith, 2001, Ch. 2). Nevertheless, having this knowledge can only positively impact, i.e., render more objective, their own experimental and observational data. Interestingly, evolutionary psychology's emphasis on the speed of the brain's processing powers turns out to be a feature of some consequence after all but not one spurred on by, or directly associated with, the stresses and strains our ancestors faced living under the harsh conditions of the Pleistocene.

Karmiloff-Smith is also poised to make observations about the capacities of primates that go beyond the ones that King is in a position to make. She does not shy away, for instance, from speaking about the representational abilities of nonhuman primates. Taking children as her main subject of study, Karmiloff-Smith has a basis upon which to draw analogies between the abilities of young children and primates who demonstrate comparable abilities. Karmiloff-Smith points out that research indicates nonhuman primates are able to make and perceive distinctions in their communicative calls. This means that the acoustical ability to process sounds rapidly even when they vary in duration, interval, order, stress and pitch is not exclusive to humans. Therefore Karmiloff-Smith concludes that Rhesus monkeys, who appear proficient at discriminating different food calls, probably "have developed internal representations of the different types of food and have categorized these according to acoustic differences in the associated calls" (2001, p. 213). 
Relative to the empirical linguists, (who never mention Jean Piaget though his views are echoed throughout their work) the developmental perspective of psychologists like Piaget's protege, Karmiloff-Smith, add the depth that is missing. Like Piaget, Lakoff and Johnson maintain that language is not an independently developing capacity at all but the product of the general structural organization of sensorimotor intelligence. In other words Language makes use of general cognitive capacities. Accordingly, on Lakoff and Johnson's view, linguistic categories reduce to cognitive categories just as they do for Piaget (Lakoff, 1987, p. 57;

Karmiloff-Smith, 1992, p. 35). Lakoff and Johnson stress that whether language is governed by a separate mechanism or not is a particularly important question since it reflects on the cognitive architecture of the human mind. They reject the modularity view and emphasize the interrelation of perception and conception. Like Piaget, Lakoff and Johnson see syntax and semantics as deriving from 'embodied' sensorimotor and conceptual capacities (Piaget, 1955; Karmioff-Smith, p. 35; Lakoff and Johnson, 1999, p. 479).

But while Lakoff and Johnson provide a highly interactionist view of human cognition, it is a view that generalizes over and misses the developmental process itself as a crucial feature of embodied being-in-the world interactions. One of the ways in which a developmental perspective adds depth to Lakoff and Johnson's linguistic one is the improvement it allows in their interpretation of how image-schemas function in cognition. For both sets of thinkers image schemas are non-propositional conceptual structures that shape thinking. Developmentalists show that these schemas operate between language and perception, thereby facilitating semantic development. They describe image schemas as emerging through a process that starts with perceptual primitives that later become redescribed into these schemas, and then later into language. Karmiloff-Smith takes this process of redescription one step further through her 
introduction of RR - a concept Lakoff and Johnson could never have arrived at either since it involves understanding a piece of knowledge as domain-bound first before it becomes available for redescription to the rest of the mind.

It is worth noting, though, that the nuances of Karmiloff-Smith's view of linguistic development are ones which Lakoff and Johnson are predisposed to reject. For they take the position that image schemas are the perceptual primitives and that they cannot be further broken down. Lakoff and Johnson cite recent neural modeling research to support their claim that the very same mechanisms responsible for perception and human sensorimotor abilities could be responsible for the conceptualization involved in language acquisition (Lakoff and Johnson, 1999, p. 38). In fact, this was precisely Piaget's view.

But Piaget's view is being challenged in the light of a growing literature on infant development that shows representational competency emerging earlier than he thought. Piaget considered the infant's ability to form concepts as a higher order form of representation dependent upon developments occurring in the sensorimotor stage - the sensorimotor stage being the earliest stage in the development of cognition. In the sensormotor stage, it was understood that infants lacked the wherewithal to access any representational knowledge for recall or thinking. The developmental psychologist, Jean Mandler now finds to the contrary, that infants are capable of symbolic activity and representational recall very early on. Mandler believes this calls for a change in our understanding of the foundations of a symbolic or representational system in humans. She argues specifically that "an accessible conceptual system develops simultaneously and in parallel with the sensorimotor system with neither system being derivative from the other" $(1988$, p. 113) She proposes that infants are capable of processes of 'perceptual analysis' - the name she gives to the mechanism that enables infants to 
encode information into an accessible system. Lakoff and Johnson overlook details of this sort. Nonetheless, details of this sort bear decisively upon the structure of the human cognitive architecture, which they are concerned to discover.

Lakoff and Johnson also link modularity theory (which they regard as faculty psychology incarnate) to our cognitive unconscious. Doing so enables them to say that modularity thinking is not only a part of the Western mythos; it's a part of the human logos. They claim it is a way of thinking about cognition instantiated neurally in our brains. Lakoff and Johnson believe that we cannot help but think that the mind is composed as modularity theorists suggest (1999, esp. 414). This sort of reasoning can be turned around, however. Tim Ingold, for instance, has criticized the Container Metaphor so basic to Lakoff and Johnson's account for precluding ontogenetic development. Simply put, the container metaphor leaves no room for growth (Ingold, 1998).

Can it be that this metaphor intrudes on Lakoff and Johnson's analysis causing them to treat the mind in complete and bounded terms that is at the root of their failure to take development seriously? We all get thrust into the world and come out with understandings in common. The role of the environment is highly general and abstract. It is as if they substituted the 'Mind as Container' metaphor on which they claim their opponents rely, with the 'World as Container' Metaphor. While this metaphor highlights our universal experiences it hides the fact that developing organisms have unique experiential histories that leaves room for individual as well as cultural variability in their embodied understandings.

What Karmiloff-Smith would point out to them, though, in something of an objectivity check (i.e., presenting to them data that they miss) is that "domain-specificity seems to win out over domain-generality in the early development of language acquisition" (Karmiloff-Smith, 1992, p. 35). She would point out that their stance, like the Piagetian, predicts that linguistic 
retardation should accompany severe cognitive retardation, however, it often does not. Studies show that children with hydrocephaly and spina bifida, as well as Williams Syndrome, demonstrate severe cognitive impairments while language ability remains intact (Karmiloff-Smith, 1992, p. 35). And while it is not an element of Lakoff and Johnson's view that infants' start out as purely sensorimotor organisms who lack the capacity to form concepts accessible for thinking until they reach a certain stage in their development (at which time they are able to transform their motor and perceptual schemas into symbolic concepts $)^{70}$ it is nevertheless relevant to their view that the data indicate overwhelmingly "that infants process linguistic data in linguistically constrained ways." These constraints or "attention biases serve to build up linguistically relevant representations, not solely domain-general sensorimotor ones" (Karmiloff-Smith, 2001, pgs. 34-35).

Further, since they give short shrift to development, Lakoff and Johnson overlook the importance of explaining conceptual change and even suggest, were it to occur, it would be slight and partial (1999, p. 18). The topic of conceptual change leads to contemplation of crucial issues for cognitive development and cognitive anthropology, such as, the question of whether cognitive development in all cultures requires conceptual change and how far these developments take the culture from the conceptual systems they were born with as children. These problems suggest the question of whether it is possible that epigenetic conceptual development is responsible for cognitive incommensurability among cultures (Carey and Spelke, 1994, p. 194). In their failure to take account of development, Lakoff and Johnson merely posit with a minimum of empirical support the universality of the metaphors we live by as a

\footnotetext{
${ }^{70}$ While Rosch, whom Lakoff cites, has done some work in the area of child development, Lakoff and Johnson never mention development in Philosophy in the Flesh or Metaphors We Live By (1980), and Lakoff only does so briefly in Women, Fire and Dangerous Things (1987). In the latter book, Lakoff states that children master basic level categories by the age of three, but that earlier on the categories mastered are different from adult categories (pgs. 49-50).
} 
consequence of people's common subjective experiences. And what we are born with, in a somewhat static fashion, remains.

More interesting still is that research indicates pronouns like 'you' and 'I' are not extensions of gestures or non-linguistic pointing. If these pronouns were extensions of gesture that would constitute support for the idea that sensorimotor action is a basis for the domaingeneral acquisition of language. As it turns out, though, data show that the child's acquisition of personal pronouns is an integral part of domain-specific language development (Karmiloff-Smith, 2001, p. 39). This finding reflects adversely on the biological anthropologists' hypothesis that orderly gesturing in apes is a precursor to human syntactical ability. For the data undermine the domain-general link in humans between the (cognizance of the) sign and its referent that this evolutionary scenario relies upon.

Notably, there is no cross-referencing between Lakoff and Johnson and Karmiloff-Smith. The closest Lakoff and Johnson come to sharing common ground with Karmiloff-Smith is through their mutual reference to research once removed, to Jean Mandler's work on conceptual primitives. Karmiloff-Smith cites Mandler directly; Lakoff and Johnson acknowledge that work through their primary reference to Eleanor Rosch's studies.

I would add, however, as a final point, that missing from all of these perspectives, and evolutionary psychology too, is any acknowledgement that the creative imagination of humans is tied to feeling and that feeling has a crucial role to play in shaping human mentality. Across the board, feeling is treated merely clinically or instrumentally in a practical/cognitive sense. For evolutionary psychologists, emotion serves the evolution-derived purpose of helping organisms prioritize their goals. For them, imagination is not the best place from which to start to get a handle on human cognition. The ratiocination that lies behind the social deconstruction of 
another's motives is evolutionary psychology's preferred place to begin theorizing. For the empirical linguists humans think and categorize the way they do - for the most part an unconscious and automatic process - because of the way human bodies interact with the world at a neural level. Theirs is a theory of imagery and bodily experience essentially devoid of feeling. Indeed, one of our most basic-level categories, according to the empirical linguists, is the very sterile albeit functional Container Schema. This schema grounds our understanding of 'in' and 'out.'

For Karmiloff-Smith, too, emotion simply does not factor in, in any central way, to an understanding of cognition. Not even biological anthropologists in line with Barbara King could generate the insight put forward by the philosopher Suzanne Langer that what distinguishes humans from other animals "is a great increase in emotionality, which entails a corresponding increase of perceptive functions, not necessarily by virtue of better receptive organs, but of increasing values imposed on what anciently developed senses convey" (1967, p. 213). King is too preoccupied with elevating the social abilities of monkeys and apes, and of trying to spot precursors to human functions to ground their similarity to be attuned to how the higher primates differ from humans.

King never even describes monkeys and apes in terms of instincts. Her language is that of co-constructed knowledge, culture and social interaction. Consequently, she cannot see that "without a true appreciation of the richness and completeness of life built on instinctive action, and of the heights to which discriminate sensibility and emotional reaction can rise on that foundation, one cannot recognize the critical point where an overcharged system of mental operations breaks over into imagery and symbolic conception, and the great shift from animal mentality to mind begins" (Langer, 1967, p. 213). Karmiloff-Smith comes closest to getting the 
pattern down since she sees human language as an ability that makes new use of old ancestral capacities.

\section{CHAPTER 6. CONCLUSION: EXPANDING PERSPECTIVE}

The sociologist Ullica Segerstrale has written a complete and authoritative account of the sociobiology debate up to the year 2000. Segerstrale had the privilege not only of interviewing the key players; she was present at crucial meetings and conferences - a "witness to the beginning and evolution" of the conflict (Preface, 2000, p. vii). Her work, Defenders of the Truth (2000), was composed with the insight that comes from participating in events as they unfolded and from the considerable knowledge that hindsight brings. By contrast, evolutionary psychology represents science still in the making at its incipient stage.

Given its recent beginnings, only a forward-looking analysis of evolutionary psychology is possible but such an analysis need not be a drawback. Indeed, during the original development of a theory, we are inclined to be more wary and critical of the new ideas we are asked to believe than when we are considering established science. ${ }^{71}$ Methodology is more likely to be scrutinized; scientists should not be surprised when (even) the lay-person digs up references and exposes empirical shortcomings: "A pinch of ethnographic evidence, a tablespoon of generalizations from the contemporary scene, many assumptions about our savanna-loving ancestors, and large chunks of psychological surmise - served up with the certitude of a scientist. But let the buyer beware: when you pick apart the ingredients you discover they are not what Pinker says they are" (Ferguson, 1998). With this remark the journalist Andrew Ferguson launches his critique of the single study Steven Pinker produces, conducted by Martin Daly and Margo Wilson, to support the claim that neonaticide "has been practiced and accepted in most

\footnotetext{
${ }^{71}$ See also Geoffrey Sampson's discussion of this issue in Educating Eve 1999, pages 11-14. Sampson disagrees with me about the scrutiny being paid to evolutionary psychology. He feels its popularity and Chomskyian heritage both work against the reader's inclination to scrutinize it closely.
} 
cultures throughout history." By contrast, the conclusions of established science are often remembered at the expense of their empirical warrant, flimsy or not.

Segerstrale's insight was that the scientists involved in the sociobiology controversy all perceived themselves as defenders of the truth with a capital ' $\mathrm{T}$ ' - the problem being they had different conceptions of where the truth lies. The STS insight I seek to bring forward relative to the debate over evolutionary psychology concerns objectivity. It is that objectivity with a lower case ' $\mathrm{o}$ ' is best achieved by expanding consideration to all the scientific viewpoints bearing on the field of problems at issue. I have tried to show this by illuminating the benefits evolutionary psychology gleans about its own knowledge from these other viewpoints.

I think it's important that the many different approaches to thinking about cognition be acknowledged and that a workable view that attends to all the diverse evidence be allowed to emerge, a synthetic view that combines the best parts of all these fields of knowledge. This is not to argue for the unity of knowledge or 'consilience' as E.O. Wilson understands it, ${ }^{72}$ but rather to suggest the fruitfulness of agreement on certain core claims (and model notions) and that the effort to nail down these claims (and notions) is a smart preliminary move requisite to the productive pursuit of more particular interests. ${ }^{73}$ In the latter case vital connections may simply prove less extensive. In the former case, causally linking the various disciplines is not the aim, though taking into account the ways diverse bodies of knowledge relate to and reinforce one another (or call for mutual readjustments) surely is. To advance this end the Habermasian

\footnotetext{
${ }^{72}$ For E.O. Wilson 'consilience' refers a casual linking of facts into one explanatory scheme (Consilience: The Unity of Knowledge,1998). This is not the meaning which William Whewell first gave the term in his Novum Organon Renovatum (London 1858). For Whewell consilience takes place "when an Induction, obtained from one class of facts, coincides with an Induction from another different class" (pgs. 138-139 in William Whewell: Theory of Scientific Method edited by Robert E. Butts (1968).

${ }^{73}$ Similar to Hardcastle (1993). She concludes her paper, "Evolutionary Epistemology as an Overlapping, Interlevel Theory" with the claim that although "we have no reason to expect that the different domains will ultimately fuse into one; each could retain its autonomy as they address a set of central concerns, linked instead by a fuzzy set of entity attributes and certain core assumptions" (emphasis added, p. 189). Autonomy is clearly requisite for equality of intellectual authority.
} 
condition of equality of intellectual authority described by the philosopher Helen Longino (1990) must be realized. At the present time, this condition is not being met.

The controversy sparked by sociobiology erupted on the field of evolutionary biology and the quarreling parties were mainly evolutionary biologists (Segerstrale, 2000, p. 3). The advent of evolutionary psychology (and its incarnation as a hybrid field) has resulted in laying bare the social sciences as new terrain for carrying on the battle. Whereas sociobiology's imperialistic intention with respect to the social sciences was among its most glaring features at its inception, its impact was only felt in the general form of a genetic determinism deemed prima facie objectionable by the disciplines through which this repercussion reverberated.

The social sciences remained insulated; testimony to this is reflected by reports that as late as 1994 there still existed experts in psychology unaware of the relevance of Darwin's ideas to their work (Crawford and Krebs, 1998, p. 485) ${ }^{74}$ One of evolutionary psychology's notable accomplishments has been the infusion of evolutionary perspective into the methodology of the social sciences. Its impact on the social sciences must now be reconsidered. As Darwin envisioned psychology being laid on a new foundation (1859/1964, p. 488), one hundred and fifty years later, evolutionary psychology claims to have discovered its composition. Not everyone is convinced that the newly laid groundwork is the genuine article, however.

Biological anthropologists, empirical linguists, and developmental psychologists have made significant advances in their thinking on the evolution of cognition. Their research represents alternative points of entry into, and interaction with, evolutionary theory. While their contributions have been marginalized, at this early stage it is not too late to attend to their work, and integrate their discoveries as the previous chapters have shown. It is in their critical edge, not in their confirming ability, in their differences from, not their similarities to, evolutionary

\footnotetext{
${ }^{74}$ Noted as the personal communication of another psychologist to Crawford, April 11, 1994.
} 
psychology that these researchers have something to contribute to evolutionary psychology. In Foucauldian terms, it may be the case that the discourse of evolutionary psychology was born of its exclusivity; its distancing itself academically from knowledge-makers in competing fields (inasmuch as newly constructed discourses, which hide subtle relations of power, operate through institutional practices of exclusion, not inclusion (Foucault, 1977, p. 101)).

But there is another side to the picture. The other side shows that power/knowledge, so constructed, is isolating. Power/knowledge built on relations that lack reciprocity dam communication channels. This leads to weakness, not strength. In order to prevail, resistance to new knowledge becomes necessary. Thus, evolutionary psychology has been criticized for neglecting findings even in evolutionary biology. According to Leland and Brown, "the fact that few evolutionary psychology studies refer to the findings of modern evolutionary biology reinforces the suspicion that evolutionary psychology has become detached from recent developments in evolutionary thinking" (2002, p. 187).

To flourish evolutionary psychology must demonstrate a willingness to engage other researchers on equal terms. Hence, the idea I have been guided by is a cardinal one in science studies. Science is a process. How science is practiced, and, in particular, whose voices are heard, influences crucially the scientific products and theories that emerge. Add to this the fact that scientific debates aired in the public forum have profound societal effects - legally, morally and politically - and the importance of guarding against miscarriages in its results is underscored. The issues of abortion, birth control, sexual discrimination and homosexuality all invite a Darwinian analysis. Evolutionary psychologists must be held accountable as attorneys, judges, 
and policy officials take an interest in their theory. ${ }^{75}$ Effectively, Joseph Rouse's question:

“About whom and past whom do they speak?” justifies this project (Rouse, 1996, p. 247).

Interdisciplinary Objectivity

In light of the above, I advance a view of objectivity delimited to disciplinary interrelations, as follows: I maintain that interdisciplinary objectivity is a feature of the (e)quality of research relations and not a feature of the standard to which the practitioners of some fields subscribe to justify their competing claims to authority vis-à-vis one another. Interdisciplinary objectivity is expressed in the nature of the involvement of a field's practitioners with practitioners in other fields, their motivation to facilitate global interconnections between theories, and their proclivity to attend to data provided by external fields concealed from their own perspective. Interdisciplinary objectivity is exhibited in researchers' receptivity to exploring where those data belongs in the overall field of constructed knowledge (a messy hodgepodge of claims which aims at common causes and explanations). Interdisciplinary objectivity is not a standard of authority but a relation among authorities. It's about practices of engagement, not terms for disengagement.

This adjusts the modernist view of academic disciplines and disciplinary relations to the postmodern realities of interdisciplinarity. The modernist view supposed that sharp and institutionally well-defined disciplinary boundaries existed and should be respected. Practitioners in disparate fields laid claim to authoritative jurisdiction over their particular areas of competence and agreed not to tread on the competencies of practitioners in other fields. Thomas Kuhn described the modern academic situation when he commented that unless practitioners share a paradigm they rarely investigate the same problems (1962, p. 161). This is

\footnotetext{
${ }^{75}$ Lionel Tiger, an anthropologist at Rutgers, says he knows of at least one Supreme Court justice and several Pentagon officials interested in applying evolutionary psychology in their professional work. See John Horgan's article (1995) “The New Social Darwinists,” Scientific American, Vol. 273, pgs. 150-157.
} 
no longer the case. Sharing problems is now the rule rather than the exception. Disciplinary relationships are taking shape among practitioners whose interests were formerly viewed as unrelated. As social conditions change, so too do conditions for the validation of knowledge. Whereas, objectivity first depended upon the individual and his resourcefulness as an impartial spectator, ${ }^{76}$ then on the claims of the (well-defined) discipline and prerogatives of the expert, objectivity now depends upon (fuzzy) disciplines and what outside experts have to say about the connections they can make to a researcher's work.

Interdisciplinary engagements facilitated through boundary-crossings are inevitable and desirable as well as the norm. A new sense of objectivity that paves the way for knowledge-production by eschewing the hegemony of any one field (without denying centrality of subject matter) and promoting effective communication among all fields is in order. This means precisely that the rhetoric of partisan practitioners asserting issues closed when they are not, findings factual when they are not, deflecting focus away from areas of potentially productive research, or forcing focus upon research that blocks such efforts, obstructs objectivity by submerging latent knowledge from full view.

Evolutionary psychology's exponents are more or less guilty on all these counts. They have dismissed comparative data from biological anthropology by fiat; they have embraced a gene-centered discourse displacing a roomier developmental one; they have affirmed the mind's hard-wired modularity against the evidence from neurobiology; and they have promoted a research program, i.e., that of describing the mind's many modules, based upon all these unwarranted claims.

\footnotetext{
${ }^{76}$ In this instance, gender-neutral phrasing would be inaccurate, since the impartial spectator of the Western intellectual tradition was male.
} 
The pressures to obstruct as well as facilitate objectivity both come with the academic territory. Both ought therefore be acknowledged. Objectivity is obstructed, in the most injurious way when, as the primatologist, Sue Savage-Rumbaugh put it: "indoctrination into the halls of Science imposes upon what it is that one is permitted to do in the name of research" (1999, p. 115). Objectivity is compromised when researchers affirm the belief that if "biologists had known Baldwin was a psychologist, they wouldn't even have read him!" (Piaget in Interview with Voneche, 1982, p. 84) It is manifest in the confession: "There is some truth in Lamarck, but one cannot say so in public" (Piaget in Interview with Voneche, 1982, p. 84).

In the present case, the biological anthropologists feel the pressure most strongly to discontinue their contributory research as evolutionary psychologists assert the demand for their withdrawal. Hence, in the anthropological literature we find such titles as "The Expulsion of Primates from the Garden of Eden" (King and Shanker, 1997), and "The Anthropomorphic and the Skeptical" (Taylor, 1994). In the latter essay its author, the anthropologist Talbott Taylor, describes the prejudicial systems of measurement utilized to compare human and nonhuman primate forms of communication. The substance of the former essay is all too self-explanatory. When made ancillary to evolutionary psychology, however, biological anthropology's freedom to extend knowledge is inhibited. In this respect, the knowledge-extension mission of science must be accorded priority over pursuit of theoretical truth for it plays the preeminent role in facilitating objectivity. It undergirds the equality of researchers. Moreover, theoretical truth is more likely to get lost when disciplines are disengaged from one another than when they are not. Theoretical truth is sturdy yet it is best thought as capable of morphing (just as we are) in response to changing conditions and disciplinary relations. Even the stalemate created between evolutionary psychology and Lakoff and Johnson on the Universal Grammar (as opposed to a 
more empirically infused semantic view of language) keeps the pressure on practitioners to continue their exchange of ideas to settle the matter.

Engagement may also point to alternative productive avenues of investigation as in the present case with neurobiological research. Absent such engagement resolution by alternative means would not necessarily be taken even if foreseen. For, as we have seen, while evolutionary psychologists have always admitted the importance of neuroscience to their view as to any other (striking a main alliance with its practitioners), they have not admitted its direct bearing in either confirming or refuting their view. This is surely consequential.

Interdisciplinary objectivity is obstructed by misguided research programs most of all. The tell-tale sign that a program is on the wrong track is disengagement, i.e., its practitioners' inward turn. Therefore when Karmiloff-Smith points out that decades of research were wasted in developmental psychology when psychologists focused "entirely on lowering the age at which children could perform a task successfully, without concern for how they processed information" (Karmiloff-Smith, 1992, p. 28), I would say objectivity was obstructed. The withdrawal of developmental psychologists from the more fundamental inquiry in this manner (and hence from more significant tasks) disrupted their relation with other fields by depreciating what they had to offer. Karmiloff-Smith's research, by contrast, engages all the cognate fields.

Anthropology's relationship with ethnography in the 1980s is another case in point. According to one of its most vocal practitioners, Tim Ingold, social anthropology professors wasted considerable effort teaching students how to get into ethnography while failing to provide the theoretical means that would teach them how to get out of it. Social anthropology transformed itself into the study of the conditions of its own inquiry, it folded in upon its own resources, becoming "esoteric" and "self-indulgent," "shielding itself from contact and dialogue 
with other disciplines in the human sciences" and thus "foreclosing upon all hopes of constructive dialogue, of mutual understanding and effective synthesis" (1985, pgs. 15-16).

Yet, engagement of this sort is precisely what social anthropology's role is, according to Ingold, relating, translating and facilitating "the concepts and insights of historians and sociologists to those of biologists and psychologists and vice versa..." One of the consequences of having deserted their traditionally defined role, he rages on, "is that social anthropologists have left a vacuum that the more bigoted practitioners of other disciplines are only too eager to fill, projecting their partial and lop-sided views of man as though they embraced all that there is of human existence. Nothing demonstrates this more clearly," Ingold declares, "than the predatory expansion of human sociobiology, and the conspicuous failure of anthropology to come up with an effective response to the challenge it presents" (Ingold, 1985, pgs. 15-16). As far as Ingold is concerned, anthropology's turn inward caused it to miss the opportunity to apply needed pressure and resistance to outside practitioners resulting in the creation of a major fissure in the structure of knowledge.

Philosophy is also familiar with this situation. The analytic approach fathered by Ludwig Wittgenstein in Philosophical Investigations $(1953)^{77}$ was originally valued for exposing the sometimes bewitching affects of ordinary language (under whose spell Wittgenstein claimed the philosophers had fallen). This new philosophical approach devolved into the tedious and often trivial analysis of concepts like time, space, and causality in the hands of lesser scholars of the so-called ordinary language philosophical school, though these analyses were intended to have wide interest, particularly to scientists. The analyses were supposed to show how the concepts employed in everyday (and esoteric) language games were misused. Analytic philosophers hoped to dissolve the problems of philosophy while they professionalized their discipline

\footnotetext{
${ }^{77}$ Published posthumously.
} 
through application of sophisticated and well-developed logical techniques (Lavine, 1984, pgs. 405-411).

However, they succeeded at neither goal very well. As philosophy became insulated, its objectivity, I would submit, diminished in measure. Indeed, as a consequence of philosophy's calculated withdrawal from its time-honored subjects, ethical study (long regarded a staple philosophical issue hand in hand with metaphysics) became the subject proper of sociobiology in the same way as anthropology's musings had about what makes us human.

The new discipline of evolutionary psychology, because it has adopted a misguided program resting on mistaken assumptions, provides another instance of a discipline whose practitioners are becoming increasingly insulated from other disciplines. Evolutionary psychologists may even be ceding to practitioners in other fields valuable matters of disciplinary concern in the process, matters upon which their own clear voice is needed.

Modernity ${ }^{78}$ faced a parallel situation of disequilibrium with respect to the relation of academic subdisciplines. Objectivity was facilitated in modernist times when vigilant biologists rediscovered Mendelism and built new theories of heredity and population genetics on Mendelian principles, thereby solving Darwin's problems over the nature of heredity bringing about the Neo-Darwinian synthesis. At the same time, though, the objectivity achieved was incomplete, since many subdisciplines of biology, including embryology, ecology and

\footnotetext{
${ }^{78}$ At the dawn of modernity, when there were polymaths, and science had yet to be separated off from philosophy we might say objectivity was facilitated when the great astronomer Edmond Halley presented Isaac Newton with the problem of proving the mathematics behind the inverse square law, which it turns out, Newton had proved mathematically some twenty years earlier. Newton had set aside the problem because he couldn't quite get the mathematics to fit. The papers he needed for precise calculations were at Cambridge University at the time; however, he had been banished from the university due to an outbreak of the plague and so could not retrieve the information he needed. At Halley's urging in the1680s, Newton searched to produce those papers and with the right figures in place, the precise calculations could be made, and the mathematics was shown to work out. According to the historian of science Charles Coulston Gillispie, Newton had some difficulty locating the old papers. "While others were looking for the law of gravity, Newton had lost it" (The Edge of Objectivity, 1960, p. 137). My point is that Haley's actions here, just as much as Newton's facilitated objectivity.
} 
microbiology were not included in the synthesis. These subdisciplines were dealing with

problems and methodologies that could not be handily integrated so their proper relationship to

the other subfields was unclear. Scholars recognize today that an exacting price was paid for the barriers erected among these subdisciplines (Burian, 2000). Objectivity comes in degrees. Today these subdisciplines seek integration.

Looking back, we also find that in the 1960s when the synthetic theory was at the zenith of its popularity, "the theory became so powerful that critics outside science accused biologists of setting up a dogmatic orthodoxy that stifled dissent" (Bowler, 1988, p. 130). Once achieved, interdisciplinary objectivity is capable of degenerating quickly and producing a backlash. Knowledge is always in flux. And it is in flux for a variety of reasons. While disciplinary disunity is the ever-present state or condition of our knowledge, connectedness and not disunity is the regulative ideal. ${ }^{79}$ But the sought after connections need to bubble up from the ground around issues that meet the specific concerns of ad hoc alliances of practitioners and not be legislated from on high by some transdisciplinary perspective or other, especially if interest in these connections is to last long enough for their implications to be fully exploited.

\footnotetext{
${ }^{79} \mathrm{My}$ intention is not to invoke the metaphor of theory or knowledge as the result of successfully fitting together the pieces in a puzzle whose image is presumed to correspond to something 'out there' a la realism. Richard Rorty has taken this metaphor to task, (See his "The Contingency of Language," Contingency, Irony and Solidarity, 1989, Cambridge University Press, pgs. 3-22.) While I am not a constructivist in the extreme sense of Rorty, I think the metaphor still has some applicability so long as we understand the puzzle pieces are not pre-fabricated pieces but cut out and shaped along the way in an ad hoc fashion, re-cut and reshaped when need be, or scrapped altogether - none of which taints the (always partial) image of the 'truth' imparted by the puzzle at any particular time.

Notably, Rorty believes that when knowledge and truth are understood to result from fittingness in the sense just qualified then certain kinds of questions become important; specifically, the kinds of questions philosophers have been asking for 2500 years. If Rorty had his way, however, we would inquire into these questions no longer. One of the questions to which Rorty refers is central to evolutionary psychology, namely, "What is the relation of language to thought?" What Rorty does not allow for is the wholly viable possibility that one of the ways we may search for answers (i.e., knowledge) to these questions just is by changing the way we talk about them (i.e., the metaphors we use). Rorty appears to believe that changing the way we talk is ipso facto to put these questions down.

Other questions Rorty disavows include: "What is the place of intentionality in a world of causation?" "What is the place of consciousness in a world of molecules?" I think that for someone preeminently concerned to keep the 'philosophical' conversation going (an objectionably elitist conversation from which many social groups have been excluded in any event) Rorty radically undercuts our means for doing so by taking away the very questions that have kept the conversation going for all this time. Quid pro quo, Rorty would find little of interest in evolutionary psychology.
} 
The problems modernists faced internally (i.e., the integration of their subdisciplines), postmodernists now face externally (i.e., the overall integration of disciplines). Even evolutionary psychology stands as an example of a new field that did not participate in the original Darwinian synthesis that seeks integration now. Biological anthropologists, empirical linguists and developmental psychologists make similar claims. These claims are not without consequence. The paleontologist Stephen Jay Gould is particularly familiar with the tumult associated with advancing interdisciplinary objectivity in that his own efforts, which culminated in the theory of punctuated equilibrium (Eldredge and Gould, 1972), recommended a restructuring of the entrenched relations that existed among researchers (i.e., that paleontology be ceded its rightful place alongside evolutionary biology). While many evolutionary biologists are sympathetic to Gould's idea of punctuated equilibrium for evidential reasons and external fields have praised Gould's theoretical contribution to neo-Darwinism, e.g., Barbara King in anthropology (2002), the empirical linguists Francisco Varela, Evan Thompson and Eleanor Rosch in cognitive science, ${ }^{80}$ many evolutionary biologists also downplay, if not overtly resist the theory, especially those sympathetic with evolutionary psychology, e.g., Richard Dawkins.

Nevertheless, Gould's discovery has helped shake up disciplinary relations enough to promote the formation of new configurations of researchers in outlying fields and these new relations have given rise to the formation of new and interesting perspectives, e.g., embodied cognitive science, for one, and the use of punctuated equilibrium as a heuristic for advancing analogical arguments from biological to sociological systems, for another. These new perspectives have, through integrating Gould's findings, encouraged the investigation of

\footnotetext{
${ }^{80}$ Varela, Thompson and Rosch see the genomic wholeness implied by drastic discontinuities found in the fossil record as further support for their notion of evolution as natural drift. They put forward evolution as natural drift to counter adaptationism. Natural drift emphasizes persistence of genetic traits as opposed to the optimal adaptation of traits (Embodied Mind, 1991).
} 
potentially fruitful lines of inquiry where new "inferential habits" (to borrow Susan Oyama's apt choice of words (1985, p. 154)) can be tried out and tested.

By cutting itself off from other sources of knowledge, evolutionary psychology runs the risk of being left out of reorganized partnerships, such as those just described, its popularity in the public domain notwithstanding. While they wish to take the lead in, and set the terms for, one grand evolutionary synthesis, their wishing will not preclude practitioners in other fields from forging vital connections without them anyway, and indeed, in taking what they need from evolutionary psychology to leave the rest remaining. Isolation is no different in the academy than anywhere else. Atomized fields and practitioners, like atomized political people cannot make their interests felt or claims acknowledged when they have no effective groupings to work through. This holds even when they have theoretical truth on their side. For theoretical truth relies on alliances.

One thing that follows from my view is that the more knowledge we have the greater the possibility that objectivity will elude us; hence, the greater the need for effective disciplinary and interdisciplinary communication and criticism. Without a doubt, it means that we may not always know prospectively whether our efforts at disciplinary objectivity will prove to be auspicious. The phenomenon of 'objectivity luck' inheres as much in the practice of science as 'moral luck ${ }^{\text {}}$ inheres in moral activity. Only the clashes produced by the situatedness of our findings in the field of overall data indicate we are close. These clashes instantiate the connection our findings have with data prized by other research communities. They resemble the clashes with reality about which Karl Popper speaks, clashes that occur when novel predictions extend reality beyond the scope of our formerly limited perspective.

${ }^{81}$ See Bernard Williams work, Ethics and the Limits of Philosophy, (1986) for further elucidation of this term. 
On the up side the sense of interdisciplinary objectivity I invoke reveals a tight connection between objectivity and creativity. As we have seen, the developmental psychologist Annette Karmiloff-Smith has proposed that creativity is a function of 'representational redescription,' the process whereby knowledge in the mind is re-presented as knowledge to the mind (1994). Not altogether obvious connections within and between domain-specific areas of cognition then become possible. Analogously, my suggestion is that interdisciplinary objectivity occurs when knowledge in a discipline is re-presented to other disciplines (or sub-disciplines) and vital connections are forged between specific knowledge-domains. Objectivity and creativity can thus be viewed as parallel processes that go on at different levels. When the process is internal and introspective, when individuals re-present to their own minds knowledge they already have, then creativity is occurring. ${ }^{82}$ When the process is social and in full public view, when individuals (or groups of individuals in research communities) re-present to other individuals or research communities submerged issues and new knowledge, then objectivity is occurring.

One of the consequences of the approach to objectivity I have described is that it implies, pace evolutionary psychology, that a principal reason we 'fail' to solve philosophical problems is that our so-called inability is testimony to our remarkable 'ability' to re-present and re-describe those problems and our answers to those problems in a multiplicity of ways. The indeterminacy of our philosophical reflections, in other words, is not to be attributed to the acclimation of our minds to Pleistocene conditions and hence, to solving survival problems only. Rather, it is the essence of this reflective process that it be repeatedly done. Therefore, the inclination to seek a final terminus is an inclination to arrest the very energies that propel the process in the first place. Finality is as antithetical to objectivity as it is to creativity.

${ }^{82}$ This is not to deny, however, the possibility of creativity being distributed across individuals and groups. 
The most effective way in which interdisciplinary objectivity has been fostered in the case of evolutionary psychology, broadly conceived, is through the cognate fields feeding off the same scientific database. That database has turned out to be neurobiology. The effort made by empirical linguists, developmental psychologists and some biological anthropologists to filter neurobiological findings through their perspective's interpretive lens effects a situation where evidence can converge. When it does not, it can also be fed back to correct mistaken starting points. In a manner of speaking, neurobiology has come to play the same role that mathematics has played for physicists, i.e., as a source of insight (Bohm, 1986, p. 134).

The tendency to believe that neurobiology reflects the truth, and all else does not, as has happened in the case of mathematics within physics must, of course, be resisted. ${ }^{83}$ This may explain the empirical linguists reification of (radical reduction of) concepts as (to) complexes of neurons or patterns of interaction among neurons discussed in Chapter 4. Like the physicists who present mathematical equations to buttress their work, social scientists who make a case for the neurobiological underpinnings of their claims, may come to encapsulate objectivity (in a way that proponents of selfish genes have tried and failed). Neurobiology may be regarded as providing the language whose terms can be trusted among researchers who do not know one another. Discourse in terms of neurons, like numbers, may be taken to directly reflect the authority and impersonality of the researcher - the latter attribute long regarded one of the hallmarks of science. ${ }^{84}$

\footnotetext{
${ }^{83}$ David Bohm sees faith in mathematics as the sole source of insight as potentially squelching other sources, in particular, the speculative ideas that precede experimentation. See The Ghost in the Atom: A Discussion of the Mysteries of Quantum Physics, edited by P. C. W. Davies and J. R. Brown. Cambridge, MA: Cambridge University Press, 1986, p. 134.

${ }^{84}$ Theodore Porter says impersonality is a hallmark of science in Trust in Numbers: The Pursuit of Objectivity in Science and Public Life 1995, Preface, p. ix.
} 
However, just like numbers, neurons too, need a narrative; and all narratives require, what the Greeks called phronesis, i.e., judgment, in their construction. Once phronesis is let in, the difficulty of achieving a univocal narrative even for one's neurobiological findings significantly increases. There must be an agreed-upon standard. And that standard seems reasonably to be the "burden of showing that neurophysiological studies have hooked up properly to the linguistic and semantic roles" that are in need of explanation (Burian, personal communication). Perhaps, the difficulty of meeting this heavy burden of proof explains why evolutionary psychologists see their theory as one step removed from research in the field of neurobiology, where the result, they contend, is that they are able to accept any of its conclusions, being empirically tied to none of them. In effect, the evolutionary psychologists position themselves to take no risks at all (when it comes to neurobiology) in their pursuit of objectivity.

Of course, one is inclined to say that if evolutionary psychologists want to stay in the game, they must also play. They take a position much like the political philosopher John Rawls did when he claimed his conception of justice was compatible with both the economic arrangements of capitalism and socialism (1971, p. 258). A scientific theory, like a moral theory, that fails to take a factual (evaluative) stand is handily criticized for being too far removed from science (the real world) to be taken seriously. Evolutionary psychologists are not exempt from passing or not passing on important scientific matters. Their reluctance to do so has exposed their confusion on the evolutionary facts (Hardcastle and Buller, 2000). Rawls was similarly criticized for being confused about the economic ones. 


\section{Concluding Remarks}

It is detrimental to science for evolutionary psychologists to act autonomously. By insulating their core tenets and elevating them to the status of meta-theoretical claims prematurely, evolutionary psychologists render these tenets impervious to critical examination rather than openly negotiating their empirical warrant. This strategy may have helped to make them popular but it cannot make them right. An evolutionary psychology that fully integrates 'development,' on the other hand, the important factor depreciated by its founders, provides perspective on the strengths of all the other approaches to the study of cognition discussed in this dissertation. Those strengths lie close at hand. From the biological anthropologists we gain an appreciation for comparative data in the study of human cognition. From the theorizing of the empirical linguists we take away a sense of the importance of neurobiological research, particularly with respect to deciphering the all-important relation between human neurophysiology and human psychology. And from developmental thinkers in the field of psychology we learn the significance of constructivism in the developmental processes humans undergo in addition to the nativist elements of our cognitive make-up that the evolutionary psychologists were right to try to explain and take into account.

What is more, where weaknesses were located in each of these perspectives a Developmental Evolutionary Perspective (DEP) provides the evidentiary findings that require assimilation or suggests where that evidence might be found. DEP even indicates the sorts of theoretical emendations that must be made for these other approaches to jell with all the empirical data that we currently have available. One way that all the fields can advance their research is by criss-crossing their investigations and feeding the insights derived from DEP back into their research. One of DEP's particular strengths is that it doesn't forget the whole organism 
even when considering the whole organism under some particular aspect. Comparative data, which evolutionary psychology works so hard to resist, prove indispensable in DEP analysis, and ecological and cultural factors dismissed by evolutionary psychologists also come back in, in reinvigorated form. Developmental processes counterbalance the element of chance in natural selection (which has seemed inscrutable to some thinkers) and allows for embracing evolution as a creative force. The connection between biology and creativity is made at several levels.

Also, in a more critical vein, DEP shows that evolutionary psychology's fundamental tenets can't be elevated to the status of meta-theoretical claims immune to further criticism because the empirical warrant just isn't there to merit this achievement. The modularity thesis must be modified in line with developmental data that show the importance of environmental and ecological factors. This emendation diminishes the importance evolutionary psychologists place on the Pleistocene past in shaping minds and bodies today. Our brains and organs are not "specified by gene complexes that were selected during human evolutionary history" but are the "products of highly plastic responses to environmental inputs" (Hardcastle and Buller, 2000, pgs. 23 and 24). This is consistent with Richard Lewontin's claim that it sometimes makes better sense to regard organisms as changing their environments, not as adapting to them, since organisms always seem already adapted (1981, p. 245) - a crucial point denied by evolutionary psychology.

Additionally, it makes sense to broaden the notion of adaptation to refer to all the behaviors of organisms that confer reproductive benefits (Burian, 1983; T.M. Caro and Monique Borgerhoff Mulder, 1987; Leland and Brown, 2002) not just to behaviors that have resulted from the processes of natural selection and which can be presumed heritable. This definitional change 
reflects the idea that all of an organism's phenotypic characteristics are the result of interactions with the environment where genes play a role, but rarely a determining one.

Finally, evolutionary psychology's posit of universality, i.e., their claim that our cognitive architecture is universal in humans, must be modified to reflect developmental plasticity as that which is universal, as that which evolution has bequeathed all human persons, not some specific content-rich formulation of its results. "And consequently, although Pleistocene hunter-gatherers may not have been great mathematicians - their lives did not require it - children today may nevertheless develop a specialized cognitive domain of mathematics" (Mithen, 1996, p. 57). In other words, "our natures are contingent, changing and multiple, but not infinitely so," for "the environment is itself structured but changing, and... it, too, imposes limits on variation" (Oyama, 1985, p. 90). This is, to be sure, a much richer understanding of human plasticity than that which evolutionary psychologists capture with their pejorative terms 'Blank Slate' and 'Silly Putty' - terms intended to convey the absence of developmental predispositions, not their presence.

On occasion, even evolutionary psychologists acknowledge the reality of developmental plasticity in its richest sense. Says Pinker: "The brain obviously has a great deal of what neuroscientists call plasticity - that's what allows us to learn." Yet, Pinker takes back what he gives in his very next comment: "But the newest research is showing that many properties of the brain are genetically organized and don't depend on information coming in from the senses" (Pinker, 2002b). Karmiloff-Smith disagrees. Due to the brain's plasticity, different people may possess different cognitive specialties that constitute elaborations upon their cultural and/or individual developmental processes. 
Of particular note is that the concepts and terms evolutionary psychologists would have us surrender or utilize in the highly meaning-constrained manner that they introduce continue to be utilized unreservedly in their larger, more robust sense by those to whom their views are opposed. The concept of 'learning' is a case in point. Evolutionary psychologists claim that other researchers reify learning by erroneously assuming the mind's functionality is a unitary process. This, of course, isn't true. Evolutionary psychology's sharpest critics admit that the mind is, or at least that it becomes, partially modularized over time (Hardcastle and Buller, 2000; Karmiloff-Smith 1992), nor do they reify learning (King, 1994a, 1997; Karmiloff-Smith 1992, 2001; Lakoff and Johnson, 1999).

King operationalizes the concept of learning in behavioral terms,${ }^{85}$ Lakoff and Johnson reduce it (though I believe in an objectionable way) to neural transactions, and Karmiloff-Smith always anchors it to the manifest processes or capacities people have. Moreover, when the distinction between 'innate' and 'acquired' behaviors is abandoned, so is the idea that the increased importance of learning must decrease the importance of development (see Oyama, 1985, p. 158). When Tooby and Cosmides state that "learning is a name given to the unknown agent imagined to cause a large and heterogeneous set of functional outcomes" they are not only mistaken, they reveal their a priori commitment to the claim that development and learning fall on two different sides of the genes-environment divide.

Nevertheless, Tooby and Cosmides say the concept of learning "will eventually disappear as cognitive psychologists and other researchers make progress in determining the actual causal

\footnotetext{
${ }^{85}$ King takes, I think, a Popperian view of concepts and their meaningfulness. As long as the theory or experiment that makes use of the term is understandable, then the particular language used, the concept and its meaning (and accordingly, its definition), is not what is important (Popper, 1963, p. 273 and 279; 1956, pgs. 44-46). For King, the concept of 'learning' is meaningful insofar as the behaviors that meet the criteria laid down for it can be identified through their overt manifestations and then systematically related to all the other concepts in the explanatory framework. King will thus reject Tooby and Cosmides supposition that learning needs to be understood as a psychological process and that its causal origins in the mind are in need of identification and explanation.
} 
sequences by which the functional business of the mind is transacted" (1992, p. 123). They conclude their piece, "The Psychological Foundations of Culture," with the proclamation that they shall replace this unexplained account of learning with knowledge (1992, p. 123). Nothing could be more indicative than this of their sense of the power of terms and the eliminativist proclivities they evoke that are designed to enhance their power. I think that they are simply wrong and that it is unlikely the concept of learning will fade away.

As we have witnessed, even Pinker shows the need to resort to the concept of learning to characterize cognition that falls at the modular fringes, e.g., thinking based on constructivist trial and error processes that depends upon "information coming in from the senses" (2002b). However, Tooby and Cosmides' determination to instigate a revolutionary change in our thinking or outlook - a paradigm shift - by recommending changes in our vocabulary really embeds a theoretical incoherence. The reason is that it is the essence of their view that ontological reality inheres in the frames in people's minds and so cannot be changed by changing concepts. Pace Quine (1968), evolutionary psychologists insist, in other words, that ontological reality is not relative to the linguistic framework.

Moreover, practitioners outside of evolutionary psychology are placing renewed emphasis on concepts and terms that treat of actions as well as perceptions; skills and practices as well as representations; relations and processes as well as objects and events. The mainly bifurcated language, and hence, mainly bifurcated view of the world that is implicit in evolutionary psychology is being de-emphasized. Levels of analysis and webs of (overlapping sources of) causality are being added to genes and environment. Emergent properties and creative activity are being added to development as normal occurrences, rather than being viewed as exceptional ones. In short, the insertion of 'development' into evolutionary thinking is 
upsetting, and I believe rightly so, evolutionary psychology's dichotomous rendering of human biology and sociology. These conceptual changes are bound to shake up social practices at disciplinary borders and set new terms for interdisciplinary engagements.

Furthermore, it is essential to recognize that beyond its commitment to certain core assumptions and its utilization of the robust and fuzzy terms named above, the DEP framework neither generates nor requires some one content-rich story about human nature in the manner of evolutionary psychology. This may account for the apparent gap that exists between the general theoretical framework and the empirical claims with which it is connected - claims which have issued from investigation into the on-the-ground, self-declared interests of researchers. This gap exists precisely because the theory does not (indeed no theory can) carry a blueprint for its realization, mandating the pursuit of specific questions and concerns.

DEP leaves room for practitioners' determinations of research questions to pursue and the contextual rendering of the evidence that they find. Tidying up knowledge under DEP's conceptual umbrella is antithetical to the autonomy that is the right of every researcher. That right is grounded in the Habermasian condition of equality of intellectual authority to which DEP is fundamentally committed. Theory thinking (associated with abstract reflective reason) and attention to microhistorical observations and events (which can only be countenanced by historical reason) each have their place in the framework.

As Susan Oyama observes "our conceptual structure and metaphors not only describe our discoveries, they guide and define them as well, and both object and knowledge of it emerge interactively" (1985, p. 142). It cannot be an accident, therefore, that evolutionary psychology's great insight, the framing of the mind, also describes its greatest contribution to evolutionary psychology, i.e., the framing of focal issues. Nor can it be an accident that the Integrated Causal 
Model (ICM) to which evolutionary psychologists subscribe, on the one hand, and their ideas about how the mind works, on the other hand, both avail themselves of the notion that specific kinds of relation among constituent factors pre-exist, that orderly processes depend upon a preformed plan (contained within the genes or the ICM) that certain factors (perspectives) have causal primacy over others, and one vocabulary, rather than many different vocabularies appropriate to different forms of analysis, is sufficient for understanding all the intricacies of the sources, processes and interactive effects that the mind undergoes and that the theoretician hopes to understand.

DEP, by contrast, does not prejudge the degree of integration and regularization of relations that either the developmental processes it studies will show or its practitioners will conform to. This is because DEP is committed to a conception of developmental systems as open; hence the questions it raises about them are open as well (see Oyama, 2001). No part of the system is privileged over any other part by virtue of some principle; no "special directive, formative or informative power"(Oyama, 2001, p. 178) is to be attributed to certain causes whether they be genes or research practitioners - making the evolutionary psychologists, for instance, more equal as practitioners than others. Rather relations among researchers, like organism-environment relations, are to be understood to emerge interactively, interdependently and co-constructively.

Practitioners' relations are not to be thought of as 'shrink-wrapped' (Oyama's term, 2001, p. 188) any more than are organism and environmental complexes. Yet, evolutionary psychology's ICM sees practitioners as having a pre-structured place in a black-boxed domain where the findings that emerge from any one box, show mutuality, by providing complementary and conceptually integrative knowledge not accessible from the disciplinary boxes of others. 
The knowledge that crosses boundaries fills holes and closes gaps between adjacent fields (Cosmides, Tooby and Barkow, 1992, pgs. 3-15). What DEP understands is that objectivity requires that practitioners' black boxes be open and transparent to view since the concerns themselves are mutual; hence, knowledge on offer from any one point of view must be allowed to seep in and dislodge as well as reinforce the propriety of the claims of another. Constructive conflict is the price paid for intellectual autonomy; preemptive harmony proves antithetical to the unity of science sought after by evolutionary psychologists.

Notably, though, proponents of evolutionary psychology are not inclined to see science as a domain that houses a multiplicity of contested stories among which their conception of human as 'thinking machine' lies side by side with the conception of human as 'animal,' as 'embodied,' and as 'child' and where adjudicating the relation of these different conceptions is a joint affair, not one delegated by evolutionary psychology from on high. Rather, evolutionary psychologists think of evolutionary psychology as providing the only suitable framework for comprehending human psychology. Evolutionary psychologists prove their theory to be masculine, modernist, and absolutist through their creation and support of the ICM which is hierarchical and propounds one truth.

Yet, evolutionary psychology's own conception of frames in the mind, when generalized to the disciplines, suggests the need for outsider points of view to act as a foil - to highlight - and thereby overcome - the very constraints that set the parameters for (and, hence make possible) that discipline's generative sources of knowledge. Granting this, the idea that interdisciplinary objectivity issues from alternating perspective among disciplinary frames follows naturally for only in this way does it become possible to render visible that which would otherwise be left unseen. Evolutionary psychologists may fail to entertain this possibility because they do not pay 
sufficient attention to the role of people as active constructors of their own mobile and fluid cognitive frames and capabilities.

The disciplinary perspectives that would be marginalized in the conversation (to follow the feminist line of reasoning through) if evolutionary psychology gains the hegemony it seeks are not to be thought of as generating knowledge that is more objective, more true and more sound just because they are outsider views. Besides, the cognate disciplines identified in this dissertation are by no means less powerful, less advantaged, less established academic voices, than the voices heard from evolutionary psychology. Indeed, as we have seen practitioners from these fields have histories and intellectual traditions as deep if not deeper than evolutionary psychology with respect to evolutionary theory that puts them on a plane of authority equal to, if not presumptively, greater than it, given its recent beginnings. This has to explain evolutionary psychology's own rhetoric of presumptive authority - a defensive mechanism displayed by a field trying to get itself established, the new kid on the academic block at the greatest risk of being silenced through institutional isolation and left out of the conversation altogether.

Still, the strong objectivity notion of Sandra Harding has its application (1991) for evolutionary psychologists would benefit by learning to see themselves as others see them. ${ }^{86}$ So too does Donna Haraway's idea of objectivity for its illustrative contrasts (1988). For in multidisciplinary debates of this sort objectivity is not so much, as Haraway suggests, about exposing the authorship of knowledge claims, as about expanding the authorship base. It is not so much about gleaning partial truths from localized domains and perspectives as about gleaning fertile truths that have the capacity to withstand multiple intersecting disciplinary interconnections. No privileged standpoint exists by virtue of one's disciplinary prerogatives but

\footnotetext{
${ }^{86}$ In interview with Elizabeth Hirsh and Gary A. Olson, Harding simplistically describes strong objectivity as "learning to see ourselves as others see us" (1995) in "Starting from Marginalized Lives: A Conversation with Sandra Harding, JAC: Journal of Composition Theory, 15.
} 
rather a composite and generally authoritative standpoint is, ultimately, sought-after and, with some luck, may come to be acknowledged by virtue of model concepts and terms conjointly affirmed. Through the lens of these shared model concepts the multidisciplines can stand in line and take their turn viewing their own knowledge. Transformative ways of seeing, then, come from seeing one's knowledge through a kaleidescope view. The knowledge seen is thus mobile, not situated. Mobile knowledges can be dislodged, looked at in different ways, and still remain. What the social conditions of knowledge production in contemporary society exposes given the diverse community of knowers studied in this dissertation is the potential for postmodern paralysis on account of too much information and the concomitant need to sort through and prioritize relevant facts and claims issuing from outside one's field. This condition impacts all the disciplines, the hybrids and multidisciplines included, because it embeds the ever-present possibility that external sources of knowledge that are germane shall be wrongfully demoted if not submerged completely, which I believe has happened in the present case.

Thus one important respect in which the social sciences and social order are linked today is with respect to the vastness of the data compared to the relative inability of, and the epistemic liabilities that hinder, the collaborations required to surmount disciplinary boundaries. Nowadays, subject matters are shared zones of interests and shared zones of contentious authority because of the recognized need to compensate for this lacuna. Authority can no longer be based on disciplinary rights but must be derived in a different way, say, in terms of the breadth of one's cross-disciplinary contribution and the priority that one's vantage point has at some level of analysis. The answer to the question: 'Why bring these other disciplines in?' has to be: 'Look at the correctives that they supply. Our knowledge is more 'objective' as a result.' 
Evolutionary psychology's longevity depends upon adjusting its claims to authority to bring them into line with the disciplinary realities of postmodern academia. Otherwise, it faces the prospect of being left behind even as it receives credit for having popularized (in a favorable way) the conversation now taking place on human cognition, credit that its predecessor theory, sociobiology, never managed to achieve. The conception of human as 'thinking machine' may generate compelling insights but so too have the conceptions of human as 'animal,' as 'embodied,' and as 'child.' Evolutionary psychology needs these outsider views from biological anthropology, empirical linguistics, and developmental psychology to keep the conversation going as much as they have demonstrated their reliance upon it to clarify their own accounts. Disciplinary objectivity is obstructed, however, when hegemonic claims are made. Hegemonic claims dam communication channels. Academic distancing results; global interconnections of theory are stymied. This dissertation stands as a modest plea to evolutionary psychologists to act now to counter this tendency. 


\section{REFERENCES}

Armstrong, David. F., William C. Stokoe, and Sherman E. Wilcox. 1995. Gesture and the nature of language. Cambridge, MA: Cambridge University Press.

Ayer, Alfred Jules. 1952. Language, truth \& logic. New York: Dover Publications.

Barkow, Jerome H. 1989. Overview. Ethology and Sociology 10:1-10.

Bateson, Pat. January 24, 1985. Sociobiology: The debate continues. New Scientist: 58-59.

Bjorklund, David F. 2003. Evolutionary psychology from a developmental systems perspective. Psychological Bulletin 129 (6):836-941.

Bjorklund, David F. and Pellegrini, Anthony D. 2000. Child development and evolutionary psychology. Child Development 71 (6):1687-1708.

Boas, Franz. 1911. Handbook of American Indian languages, Part I. Washington, D.C.: Bureau of American Ethnology, Bulletin 40, Smithsonian Institution.

Bohm, David. 1986. David Bohm. In The ghost in the atom: A discussion of the mysteries of quantum physics, edited by P. C. W. Davies and J. R. Brown. Cambridge, MA: Cambridge University Press.

Bowler, Peter J. 1988. The non-Darwinian revolution: Reinterpreting a historical myth. Baltimore, MD: Johns Hopkins University Press.

Brockman, John. 1995. The third culture. New York: Simon and Schuster.

Brown, Andrew. 1999. The Darwin wars: How stupid genes became selfish gods. London: Simon and Schuster.

Brown, Penelope. 2002. Language as model for culture. In Anthropology beyond culture, edited by R. Fox and B. King. New York: Berg Publishers. 169-192.

Buller, David J. 1999. Defreuding evolutionary psychology: Adaptation and human motivation. In Where biology meets psychology, edited by V. G. Hardcastle. Cambridge, MA: MIT Press. 99-114.

Burian, Richard M. 1983. Adaptation. In Dimensions in Darwinism, edited by M. Greene. Cambridge, MA: Cambridge University Press. 287-314.

Burian, Richard M. 1986. On integrating the study of evolution and of development. In Integrating Scientific Disciplines, edited by W. Bechtel. The Netherlands: Martinus Nijhoff Publishers 209-228. 
Burian, Richard M., Scott Gilbert, Paula Mabee, and Billie Swalla. 2000. General introduction to the symposium on evolutionary developmental biology: Paradigms, problems, and prospects. American Zoologist 40:711-717.

Buss, David M. 1999. Evolutionary psychology: The new science of the mind. Needham Heights, MA: Allyn \& Bacon.

Buss, David M; Haselton, Martie G.; Shackelford, Todd K.; Bleske, April L.; and Wakefield, Jerome C. 1999a. Interactionism, flexibility and inferences about the past. American Psychologist 54 (6):443-445.

Caporael, Linnda R., and Marilynn B. Brewer. 2000. Metatheories, evolution, and psychology: Once more with feeling. Psychological Inquiry 11 (1):23-26.

Carey, Susan, and Elizabeth Spelke. 1994. Domain-specific knowledge and conceptual change. In Mapping the mind: Domain specificity in cognition and culture, edited by L. A. Hirshfield and S. A. Gelman. Cambridge, MA: Cambridge University Press. 169-200.

Caro, T.M. and Borgerhoff Mulder. 1987. The problem of adaptation in the study of human behavior. Ethology and Sociology 8:61-72.

Cartmill, Matt. 1990. Human uniqueness and theoretical content in paleoanthropology. International Journal of Primatology 11 (3): 173-192.

Ceccarelli, Leah. 2001. Shaping science with rhetoric: The cases of Dobzhansky, Schrödinger and Wilson. Chicago: University of Chicago Press.

Cervone, Daniel. 2000. Evolutionary psychology and explanation in personality psychology. American Behavioral Scientist. March. 43 (6):1001-1014.

Chomsky, Noam. 1968. Language and mind. New York: Harcourt Brace Jovanovich, Inc.

Chomsky, Noam. 1975. Reflections on language. New York: Random House.

Chomsky, Noam. 1978. The ideas of Chomsky: Dialogue with Chomsky. In Talking philosophy, edited by B. Magee. Oxford and New York: Oxford University Press 173-193.

Chomsky, Noam. 1980. Initial states and steady states. In Language and learning: The debate between Jean Piaget and Noam Chomsky, edited by M. Piattelli-Palmarini. Cambridge, MA: Harvard University Press 107-130.

Chomsky, Noam. 1988. Language and the problems of knowledge. Cambridge, MA: The MIT Press. 
Cornford, F.M. 1932/1993. Before and after Socrates. Cambridge, MA: Cambridge University Press.

Cosmides, Leda. Interview with Leda Cosmides, by Alvara Fischer and Roberto Araya for the Chiliean newspaper El Mercurio, portions were published October 28, 20012001 [cited. Available from: http://www.psych.ucsb.edu/research/cep/ledainterview.htm.

Cosmides, Leda and Tooby, John. 1987. From evolution to behavior: Evolutionary psychology as the missing link. In The latest on the best: Essays on evolution and optimality, edited by J. Dupre. Cambridge, MA: MIT Press. 277-306.

Cosmides, Leda and Tooby, John. 1989. Evolutionary psychology and the generation of culture, part II. Ethology and Sociology 10:51-97.

Cosmides, Leda, John Tooby and Jermone Barkow. 1992. Introduction: Evolutionary psychology and conceptual integration. In The adapted mind, edited by J. H. Barkow, L. Cosmides and J. Tooby. New York: Oxford University Press 3-15.

Cosmides, Leda and Tooby, John. 1994. Beyond intuition and instinct blindness: Toward an evolutionarily rigorous cognitive science. Cognition 50:41-77.

Crawford, Charles. 2003. A prolegomenon for a viable evolutionary psychology - The myth and the reality: comment on Lickliter and Honeycutt (2003). Psychological Bulletin 129 (6):854-857.

Darwin, Charles. 1859 (1964). On the origin of species. Cambridge, MA: Harvard University Press.

Darwin, Charles. 1952 (1871). The descent of man and selection in relation to sex. Edited by R. M. Hutchins. Vol. 49, Great Books of the Western World. Chicago: University of Chicago.

Dawkins, Richard. 1982. The extended phenotype. New York: Oxford University Press.

Deacon, Terrence. 1988. Human Brain evolution I. Evolution of language circuits. In Intelligence and evolutionary biology, edited by H. Jerison and I. Jerison. Berlin: Springer. 383-416.

Deacon, Terrence. 1989. The neural circuitry underlying primate calls and human language. Human Evolution 4:367-401.

Deacon, Terrence. 1997. The symbolic species: The co-evolution of language and the human brain. New York: W.W. Norton and Company. 
Degler, Carl N. 1991. In search of human nature: The decline and revival of Darwinism in American social thought. New York and Oxford: Oxford University Press.

Dennett, Daniel. 1991. Consciousness explained. Boston, New York, London: Little, Brown and Company.

Dennett, Daniel. 1995. Darwin's dangerous idea: Evolution and the meaning of life. New York: Touchstone.

Dogan, Mattei and Pahre, Robert. 1990. Creative marginality: Innovation at the intersections of social sciences. Boulder, San Francisco and Oxford: Westview Press.

Edelman, Gerald M. 1992. Bright air, brilliant fire: On the matter of the mind. New York: Basic Books.

Eldredge, Niles, and Stephen Jay Gould. 1972. Punctuated equilibria: An alternative to phyletic gradualism. In Models in Paleobiology, edited by T. J. M. Schopf. San Francisco, CA: Freeman, Cooper and Company. 82-115.

Ellis, Bruce J. and Ketalaar, Timothy. 2000. On the natural selection of alternative models: Evaluation of explanations in evolutionary psychology. Psychological Inquiry 11 (1): 56-68.

Elman, Jeffrey, Elizabeth Bates, Mark Turner, Annette Karmiloff-Smith, Dominico Parisi, and Kim Plunkett. 1996. Rethinking innateness. Cambridge: MIT Press.

Ferguson, Andrew. 1998. How Steven Pinker's mind works. Quadrant, 31(8).

Fine, Arthur. 1996. The Shaky game. Second ed. Chicago and London: Chicago University Press.

Fisk, Milton. 1975. History and reason in Rawls' moral theory. In Reading Rawls: Critical studies on Rawls' 'A Theory of Justice'. Stanford, CA: Stanford University Press 53-80.

Fodor, Jerry. 1983. The modularity of mind: An essay on faculty psychology. Cambridge, MA: MIT Press.

Fodor, Jerry. 1985. Precis of 'the modularity of mind'. Behavioral and Brain Sciences 8: 1-42.

Foucault, Michel. 1977. Power/Knowledge: Selected interviews and other writings 1972-1977. New York: Pantheon Books.

Fox, Richard and King, Barbara. 2002. Introduction: Beyond culture worry. In Anthropology beyond culture, edited by R. Fox and B. King. New York: Berg Publishers. 1-19.

Gardner, Howard. 1985. The mind's new science. New York: Basic Books.

Geertz, Clifford. 1973. The interpretation of cultures. New York: Basic Books. 
Gibson, Kathleen Rita. 1994. Continuity theories of human language origins versus the Lieberman model. Language and Communication 14 (97-114).

Gould, Stephen Jay. 1977. Ever since Darwin. London and New York: WW Norton \& Company, Inc.

Gould, Stephen Jay and Lewontin, Richard. 1979. The spandrels of San Marco and the Panglossian paradigm: A critique of the adaptationist programme. Proceedings of the Royal Society: 581-598.

Griffiths, Anthony J.F., Jeffrey H. Miller, David T. Suzuki, Richard C. Lewontin, and William M. Gelbart, eds. 2000. An introduction to genetic analysis. New York: W. H. Freeman.

Guthrie, W.K.C. 1950. The Greek philosophers: From Thales to Aristotle. New York: Harper \& Row.

Habermas, Jürgen. 1984. The theory of communicative action: Volume I: Reason and the rationalization of society. Boston, MA: Beacon Press.

Habermas, Jürgen. 1987. The theory of communicative action: Volume II: Lifeworld and system. Boston, MA: Beacon Press.

Haig, Brian D., and Russil Durrant. 2000. Theory evaluation in evolutionary psychology. Psychological Inquiry 11 (1):34-38.

Haraway, Donna. 1988. Situated knowledges: The science question in feminism and the privilege of the partial perspective. Feminist Studies 14 (3):575-599.

Hardcastle, Valerie. 1993. Evolutionary epistemology as an overlapping, interlevel theory. Biology and Philosophy 8: 173-192.

Hardcastle, Valerie and Buller, David. 2000. Evolutionary psychology, meet developmental neurobiology: Against promiscuous modularity. Brain and Mind 1: 307-325.

Harding, Sandra. 1991. Whose science? Whose knowledge? Ithica, NY: Cornell University Press. Harding, Sandra. 1995. Starting from marginalized lives: A conversation with Sandra Harding. JAC: A Journal of Composition Theory 15:193-225.

Hinde, Robert. 1987. Individuals, relationships and culture. Cambridge, MA: Cambridge University Press.

Horgan, John. 1995. The new social Darwinists. Scientific American 273:150-157.

Ingold, Tim. December, 1985. Who studies humanity? The scope of anthropology. Anthropology Today. December. 1 (6): 15-16. 
Ingold, Tim. December, 1988. Individuals, relationships and culture: Links between ethnology and the social sciences. Man. December. 23 (4): 782-784.

Ingold, Tim. 1990. An anthropologist looks at biology. Man 25 (2):208-229.

Ingold, Tim. June, 1993. The dynamics of evolution: The punctuated equilibrium debate in the natural and social sciences. Man, 1993, 28 (2): 374-375.

Ingold, Tim. 1998. From complementarity to obviation: On dissolving the boundaries between social and biological anthropology. Zeitschrift für Ethnologie. 123: 21-52.

Ingold, Tim. 2000. Evolving Skills. In Alas poor Darwin: Arguments against evolutionary psychology, edited by H. Rose and S. Rose. New York: Random House.273-298.

Ingold, Tim. 2002. Between evolution and history: Biology, culture and the myth of human origins. Proceedings of the British Academy 112:43-66.

James, William. 1890/1952. The principles of psychology. Edited by R. M. Hutchins, Great Books of the Western World. Chicago: Encyclopedia Britannica.

Johnson, Mark. 1987. The Body in the Mind. Chicago: University of Chicago Press.

Johnston, Timothy D. and Gottlieb, Gilbert. 1990. Neophenogensis: A developmental theory of phenotypic evolution. Journal of Theoretical Biology 147:471-495.

Karmiloff-Smith, Annette. 1983. A new abstract code or the new possibility of multiple codes? Behavioral and Brain Sciences 6 (1):149-150.

Karmiloff-Smith, Annette. 1988. The child is theoretician, not an inductivist. Mind \& Language $3(3): 183-195$.

Karmiloff-Smith, Annette. 1990. Piaget and Chomsky on language acquisition: Divorce or marriage? Abstracts of the 1990 Child Language Seminar 10:255-270.

Karmiloff-Smith, Annette. 1992. Beyond modularity: A developmental perspective on cognitive science. Cambridge, MA: MIT Press.

Karmiloff-Smith, Annette. 1993. What's special about the human mind/brain? Mind \& Language $8(3): 569-582$.

Karmiloff-Smith, Annette. 1994. Precis of 'beyond modularity:' a developmental perspective on cognitive science. Behavioral and Brain Sciences 17: 693-745.

Karmiloff-Smith, Annette. 2001. Pathways to language: From fetus to adolescent. Cambridge, MA: Harvard University Press. 
Ketelaar, Timothy and Ellis, Bruce J. 2000. Are evolutionary explanations unfalsifiable? Evolutionary psychology and the Lakatosian philosophy of science. Psychological Inquiry. 11 (1): 1-21.

King, Barbara. 1991. Social information transfer in monkeys, apes, and hominids. Yearbook of Physical Anthropology 34: 97-115.

King, Barbara. 1994. Evolution, essentialism, and evolutionary perspective on language: moving beyond a human standard. Language and Communication 14: 1-13.

King, Barbara. 1994a. The information continuum: Evolution of social information transfer in monkeys, apes, and hominids. Sante Fe, NM: School of American Research Press.

King, Barbara. 1996. Syntax and language origins. Language and Communication 16 (2): 193-203.

King, Barbara. 1999. Introduction: Primatological perspectives on language. In Origins of language. Sante Fe: School of American Research. 3-21.

King, Barbara. 1999a. Viewed from up close: Monkeys, apes, and language-origins theories. In Origins of language. Sante Fe: School of American Research. 21-54.

King, Barbara. 2000. Another frame shift: Cultural transmission to cultural co-construction. Behavioral and Brain Sciences 23:154-155.

King, Barbara. 2001. Dynamics of social communication. Chantilly, VA: The Teaching Company.

King, Barbara. 2002. On patterned interactions and culture in great apes. In Anthropology beyond culture, edited by R. Fox and B. King. Oxford and New York: Berg Publishers. 83-104.

King, Barbara. 2002a. Biological anthropology: An evolutionary perspective Part 2. Chantilly, VA: The Teaching Company.

King, Barbara. 2004. The dynamic dance: Nonvocal communication in African great apes. Cambridge, MA: Harvard University Press.

King, Barbara and Shanker, Stuart A. 1997. The expulsion of primates from the garden of language. Evolution of Communication 1 (1): 59-99.

Klein, Julie Thompson. 1990. Interdisciplinarity: History, theory and practice. Detroit: Wayne State University Press. 
Klein, Julie Thompson. 1996. Crossing boundaries: Knowledge, disciplinarities and interdisciplinarities. Charlottesville: University of Virginia Press.

Kuhn, Thomas S. 1962. The structure of scientific revolutions. Chicago: University of Chicago Press.

Lakoff, George. 1987. Women, fire and dangerous things: What categories reveal about the mind. Chicago: Chicago University Press.

Lakoff, George. 1988. Cognitive semantics. In Meaning and mental representations, edited by U. Eco. Bloomington: Indiana University Press.

Lakoff, George, and Mark Johnson. 1980. Metaphors we live by. Chicago: University of Chicago Press.

Lakoff, George and Johnson, Mark. 1999. Philosophy in the flesh. New York: Basic Books.

Laland, Kevin N.; Odling-Smee, John and Feldman, Marcus W. 2000. Niche construction, biological evolution and cultural change. Behavioral and Brain Sciences. 23: 131-175.

Langer, Suzanne E. 1967. Mind: An essay on human feeling. Baltimore: Johns Hopkins Press.

Lavine, T.Z. 1984. From Socrates to Sartre. New York: Bantum Books.

Leland, Kevin and Brown, Gillian. 2002. Sense and nonsense: Evolutionary perspectives on human behavior. Oxford: Oxford University Press.

Levins, Richard and Lewontin, Richard. 1985. The dialectical biologist. Cambridge: Harvard University Press.

Levi-Strauss. 1963. Structural anthropology. Translated by C. Jacobson and B. G. Schoepf. New York: Basic Books.

Lewontin, Richard. 1981. On constraints and adaptation. Behavioral and Brain Sciences Vol. 4: 244-245.

Lewontin, Richard. 1990. How much did the brain have to change for speech? Behavioral and Brain Sciences 13: 740-741.

Lewontin, Richard. 1990a. Evolution of cognition. In Thinking: An invitation to cognitive science. Vol. 3, edited by D. Osherson and E. E. Smith. Cambridge, MA: Cambridge University Press. 229-246.

Lickliter, Robert and Honeycutt, Hunter. 2003. Developmental dynamics: Toward a biologically plausible evolutionary psychology. Psychological Bulletin 129 (6): 819-835. 
Lieberman. 1994. Human language and human uniqueness. Language and Communication 14:87-95.

Linden, Eugene. 1974. Apes, men and language. New York: Penguin Books.

Lloyd, Elisabeth A. and Feldman, Marcus W. 2002. Evolutionary psychology: A view from evolutionary biology. Psychological Inquiry. 13 (2): 150-156.

Locke, John. 1689 (1952). An essay concerning human understanding. Chicago: William Benton, Encyclopedia Britannica.

Longino, Helen. 1990. Science as social knowledge. Princeton, NJ: Princeton University Press. Lumsden, C.J. and Wilson, E.O. 1981. Genes, mind and culture: The co-evolutionary process. Cambridge, MA: Harvard University Press.

Magee. Bryan. 1978. Talking philosophy. Oxford and New York: Oxford University Press.

Mandler, Jean M. 1988. How to build a baby: On the development of an accessible representational system. Cognitive Development 3:113-136.

Mandler, Jean M. 1992. How to build a baby II: Conceptual primitives. Psychological Review 99 (4):587-604.

Mayr, Ernst. 1982. The growth of biological thought. Cambridge, MA: Harvard University Press. McGinn, Colin. February 23, 1998. The know-it-all. The New Republic, 34+.

McGinn, Colin. October 13, 2002. All in our heads. The Washington Post, 3.

McKie, Robin and Thorpe, Vanessa. Raging Boffins The Observer, Sept. 22, 2002 [cited. Available from: http://observer.guardian.co.uk/print/0,3858,4506082-110190,00.html.

Midgley, Mary. 2004. It's all in the mind. The Guardian(London).September 21, 2002 [cited 2004]. Available from:http://books.guardian.co.uk/review/story/1,12084,795048,00.html.

Miller, Raymond. 1982. Varieties of interdisciplinary approaches in the social sciences. Issues In Integrative Studies 1:1-37.

Millikan, Ruth Garrett. 1989. Biosemantics. The Journal of Philosophy LXXXVI (6):281-297.

Mithen, Steven. 1996. The prehistory of the mind. New York: Thames \& Hudson.

Mithen, Steven. 1997. Review of the adapted mind. Journal of Anthropological Research 53:100-102.

Oyama, Susan. 1985. The ontogeny of information: Developmental systems and evolution. Cambridge and New York: Cambridge University Press. 
Oyama, Susan. 1989. Ontogeny and the central dogma: Do we need the concept of genetic programming in order to have an evolutionary perspective? Edited by M. Gunner and E. Thelen. Vol. 22, Systems in development: The Minnesota symposia on child psychology. Hillsdale: NJ: Erlbaum 1-34.

Oyama, Susan, Griffiths, Paul E. and Gray, Russell D. 2001. Terms in tension: What do you do when all the good words are taken? In Cycles of contingency. Cambridge, MA: The MIT Press. 177-193.

Piaget, Jean. 1955. The language and thought of the child. New Haven, CT: Meridian Books. Piaget, Jean. 1978. Behavior and evolution. New York: Pantheon Books.

Piaget, Jean. 1980. Opening the debate: The psychogensis of knowledge and its epistemological significance. In Language and learning: The debate between Jean Piaget and Noam Chomsky, edited by M. Piatelli-Palmarini. Cambridge, MA: Harvard University Press 23-54.

Piaget, Jean. 1980a. About the fixed nucleus and its innateness. In Language and learning: The debate between Jean Piaget and Noam Chomsky, edited by M. Piatelli-Palmarini. Cambridge, MA: Harvard University Press 55-88.

Piaget, Jean and Inhelder, Barbel. 1969. The psychology of the child. New York: Basic Books. Piatelli-Palmarini. 1980. Language and learning: The debate between Jean Piaget and Noam Chomsky. Cambridge: Harvard University Press.

Pinker, Steven. 1994. The language instinct. New York: W. Morris and Company.

Pinker, Steven. 1997. How the mind works. New York: W.W. Norton \& Company.

Pinker, Steven. 1997a. Words and rules. New York: Basic Books.

Pinker, Steven. 1997b. How the mind works (book reviews) J. Madeline Nash. Time. October 20, 92(1).

Pinker, Steven. 1998. A mind to love. The Guardian Newspapers, January 17, 22.

Pinker, Steven. February 7, 1999. How much art can a brain take? We need art, but cannot explain why. Is it merely the mind's cheescake? Independent, 3 .

Pinker, Steven . 2000. Mind, morality, and evolution: An interview with Steven Pinker. Free Inquiry, Spring 20 (2):55.

Pinker, Steven. 2001. The Pinker instinct. Interviewed by Michael Shermer, Skeptic 9 (1): 88-96. 
Pinker, Steven. 2002. The blank slate: The modern denial of human nature. New York: Viking Press.

Pinker, Steven. 2002a. In conversation with Steven Pinker the evolutionist, [cited December 6 2002a]. Available from: http://www.Lse.ac.uk/Depts/cpnss/darwin/evo/pinker.htm.

Pinker, Steven.2002b. A biological understanding of human nature: A talk with Steven Pinker. Interviewed by John Brockman, the edge, September 9, 2002 [cited. Available from: www.edge.org/3rd_culture/pinker_blank/.

Pinker, Steven and Bloom, Paul. 1990. Natural language and natural selection. Behavioral and Brain Sciences 13: 707-784.

Pinker, Steven and Bloom, Paul. 1996. The nature of human concepts/evidence from an unusual source. Communication \& Cognition 29:307-361.

Pitt, Joseph. 2000. Thinking about technology. New York: Seven Bridges Press.

Plotkin, Henry. 1997. Evolution in mind. Cambridge, MA: Harvard University Press.

Popper, Karl. 1956. Quantum theory and the schism in physics. Edited by I. W.W. Bartley. Totowa, NJ: Rowman and Littlefield.

Popper, Karl. 1963. Conjectures and refutations. New York: Routledge.

Porter, Theodore M. 1995. Trust in numbers: The pursuit of objectivity in science and public life. Princeton, NJ: Princeton University Press.

Post, John F. 1991. Metaphysics: A contemporary introduction. New York: Paragon House.

Premack, David. 1980. Discussion. In Language and learning: The debate between Jean Piaget and Noam Chomsky, edited by M. Piatelli-Palmarini. Cambridge, MA: Harvard University Press. 181.

Quine, W.V. 1953 (1987). Two dogmas of empiricism. In A priori knowledge, edited by P. K. Moser. New York: Oxford University Press. 42-67.

Quine, W.V. April 4, 1968. Ontological relativity. The Journal of Philosophy 65 (7):185-212.

Quine, W.V. 1969. Linguistics and philosophy. In Language and philosophy: A symposium. New York: New York University Press.

Rawls, John. 1971. A theory of justice. Cambridge, MA: Harvard University Press.

Richards, Robert J. 1987. Darwin and the emergence of evolutionary theories of mind and behavior. Chicago: University of Chicago Press.

Richards, Robert J. 1992. The meaning of evolution. Chicago: The University of Chicago Press. 
Riggs, Fred. February 1987. A conceptual encyclopedia for the social sciences. International Social Science Journal. 39 (1): 109-125.

Robinson, Daniel. 1980. The enlightened machine. New York: Columbia University Press.

Robinson, Daniel. 1995. An intellectual history of psychology. Madison: University of Wisconsin Press.

Rorty, Richard. 1989. Contingency, irony, and solidarity. Cambridge, MA: Cambridge University Press.

Rose, Steven. 1998. Maybe I'm a machine. New Scientist:4242.

Rose, Steven and Rose, Hilary. 2000. Alas, poor Darwin. New York: Harmony Books.

Rouse, Joseph. 1996. Engaging science: How to understand its practices philosophically. Ithica and London: Cornell University Press.

Sampson, Geoffrey. 1980. Schools of linguistics. Stanford: Stanford University Press.

Sampson, Geoffrey. 1999. Educating Eve: The 'language instinct' debate. New York: Continuum International Publishing Group.

Sarles, Harvey B. 1969. The study of language and communication across species. Current Anthropology 10 (2/3):211-221.

Savage-Rumbaugh. 1999. Ape language: Between a rock and a hard place. In The origins of language, edited by B. King. Sante Fe: School of American Research 115-188.

Schleicher, August. 1869/1983. Darwin tested by the science of language. In Linguistics and evolutionary theory: Three essays by August Schleicher, Ernst Haeckel and Wilhelm Bleek, edited by K. Koerner. Amsterdam/Philadelphia: John Benjamins Publishing Company.

Searle, John. June 29,1972. Chomsky's revolution in linguistics. The New York Review of Books:16+.

Searle, John. 1978. The philosophy of language: Dialogue with John Searle. In Talking Philosophy, edited by B. Magee. Oxford and New York: Oxford University Press 152-172.

Searle, John. 1989. Storm over the university. New York Review of Books, July 3, 34-+. Searle, John. 1999. Limits of phenomenology [on-line]. http://philosophy.berkeley.edu/jsearle/html/articles.html, January 12, 1999 [cited. Available from: http://philosophy.berkeley.edu/jsearle/html/articles.html. 
Searle, John. Interview with John Searle by Julian Moore. Available from:

http://philosophy.berkeley.edu/jsearle/html/articles.html. Accessed on-line October, 2004 [cited.

Segerstrale, Ullica. 2000. Defenders of the truth: The sociobiology debate. New York: Oxford University Press.

Sellars, Wilfrid. 1963/1992. Science, perception and reality. Atascadero, CA: Ridgeview Publishing Company.

Shanker, Stuart. 2002. The broader implications of borderline areas of language research. In Anthropology beyond culture, edited by R. Fox and B. King. New York: Berg Publishers. 125-144.

Shanker, Stuart and Taylor, Talbott. 2001. The house that Bruno built. In Language, culture, self, edited by J. Bruner. Thousand Oaks, CA: Sage. 50-70.

Shapiro, Lawrence and Epstein, William. 1998. Evolutionary theory meets cognitive psychology: A more selective perspective. Mind \& Language 13 (No. 2): 177-194.

Simpson, George Gaylord and Sarles, Harvey B. 1970. On Sarle's views on language and communication. Current Anthropology 11 (1):71-72.

Smith, John. 1970. "William James as Philosophical Psychologist." in Themes in American Philosophy: Purpose, experience and community. New York: Harper \& Row. 61-79.

Stevenson, Leslie. 1974. Seven theories of human nature. New York: Oxford University Press.

Taylor, Talbot J. 1994. The anthropomorphic and the skeptical. Language and Communication 14: 115-127.

Taylor, Talbot J. 1997. The origin of language: Why it never happened. Language Sciences 19 (1): 67-77.

Tooby, John and Cosmides, Leda. 1992. The psychological foundations of culture. In The adapted mind: Evolutionary psychology and the generation of culture, edited by J. H. Barkow, L. Cosmides and J. Tooby. New York: Oxford University Press. 19-136.

Tooby, John and Cosmides, Leda. 1995. Foreword. In Mindblindness: An essay on autism and theory of mind, edited by S. Baron-Cohen. Cambridge, MA: MIT Press.

Toren, Christina. 1993. Making history: The significance of childhood cognition for a comparative anthropology of mind. Man 28 (3):461-478. 
Toren, Christina. 2002. Anthropology as the whole science of what it is to be human. In Anthropology beyond culture, edited by R. Fox and B. King. New York: Berg Publishers 105-124.

Trivers, Robert L. 1971. The evolution of reciprocal altruism. The Quarterly Review of Biology 46 (No. 1):35-57.

Varela, Francisco J.; Thompson, Evan and Rosch, Eleanor. 1991. The embodied mind. Cambridge, MA: MIT Press.

van Fraassen, Bas C. 1980. The scientific image. Oxford: Clarendon Press.

Voneche, Jacque. 1982. An interview conducted with Piaget: Reflections on Baldwin. In The cognitive developmental psychology of James Mark Baldwin, edited by J. Brougthton and D. Freeman-Moir. Norwood, NJ: Ablex. 80-86.

Whewell, William. 1989. Theory of scientific method. Edited by R. E. Butts. Indianapolis/Cambridge: Hackett Publishing Company.

Whitehead, Alfred North. 1925. Science and the modern world. New York: Macmillan.

Williams, Bernard. 1985. Ethics and the limits of philosophy. Cambridge, MA: Harvard University Press.

Wilson, Edward O. 1975. Sociobiology: The new synthesis. Cambridge, MA: Harvard University Press.

Wilson, Edward O. 1999. Consilience. New York: Vintage Books Random House.

Wittgenstein, Ludwig. 1953. Philosophical investigations. Translated by G. E. M. Anscombe. Oxford: Blackwell.

Young, Jason and Persell, Roger. 2000. The evolution of misunderstandings about evolutionary psychology. Paper read at Annals of the New York Academy of Science 218-223. 